\title{
Dynamic covalent identification of an efficient heparin ligand
}

\author{
Miriam Corredor, ${ }^{[a]}$ Daniel Carbajo,,${ }^{[a]}$ Cecilia Domingo, ${ }^{[a]}$ Yolanda Pérez,,${ }^{[b]}$ Jordi Bujons, ${ }^{[a]}$ Angel \\ Messeguer, ${ }^{[a]}$ Ignacio Alfonso*,[a]
}

\begin{abstract}
Despite heparin being the most widely used macromolecular drug, the design of small-molecule ligands to modulate its effects has been hampered by the structural properties of this polyanionic polysaccharide. In this work we used a dynamic covalent selection approach to identify a new ligand for heparin, assembled from extremely simple building blocks. The amplified molecule strongly binds to heparin ( $K_{\mathrm{D}}$ in the low $\mu \mathrm{M}$ range, ITC) by a combination of electrostatic, hydrogen bonding and $\mathrm{CH}-\pi$ interactions as shown by NMR and molecular modeling. Moreover, this ligand reverts the inhibitory effect of heparin within an enzymatic cascade reaction related to blood coagulation. Our study demonstrates the power of dynamic covalent chemistry for the discovery of new modulators of biologically relevant glycosaminoglycans.
\end{abstract}

Heparin is a polyanionic polysaccharide that plays a fundamental role in blood coagulation, ${ }^{[1]}$ bone growth, ${ }^{[2]}$ and cell signaling, ${ }^{[3]}$ which are closely related with important processes such as angiogenesis ${ }^{[4]}$ and cancer progression. ${ }^{[5]}$ Thus, heparin is a macromolecular drug ${ }^{[6]}$ commonly used as anticoagulant for blood vessels clot prevention ${ }^{[7]}$ and some types of surgery. ${ }^{[8]}$ From a structural point of view, heparin (1 in Figure $1 \mathrm{~A})$ is the organic biomolecule with the highest anionic charge density, ${ }^{\left[{ }^{[9}\right.}$ and is usually obtained from natural sources as a polydispersed polymer mixture. ${ }^{[10]}$ For uses in both surgery and long-term diseases, the modulation of the available heparin in plasma is essential to achieve a delicate control of its pharmacological action while avoiding bleeding disorders and overdose..$^{[11]}$ Unfortunately, the number of small molecules able to tune the heparin action is quite limited. ${ }^{[12]}$ This is due to the chemical peculiarities of heparin (highly negative charge density, polydispersity) in addition to its conformational flexibility, ${ }^{[13]}$ which have made the molecular recognition of heparin and the rational design of synthetic ligands very challenging tasks. ${ }^{[12,14]}$ We envisioned that dynamic covalent chemistry ${ }^{[15]}$ could help in the discovery of specific ligands for intrinsically heterogeneous and elusive biomolecular targets. ${ }^{[16]}$ To the best of our knowledge, neither heparin nor any other glycosaminoglycan have ever been used as templates in dynamic covalent chemistry studies, which represented an additional

[a] Dr. M. Corredor, Dr. D. Carbajo, C. Domingo, Dr. J. Bujons, Prof. Dr. A. Messeguer, Dr. I. Alfonso

Department of Biological Chemistry

Institute of Advanced Chemistry of Catalonia, IQAC-CSIC

Jordi Girona 18-26, 08034, Barcelona, Spain

E-mail: Ignacio.alfonso@iqac.csic.es

[b] Dr. Y. Pérez

NMR Facility

Institute of Advanced Chemistry of Catalonia, IQAC-CSIC Jordi Girona 18-26, 08034, Barcelona, Spain

Supporting information for this article is given via a link at the end of the document.((Please delete this text if not appropriate)) appeal. Here we report the dynamic covalent identification of a simple but efficient ligand for heparin, which shows a low $\mu \mathrm{M}$ affinity and is able to revert the inhibitory effect of heparin in an enzymatic cascade reaction related to blood coagulation.

For the generation of a structurally diverse library with potential non-covalent interactions with heparin, we focused on the two main supramolecular binding motives of this polysaccharide. First, the anionic sulfates and carboxylates are obvious interaction sites. Therefore, a polyammonium framework such as the naturally occurring spermine ( 2 in Figure 1B) seemed a suitable structural scaffold for anion recognition in aqueous media at neutral $\mathrm{pH}^{\left[{ }^{[17]}\right.}$ Secondly, the axial positions on the carbohydrates have shown to establish attractive $\mathrm{CH}-\pi$ interactions with aromatic rings. ${ }^{[18]}$ Thus, we inserted aromatic moieties by setting up a reductive amination reaction between 2 $(1 \mathrm{mM})$ and a mixture of five different aromatic aldehydes (A, B, $\mathrm{C}, \mathrm{K}, \mathrm{L}, 1 \mathrm{mM}$ each), leading to the combinatorial alkylation of 2 (Figure 1B). Within this experimental design, the reversible nature of the imines formed by the condensation of $\mathbf{2}$ with the aromatic aldehydes would allow adaptation to the presence of the heparin template. Accordingly, the non-covalent interactions of the dynamic library with $\mathbf{1}$ would stabilize and select the best binders from the mixture, which are finally frozen by the in situ reduction. The UPLC-MS analysis of the reaction mixtures performed in the absence or in the presence of $1(1 \mathrm{mM})$ clearly showed that some of the members of the mixture were amplified in the presence of the polysaccharide, as shown in the plot of the corresponding amplification factors (AF) in Figure 1C. From this screening, the spermine derivatives alkylated with one polar aromatic ring (phenol or pyridine) and one naphthyl moiety were identified as potential ligands. Among them, 3AL (phenol and 1-naphthyl) rendered more reproducible results in the $\mathrm{DCL}$ assays $(3 \mathrm{CL}$ showed a large dispersion of AF along replicates). Thus, the dialkylated spermine 3AL was synthesized at preparative scale. The results obtained for the corresponding symmetric derivatives (3AA and 3LL, Figure 1C) were intriguing and, accordingly, they were also prepared as control molecules.

The fluorescence emission spectrum of $\mathbf{3 A L}$ in aqueous Tris buffer at $\mathrm{pH} 7.5$ was strongly affected by the presence of 1 (Figure $2 A)$. Thus, the addition of heparin led to a decrease of the original band at $345 \mathrm{~nm}$ and the concomitant appearance of a broad emission band centered at $400 \mathrm{~nm}$, suggesting the formation of an excimer of the naphthyl moiety of $3 \mathrm{AL}$ upon binding to 1 . The evolution of the emission band at $400 \mathrm{~nm}$ was used to titrate $\mathbf{3 A L}$ and 3LL (bearing two naphthyl moieties) with 1. Qualitative comparison of the fluorescence titration curves (Figure 2B) showed that the interaction of $\mathbf{1}$ with $\mathbf{3 L L}$ was weaker than with $\mathbf{3 A L}$, in agreement with the dynamic covalent selection experiments. 
A

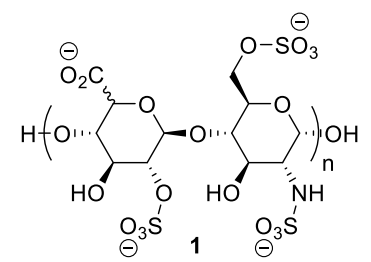

B<smiles>Cc1ccc(C=O)c(O)c1</smiles>

C

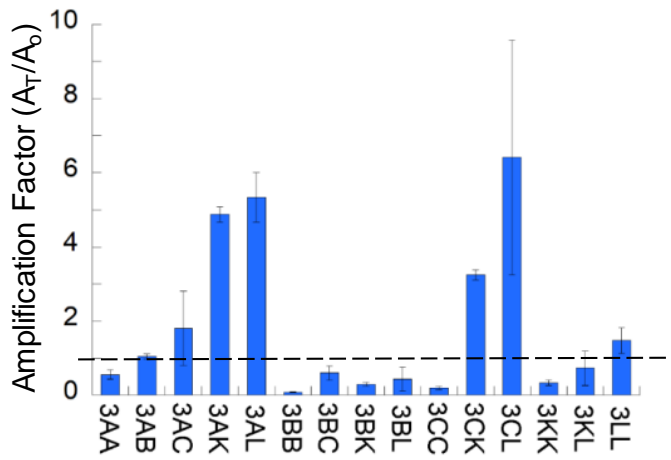

Figure 1. (A) Structure of heparin. (B) Dynamic combinatorial reductive amination sequence used for screening heparin ligands. (C) Plot of the amplification factors, defined as the ratio of the corresponding HPLC peak areas obtained from reactions performed in the presence $\left(A_{T}\right)$ and in the absence $\left(A_{0}\right)$ of heparin. Bars above and below the dashed line mean favored and disfavored members of the library, respectively, due to the presence of heparin

Since the attempts to extract quantitative data from the fluorescence titrations proved to be troublesome, we decided to move to ITC, which allowed a quantitative picture of the process. The calorimetric titration (Figure $2 \mathrm{C}$ ) of $\mathbf{1}$ into a solution of $\mathbf{3 A L}$ rendered a dissociation constant in the low micromolar range $\left(K_{d}\right.$ $=1.3 \mu \mathrm{M}$ ) with an apparent stoichiometry of 7.5 molecules of $3 \mathrm{AL}$ per heparin molecule (on average), implying the existence of a complex multi-equilibria binding. The interaction is endothermic and entropically favored, suggesting important electrostatic and hydrophobic contacts. Remarkably, the ITC of 3LL or 3AA with 1 led to a much weaker interaction with heparin (Figures S6-S7 and Table S1), as expected considering their respective AF in Figure $1 \mathrm{C}$.
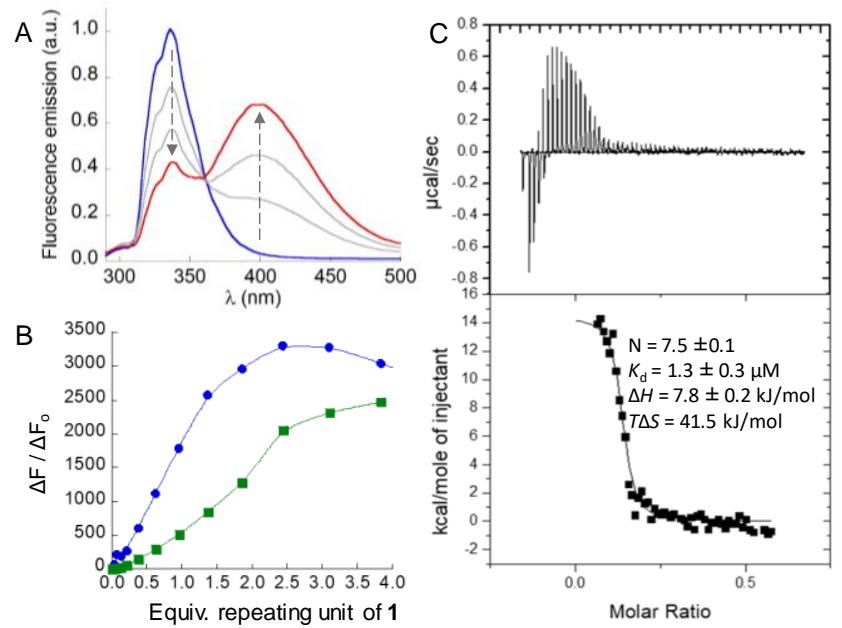

Figure 2. (A) Fluorescence emission $\left(\lambda_{\mathrm{exc}}=280 \mathrm{~nm}\right)$ spectra of $3 \mathrm{AL}(49 \mu \mathrm{M}$ in $5 \mathrm{mM}$ Tris buffer $\mathrm{pH} 7.5$ ) in the absence (blue) and in the presence of increasing amounts of $\mathbf{1}$ (grey to red). (B) Fluorescence titration curves for $3 \mathrm{AL}$ (blue) and 3LL (green) upon addition of 1. (C) ITC curves for the titration of 1 into $3 A L$, with the thermodynamic values obtained from the fitting of the data to a one-site model (see ESI for details). A polydispersed heparin of an average $\mathrm{MW}=12$ $\mathrm{kDa}$ (sodium salt, $\mathrm{n} \sim 17-18$ ) was used in these experiments.

We also performed a set of ${ }^{1} \mathrm{H}$ NMR experiments to obtain a clearer picture of the binding event between $3 \mathrm{AL}$ and heparin. The ${ }^{1} \mathrm{H}$ NMR spectra of $3 \mathrm{AL}$ were acquired in aqueous deuterated Tris buffer at $\mathrm{pH} 7.5$ in the absence and in the presence of a heparin derivative. For a better performance in the ${ }^{1} \mathrm{H}$ NMR experiments, we used dp14 ( $\mathrm{n} 7$ in Figure $1 \mathrm{~A})$, which is a low molecular weight heparin oligosaccharide. Similar trends were obtained with regular unfractionated heparin (Figure S12), although in this case, the analysis was complicated by much broader NMR signals. The addition of dp14 into the solution of 3AL led to a very informative chemical shift perturbation of the ligand signals (Figure $3 \mathrm{~A}$ and S13). The protons in the central spermine moiety moved downfield supporting electrostatic and $\mathrm{H}$ bonding interactions with the anionic groups of dp14. Likewise, most of the naphthyl protons moved upfield, suggesting the participation of the naphthyl ring in the binding, either through $\mathrm{CH}$ $\pi$ interactions with the sugars or by $\pi$-stacking of aromatic rings of different 3AL molecules. On the other hand, the shielding of the anomeric proton signals of dp14 upon addition of 3AL supported the establishment of $\mathrm{CH}-\mathrm{m}$ interactions (Figure S13). Additionally, transferred NOEs (Figure S15) were observed between protons that would be distant in an extended conformation of 3AL (red arrows in Figure $3 \mathrm{~A}$ ), implying the folding of the flexible polyamine to interact with the anionic oligosaccharide.

We aimed at building a structural model for the 3AL-heparin complex, that could explain the experimental data obtained by fluorescence, ITC and NMR. Thus, taking into account the high stoichiometric ratio of the 3AL-heparin complex, a molecular dynamics simulation of a dp16 heparin model $(n=8$ in Figure $1 A)$ plus five $3 \mathbf{A L}$ molecules in explicit water was performed. Starting from a system with the five ligands unbound, the simulation showed a rapid binding of the $3 \mathrm{AL}$ molecules that, once bound, did not leave the heparin surface (Figure S19). 
A
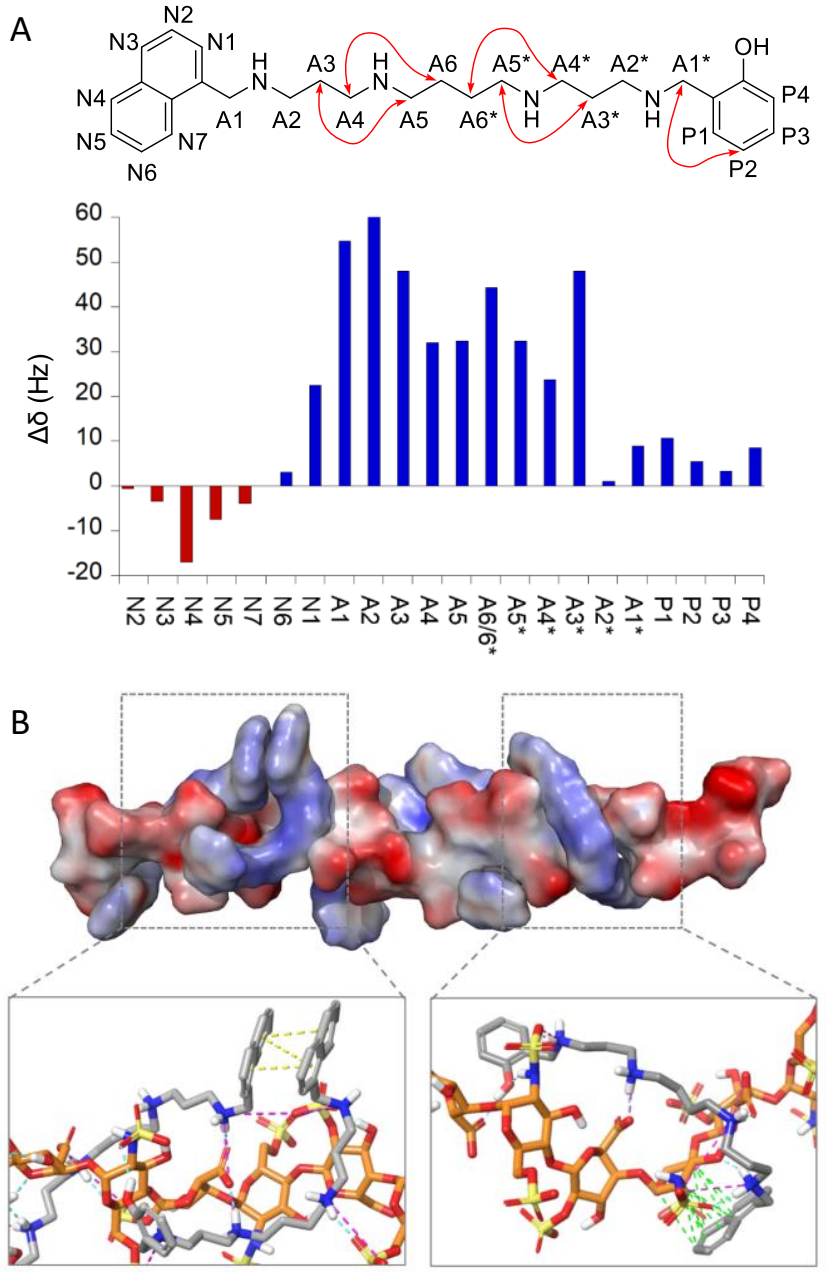

Figure 3. (A) NMR ( $500 \mathrm{MHz}, 5 \mathrm{mM}$ Tris-d11 and $50 \mathrm{mM} \mathrm{NaCl}$ in $\mathrm{D}_{2} 0, \mathrm{pD} 7.5$ ) downfield (blue) and upfield (red) chemical shift perturbation of the protons of 3AL $(0.55 \mathrm{mM})$ upon addition of an excess of dp14 (2.88 $\mathrm{mM}$ in the disaccharide repeating unit). Also the observed trNOE are shown with red double-headed arrows. (B) Representative snapshot (i.e. closest to centroid) of the most populated cluster from an MD simulation ( $500 \mathrm{~ns}$ ) of a system composed of one dp16 heparin model plus five 3AL molecules in explicit water (top), and detail of the dp16/3AL and 3AL/3AL interactions (bottom). The dp16-3AL complex is shown either as electrostatic potential colored surfaces (top) or as sticks (bottom): dp16 with orange C-atoms, 3AL with gray C-atoms, and interactions shown with dashed lines in cyan (H-bonds), purple (salt bridges), yellow ( $\pi-\pi$ stacking) or green ( $\mathrm{CH}-\pi$ interactions).

Cluster analysis of the simulation (2500 frames) yielded one most populated cluster including more than $60 \%$ of the snapshots (Figure S20). A representative snapshot of that cluster shows five bound 3AL molecules, with different binding modes (Figure 3B, top) that go from tightly wrapped around the heparin strand to more loosely bound and establishing $\pi-\pi$ interactions between naphthyl moieties of contiguous 3AL molecules (Figure 3B, bottom left). This naphthyl stacking could account for the excimer band observed in the fluorescence spectra. Figure 3B (bottom right) also shows a detailed view of one of the heparin-3AL complexes stabilized by hydrogen bonds, salt bridges and $\mathrm{CH}-\pi$ interactions between a naphthyl moiety and the non-polar face of one of the sugar rings. Noteworthy, analysis of the intermolecular hydrogen bond interactions during the simulation shows that the five 3AL molecules establish, on average, ca. four $\mathrm{H}$-bonds with heparin (Figure S21). These results agree with the chemical shift perturbation data (Figure 3A) and also support our initial guess of the putative supramolecular binding motives. Moreover, the aliphatic proton-pairs $A 3-A 5, A 4-A 6, A 3^{*}-A 5^{*}$ and $A 4^{*}-A 6^{*}$ transiently reach distances between 2-3 $\AA$ during the simulation (Figure S21), which explains the observed transferred NOEs.

In order to establish the potential biological activity of $\mathbf{3 A L}$, we designed an enzymatic assay as a simplified model of the blood coagulation cascade reaction (Figure 4A). Thus, recombinant human coagulation factor $\mathrm{Xa}(\mathrm{FXa})$ and antithrombin III (AT III) were used in combination with a synthetic peptide (Z-D-LGR$\mathrm{N}(\mathrm{Me}) \mathrm{ANBA}$ ) that mimics the substrate of the human coagulation factor $\mathrm{FXa}$, which in this case releases a chromogenic moiety (ANBA-NHMe). ${ }^{[19]}$ In the absence of other heparin binders, the antithrombin III-heparin complex is a very efficient inhibitor of the FXa protease (Figure 4A). This inhibition of Factor Xa protease activity leads to a slower rate of the peptide hydrolysis in the presence of heparin (brown trace in Figure 4B) than in its absence (black trace in Figure 4B). Addition of increasing concentrations of $3 \mathrm{AL}$ efficiently restored the hydrolytic activity of the FXa protease, probably by displacing the heparin from its complex with $A T_{\text {III }}$ (Figure 4B). The same experiment performed with a higher concentration of heparin (Figure S17) required also a proportionally higher concentration of $3 \mathrm{AL}$. Moreover, a reaction containing 1 and fixed amounts of $3 \mathbf{A L}, \mathrm{FXa}$ and $A \mathrm{~T}_{|| \mid}$recovered the inhibitory effect of the [AT III-1] complex upon additional heparin (Figure S18). These control experiments imply that the effect of $3 A L$ on FXa (hydrolysis of the peptide) is exclusively determined by the interaction of $\mathbf{3 A L}$ with 1 .
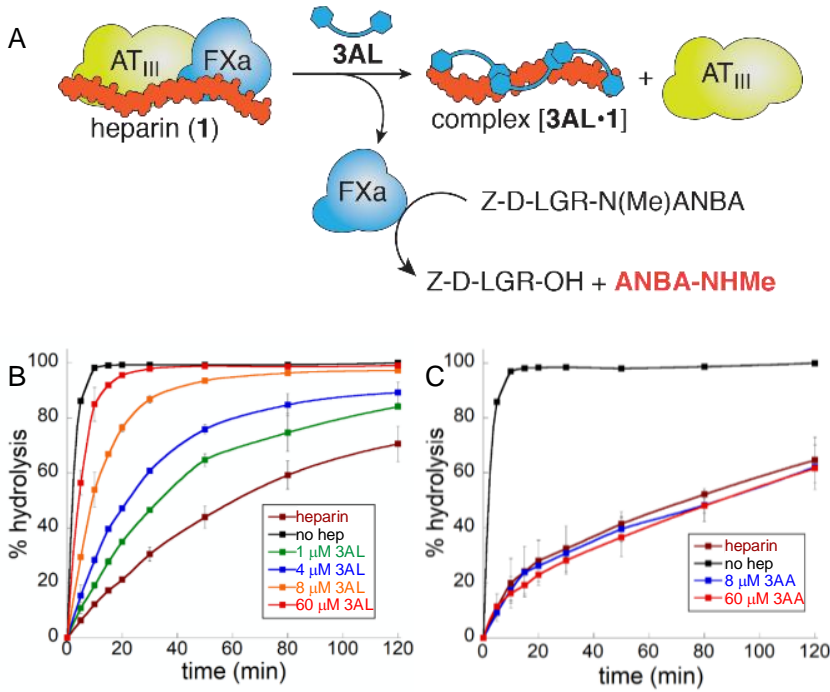

Figure 4. Effect of a heparin ligand (3AL) on the blood coagulation enzymatic cascade. (A) Schematic representation of the heparin/ATw/FXa interaction. (B) Plot of the percent of the hydrolysis of the Z-D-Leu-Gly-Arg-NMe-AMBA peptide (measured by HPLC) catalyzed by the FXa/AT III system in the absence (black) or in the presence of $0.4 \mathrm{IU} / \mathrm{mL}$ of 1 (brown). Increasing concentrations of the ligand 3AL (green, blue, orange, red) inhibits the action of $\mathbf{1}$ by competing with $A T_{I I I}$ for the binding to heparin, restoring the proteolytic activity of FXa. (C) As in (B) but using 3AA. 
More interestingly, the closely related ligand 3AA produced no effect on the same enzymatic assay (Figure 4C). This result definitively validated our dynamic covalent screening protocol for the identification of a selective heparin ligand. The most amplified compound in the dynamic combinatorial library upon addition of heparin (3AL) is able to bind and inhibit the effect of the polysaccharide. Meanwhile, a structurally related polycation that is disfavored in the dynamic covalent experiment (3AA, with an $\mathrm{AF}<1$ ) shows a much weaker interaction and, accordingly, no inhibition of heparin.

In conclusion, an efficient small molecule ligand for heparin has been identified using a dynamic covalent chemistry approach. The amplified structure strongly interacts with heparin in aqueous medium and it also reverses the inhibition effect of heparin on a blood coagulation enzymatic model reaction. These results underscore the power of dynamic combinatorial solutions to specially challenging biomolecular recognition processes, such as those implicating structurally ill-defined targets. Moreover, our proof-of-concept study paves the way toward a simple and general methodology for the discovery of new modulators against different biologically relevant glycosaminoglycans. ${ }^{[20]}$

\section{Acknowledgements}

Financial Support from the Spanish Ministry of Economy, Industry and Competitiveness (MINECO/FEDER, CTQ2015-70117-R) and AGAUR (2017 SGR 208) is gratefully acknowledged. The 500 $\mathrm{MHz}$ spectrometer and cryoprobe in the IQAC NMR facility were funded by the CSIC13-4E2076 MINECO-FEDER grant.

Keywords: heparin $\cdot$ dynamic covalent chemistry $\cdot$ molecular recognition $\cdot$ supramolecular chemistry $\bullet$ glycosaminoglycans

[1] J. I. Weitz, J. Haremberg, Thromb. Haemost. 2017, 7, 1283-1288.

[2] (a) B. I. Ayerst, C. L. R. Merry, A. J. Day, Pharmaceuticals 2017, 10, 54 (b) M. M. Martino, P. S. Briquez, K. Maruyama, J. A. Hubbell, Adv. Drug Deliv. Rev. 2015, 94, 41-52.

[3] E. Young, Thromb. Res. 2008, 122, 743-752.

[4] (a) B. Ricciuti, J. Foglietta, R. Chiari, A. Sahebkar, M. Banach, V. Bianconi, M. Pirro, Med. Oncol. 2018, 35, 4; (b) E. Donnellan, A. A. Khorana, Oncologist 2017, 22, 199-207.

[5] C. Tieken, H. H. Versteeg, Thromb. Res. 2016, 140S1, S148-S153.

[6] N. S. Gandhi, R. L. Mancera, Drug Discov. Today 2010, 15, 1058-1069.

[7] (a) I. Fernández-Ruiz, Nat. Rev. Cardiol. doi:10.1038/nrcardio.2017.175; (b) G. B. Lim, Nat. Rev. Cardiol. doi:10.1038/nrcardio.2017.174

[8] B. Williams, B. Wehman, M. A. Mazzeffi, P. Odonkor, R. L. Harris, Z. Kon, K. A. Tanaka, Anesth. Analg. 2018, 126, 425-434.
[9] (a) J. M. Whitelock, R. V. lozzo, Chem. Rev. 2005, 105, 2745-2764; (b) D. L. Rabenstein, Nat. Prod. Rep. 2002, 19, 312-331.

[10] (a) Z. Zhang, B. Li, J. Suwan, F. Zhang, Z. Wang, H. Liu, B. Mulloy, R. J. Linhardt, J. Pharm. Sci. 2009, 98, 4017-4026; (b) S. Middeldorp, Thromb. Res. 2008, 122, 753-762.

[11] C. Boer, M. I. Meesters, D. Veerhoek, A. B. A. Vonk, Brit. J. Anaesth 2018, 120, 914-927.

[12] (a) R. J. Weiss, J. D. Esko, Y. Tor, Org. Biomol. Chem. 2017, 15, 5656 5668. (b) R. J. Weiss, P. L. S. M. Gordts, D. Le, D. Xu, J. D. Esko, Y. Tor, Chem. Sci. 2015, 6, 5984-5993.

[13] (a) C. Noti, P. H. Seeberger, Chem. Biol. 2005, 12, 731-756; (b) I.; Capila, R. J. Linhardt, Angew. Chem., Int. Ed. 2002, 41, 390-412; Angew. Chem. 2002, 114, 426-450.

[14] (a) S. M. Bromfield, A. Barnard, P. Posocco, M. Fermeglia, S. Pricl, D. K. Smith, J. Am. Chem. Soc. 2013, 135, 2911-2914; (b) D. Maity, C Schmuck, Chem. Eur. J. 2016, 22, 13156-13161.

[15] (a) G. Ashkenasy, T. M. Hermans, S. Otto, A. F. Taylor, Chem. Soc. Rev. 2017,46, 2543-2554; (b) E. Mattia, S. Otto, Nat. Nanotechnol. 2015, 10 111; (c) J. Li, P. Nowak, S. Otto, J. Am. Chem. Soc. 2013, 135, 9222 9239; (d) S. Otto, Acc. Chem. Res. 2012, 45, 2200-2210; (e) M. Barboiu, Constitutional Dynamic Chemistry: Bridge from Supramolecular Chemistry to Adaptive Chemistry. Springer-Verlag Berlin Heidelberg 2012; (f) R. F. Ludlow, S. Otto, Chem. Soc. Rev. 2008, 37, 101-108; (g) P. T. Corbett, J. Leclaire, L. Vial, K. R. West, V. Wietor, J. K. M. Sanders S. Otto, Chem. Rev. 2006, 106, 3652-3711; (h) J. M. Lehn, A. V. Eliseev Science. 2001, 291, 2331-2332.

[16] (a) K. A. McCarthy, M. A. Kelly, K. Li, S. Cambray, A. S. Hosseini, van T. Opijnen, J. Gao, J. Am. Chem. Soc. 2018, 140, 6137-6145; (b) J. F. Reuther, A. C. Goodrich, P. R. Escamilla, T. A. Lu, V. Del Rio, B. W Davies, E. V. Anslyn, J. Am. Chem. Soc. 2018, 140, 3768-3774; (c) M. Mondal, A. K. H. Hirsch, Chem. Soc. Rev. 2015, 44, 2455-2488; (d) A Herrmann, Chem. Soc. Rev. 2014, 43, 1899-1933; (e) O. Ramström, J. M. Lehn, Nat. Rev. Drug Discov. 2002, 1, 26-36.

[17] (a) A. De Robertis, C. De Stefano, A. Gianguzza, S. Sammartano, Talanta 1999, 48, 119-126; (b) C. Bazzicalupi, A. Bencini, A. Bianchi, M. Cecchi, B. Escuder, V. Fusi, E. García-España, C. Giorgi, S. V. Luis, G. Maccagni, V. Marcelino, P. Paoletti, B. Valtancoli, J. Am. Chem. Soc. 1999, 121, 6807-6815.

[18] (a) T. J. Mooibroek, J. M. Casas-Solvas, R. L. Harniman, C. M. Renney, T. S. Carter, M. P. Crump, A. P. Davis, Nat. Chem. 2016, 8, 69-74; (b) E. Jiménez-Moreno, A. M. Gómez, F. Corzana, G. Jiménez-Osés, A. Bastida, J. Jiménez-Barbero, J. L. Asensio, Angew.Chem. Int. Ed. 2015 54, 4344-434; Angew. Chem. 2015, 127,4418-4422; (b) E. JiménezMoreno, G. Jiménez-Osés, A. M. Gómez, A. G. Santana, F. Corzana, A. Bastida, J. Jiménez-Barbero, J. L. Asensio, Chem. Sci. 2015, 6, 60766085; (c) J. L. Asensio, A. Ardá, F. J. Cañada, J. Jiménez-Barbero, Acc. Chem. Res. 2013, 46, 946-954.

[19] A. N. Teien, M. Lie, Thromb. Res. 1977, 10, 399-410.

[20] (a) T. Adage, A.-M. Piccinini, A. Falsone, M. Trinker, J. Robinson, B. Gesslbauer, A. J. Kungl, Br. J. Pharmacol. 2012, 167, 1195-1205; (b) A Rek, E. Krenn, A. J. Kungl, Br. J. Pharmacol. 2009, 157, 686-694; (c) C I. Gama, L. C. Hsieh-Wilson, Curr. Opin. Chem Biol. 2005, 9, 609-619. 
Entry for the Table of Contents (Please choose one layout)

Layout 1:

\section{COMMUNICATION}

A dynamic covalent chemistry approach leads to the identification of an efficient ligand for heparin, which strongly binds and inhibits this anionic polysaccharide. The simple and modular methodology could be easily applied to other glycosaminoglycans.

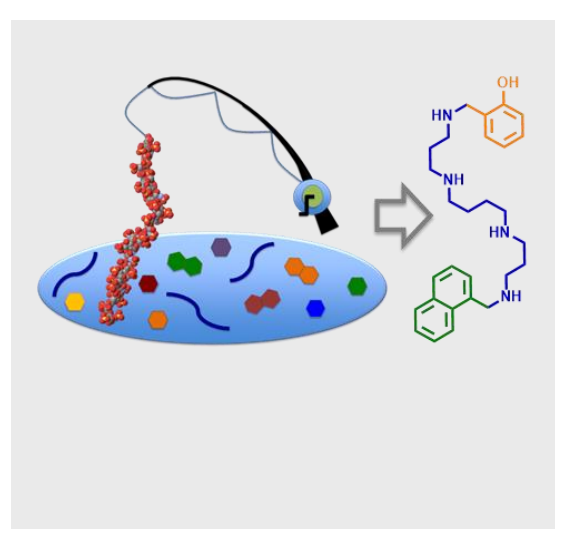

Miriam Corredor, Daniel Carbajo, Cecilia Domingo, Yolanda Pérez, Jordi Bujons, Angel Messeguer, Ignacio Alfonso*

Page No. - Page No.

Dynamic covalent identification of an efficient heparin ligand

Layout 2:

COMMUNICATION

Author(s), Corresponding Author(s)*

Page No. - Page No.

Title

Text for Table of Contents 


\section{Table of contents:}

General methods

Dynamic covalent chemistry assays for the heparin ligand screening....................................................S2

Preparative scale synthesis of the dialkylated spermine derivatives ............................................................S5

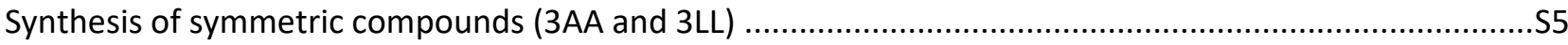

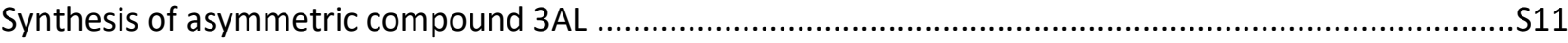

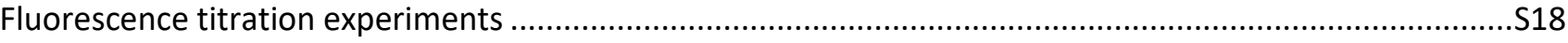

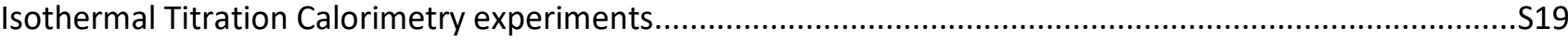

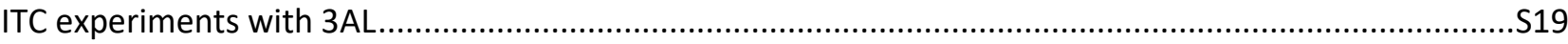

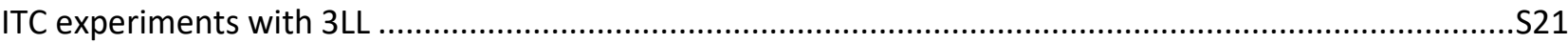

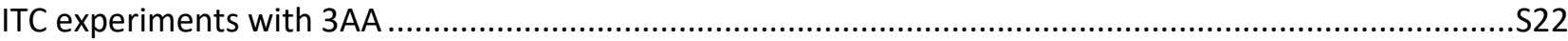

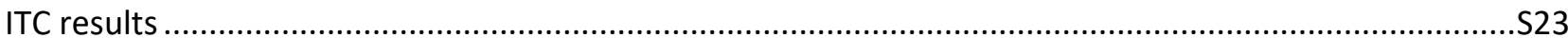

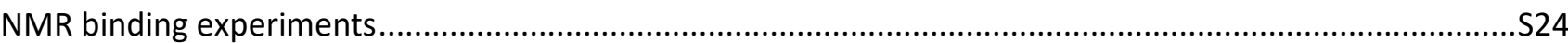

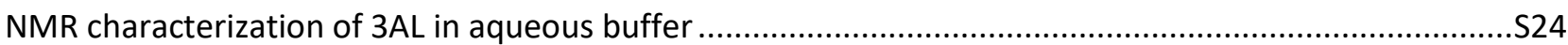

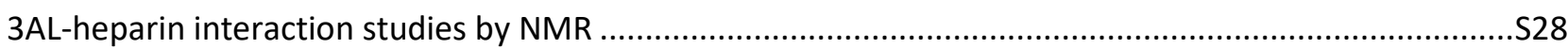

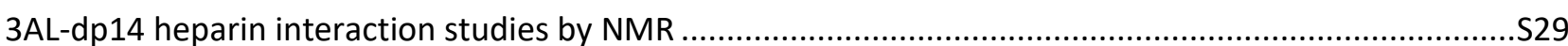

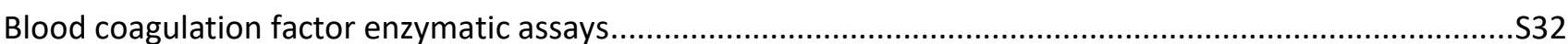

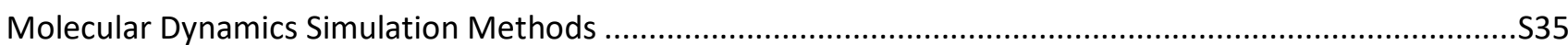

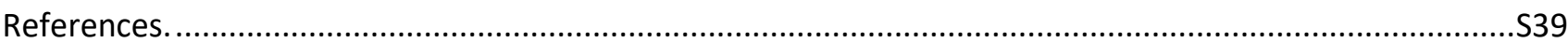




\section{General methods}

General: Reagents and solvents were purchased from commercial suppliers (Aldrich, Fluka or Merck) and were used without further purification. Flash chromatographic purifications and preparative reversed-phase purifications were performed on a Biotage ${ }^{-}$Isolera Prime ${ }^{\mathrm{TM}}$ equipment. TLCs were performed using $6 \times 3 \mathrm{~cm}$ $\mathrm{SiO}_{2}$ pre-coated aluminium plates (ALUGRAM ${ }^{\circ} \mathrm{SIL} \mathrm{G} / \mathrm{UV}_{254}$ ).

Nuclear Magnetic Resonance (NMR): Spectroscopic experiments for the characterization of compounds were carried out on a Varian Mercury 400 instrument ( $400 \mathrm{MHz}$ for ${ }^{1} \mathrm{H}$ and $101 \mathrm{MHz}$ for ${ }^{13} \mathrm{C}$ ). Chemical shifts $\left(\delta_{\mathrm{H}}\right)$ are quoted in parts per million (ppm) and referenced to the appropriate NMR solvent peak(s). 2D-NMR experiments COSY, HSQC and HMBC were used where necessary in assigning NMR spectra. Spin-spin coupling constants $(J)$ are reported in Hertz $(\mathrm{Hz})$. For the experiments performed in aqueous buffer a low molecular weight heparin was used: dp14 (from Iduron, prepared by high resolution gel filtration of partial heparin lyase digestion of high quality heparin, MW average 4100). One- and two-dimensional (1D and 2D) NMR experiments were performed at $298 \mathrm{~K}$ on a $500 \mathrm{MHz}$ Bruker AVANCEIII-HD equipped with a z-gradient (65.7 G $\mathrm{cm}^{-1}$ ) inverse $\mathrm{TCl}$-cryoprobe. Samples were dissolved in $5 \mathrm{mM}$ Tris-d11 buffer with $50 \mathrm{mM} \mathrm{NaCl}$ (in $\mathrm{D}_{2} \mathrm{O}, \mathrm{pH}$ 7.5, uncorrected $\mathrm{pH}$ meter reading). Bruker TopSspin 3.5pl6 standard pulse sequences were used for 1D and 2D experiments. 2D ${ }^{1} \mathrm{H}-{ }^{1} \mathrm{H}$ experiments, TOCSY with zero-quantum suppression (DIPSI2GPPHZS, TM=70ms), NOESY with zero-quantum suppression (NOESYGPPHZS, TM=200ms) and TROESY (ROESYGPPH19.2, $\mathrm{TM}=250 \mathrm{~ms}$ ) were adquired for $3 \mathrm{AL}$ with and without dp14 heparin. Also, for $3 \mathrm{AL}$ compound, $2 \mathrm{D}{ }^{1} \mathrm{H}-{ }^{13} \mathrm{C}$ (HSQCETGPSISP2 and HMBCETGPL3ND) experiments were acquired. For full-length heparin-3AL titration (Figure S9), the CPMG spin-echo pulse sequence with pre-saturation (CPMGPR1D) was used, which follows the scheme: recycle delay $-\left[-90^{\circ}-\left(\tau-180^{\circ}-\tau\right) n-F I D\right]$, with a $\tau=$ 'variable' and $n=$ 'variable' (for a fixed CPMG loop cycle) as a T2-filter; these experiments were acquired with $\mathrm{n}$ fixed to 6 cycles and a $\tau$ value of $1 \mathrm{~ms}$.

Liquid Chromatography coupled to Mass Spectrometry: Analyses were carried out at the IQAC Mass Spectrometry Facility, using a UPLC-ESI-TOF equipment: [Acquity UPLC ${ }^{\circ}$ BEH $C_{18} 1.7 \mathrm{~mm}, 2.1 \times 100 \mathrm{~mm}$, LCT Premier Xe, Waters]. $\left(\mathrm{CH}_{3} \mathrm{CN}+20 \mathrm{mM} \mathrm{HCOOH}\right.$ and $\left.\mathrm{H}_{2} \mathrm{O}+20 \mathrm{mM} \mathrm{HCOOH}\right)$ mixtures at $0.3 \mathrm{~mL} / \mathrm{min}$ were used as mobile phase.

Fluorescence spectroscopy: Fluorescence emission and excitation spectra were collected on a Photon Technology International Instrument, the Fluorescence Master Systems, using the Software Felix32 and cuvettes with $10 \mathrm{~mm}$ path length.

\section{Dynamic covalent chemistry assays for the heparin ligand screening}

A stock solution of imines was prepared by dissolving the necessary amounts of spermine and the aromatic aldehydes in $\mathrm{MeOH}$ rendering a final concentration of $10 \mathrm{mM}$ in all the reagents. Then, two reaction mixtures were prepared in separate eppendorfs from the same stock solution of the imines by mixing $10 \mu \mathrm{L}$ of the imine stock solution with $90 \mu \mathrm{L}$ of a solution of $5 \mathrm{mM} \mathrm{NaBH}{ }_{3} \mathrm{CN}$ in aqueous $50 \mathrm{mM}$ Tris Buffer at $\mathrm{pH} 7.5$ ( $1 \mathrm{mM}$ final concentration of both spermine and each of the aldehydes) either in the absence or the presence of $1.2 \mathrm{mg}$ of heparin ( $1 \mathrm{mM}$ final concentration of heparin, $\sim 17-18 \mathrm{mM}$ on repeating unit). The mixtures were allowed to react at room temperature for 24 hours and after that quenched with $50 \mu \mathrm{L}$ of $2 \mathrm{M} \mathrm{HCl}$, two-fold diluted with water and analyzed by UPLC-MS. The assignment of the peaks observed in the reactions was done on the basis of the $\mathrm{m} / \mathrm{z}$ values and confirmed by injection of samples obtained from deconvoluted sublibraries. The amplification factors were calculated by dividing the normalized areas of the corresponding HPLC peaks in the presence of heparin $\left(A_{T}\right)$ by the areas obtained in the absence of heparin $\left(A_{0}\right)$. The results shown in Figure $1 C$ of the manuscript are the average of three independent assays under the optimized reaction conditions.

The observed species were assigned by ion-detection UPLC-MS experiments. 


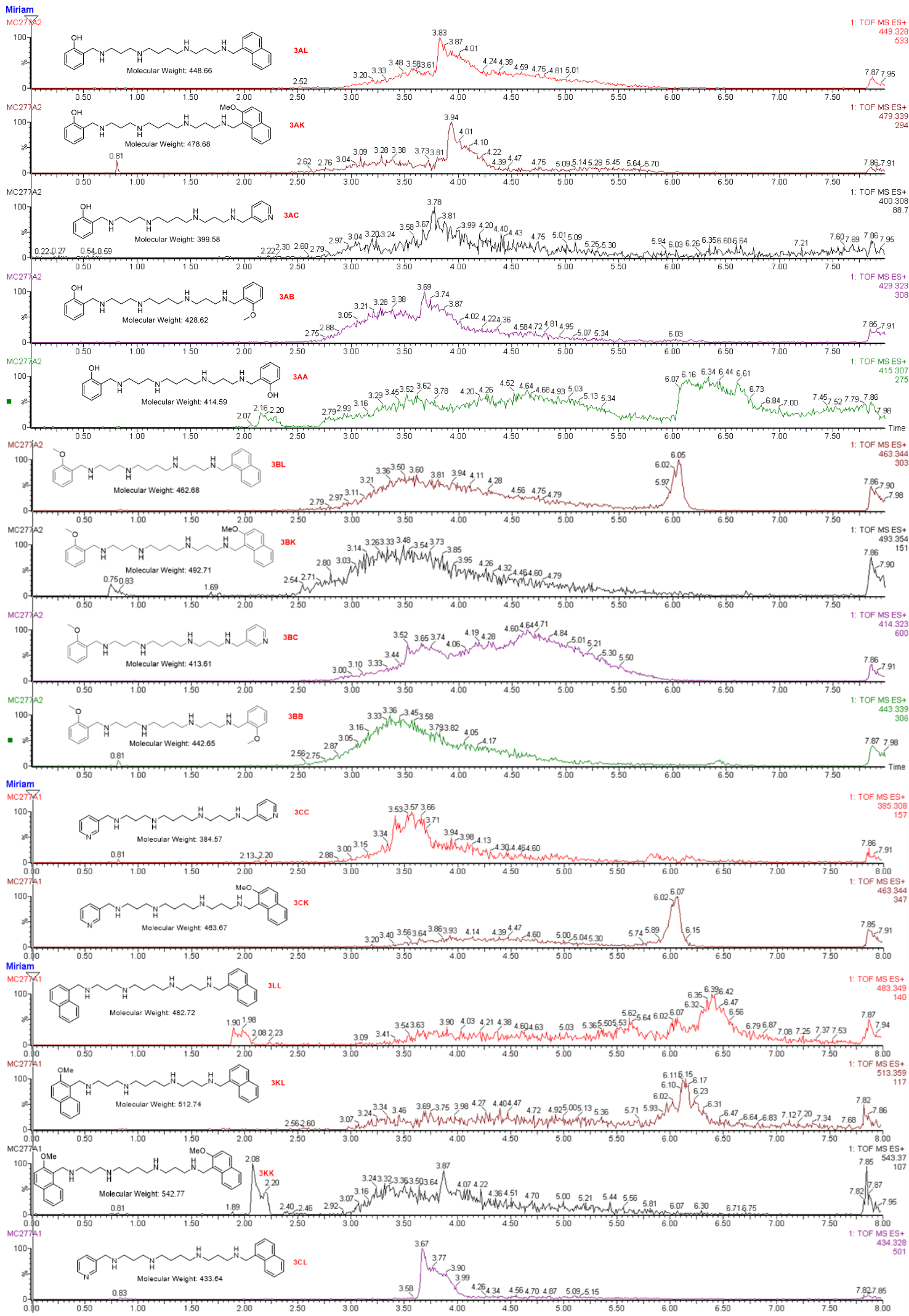

Figure S1. Ion-selective HPLC traces for each library member obtained from the reductive amination reaction in the absence of heparin. The two numbers on the right corner of each chromatogram correspond to the $\mathrm{m} / \mathrm{z}$ values and the peak area, respectively. 


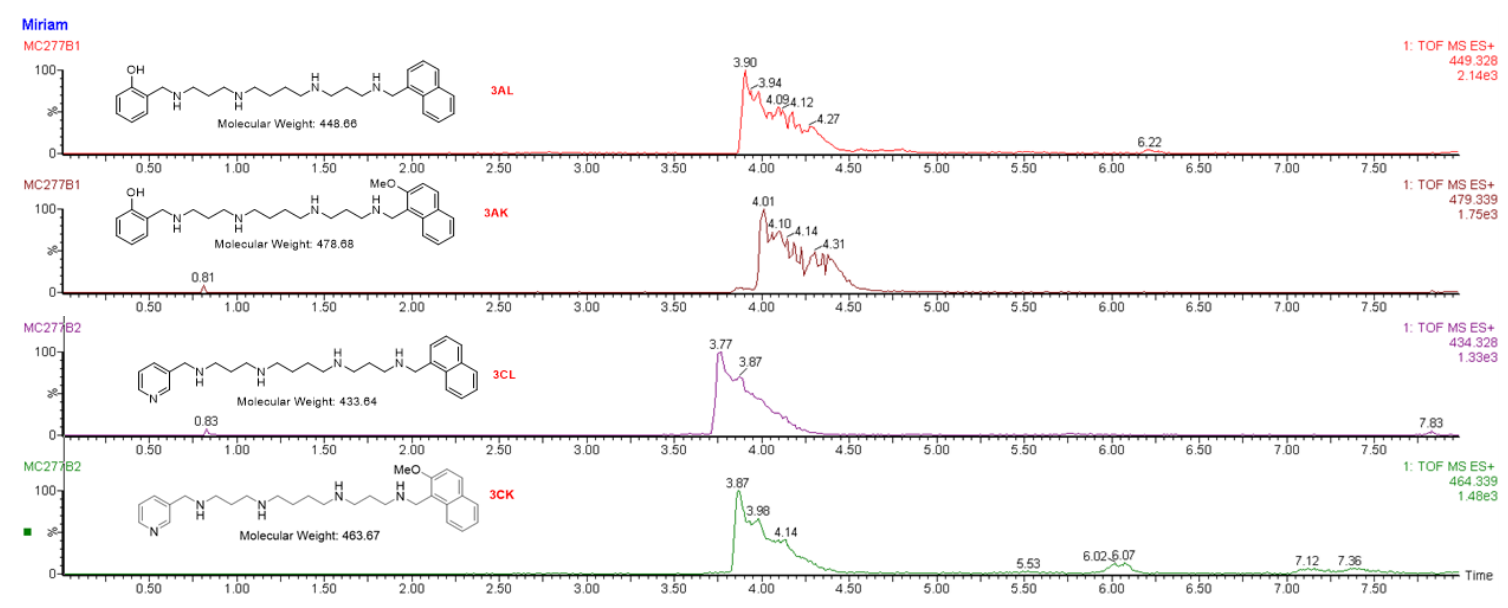

Figure S2. Ion-selective UPLC traces for selected library members obtained from the reductive amination reaction in the presence of heparin. The most amplified members are shown. 


\section{Preparative scale synthesis of the dialkylated spermine derivatives}

Synthesis of symmetric compounds (3AA and $3 \mathrm{LL}$ )

\section{Synthesis of 3AA:}<smiles>CCON(CC)CCCNCCCNCCCNCc1ccccc1O</smiles>

To a spermine ( $81 \mathrm{mg}, 0.4 \mathrm{mmol})$ solution in $\mathrm{MeOH}(2 \mathrm{~mL})$ a solution of salicylaldehyde $(84 \mu \mathrm{L}, 0.8 \mathrm{mmol})$ in $\mathrm{MeOH}(1 \mathrm{~mL})$ was added drop by drop. The resulting reaction mixture was stirred overnight at ambient temperature. Then, $\mathrm{NaBH}_{4}(120 \mathrm{mg}, 8 \mathrm{eq})$ was added and the reaction was stirred for 6 hours. After addition of $\mathrm{H}_{2} \mathrm{O}(1 \mathrm{~mL})$ and $\mathrm{HCl} 2 \mathrm{~N}(2 \mathrm{~mL})$, the reaction mixture was stirred for 3 hours, evaporated and purified by reverse phase chromatography with a gradient of ACN (1\% TFA) and water (1\% TFA) to yield $134 \mathrm{mg}(0.15$ $\mathrm{mmol}, 38 \%)$ as a TFA salt with $95 \%$ purity.<smiles>CC(NCCCNCCCCCNCCCNCc1ccccc1O)c1ccccc1O</smiles>

${ }^{1} \mathrm{H}-\mathrm{NMR}$ (MeOD, $400 \mathrm{MHz}$ ): $\delta$ (ppm) 7.39-7.15 (m, 4H, H10,12), 7.03-6.78 (m, 4H, H9, 10), 4.22 (s, 4H, H1), 3.18-3.09 (m, 8H, H2,4), 3.07 (m, 4H, H5), $2.16(\mathrm{~m}, 4 \mathrm{H}, 3 \mathrm{H}), 1.80(\mathrm{~m}, 4 \mathrm{H}, \mathrm{H} 6){ }^{13} \mathrm{C}-\mathrm{NMR}$ (MeOD, $\left.100 \mathrm{MHz}\right): \delta$ (ppm) 156.1 (C8), 131.1 (C10), 131.0 (C12), 119.6 (C11), 117.0 (C7), 114.9 (C9), 46.7 (C5), 46.6 (C1), 44.4 (C4), 43.8 (C2), 22.8 (C6), 22.5 (C3) HRMS for $\mathrm{C}_{24} \mathrm{H}_{39} \mathrm{~N}_{4} \mathrm{O}_{2}$ : Calculated: $415.3073(\mathrm{M}+\mathrm{H})^{+}$; found: 415.3056.

\section{HPLC and HRMS}
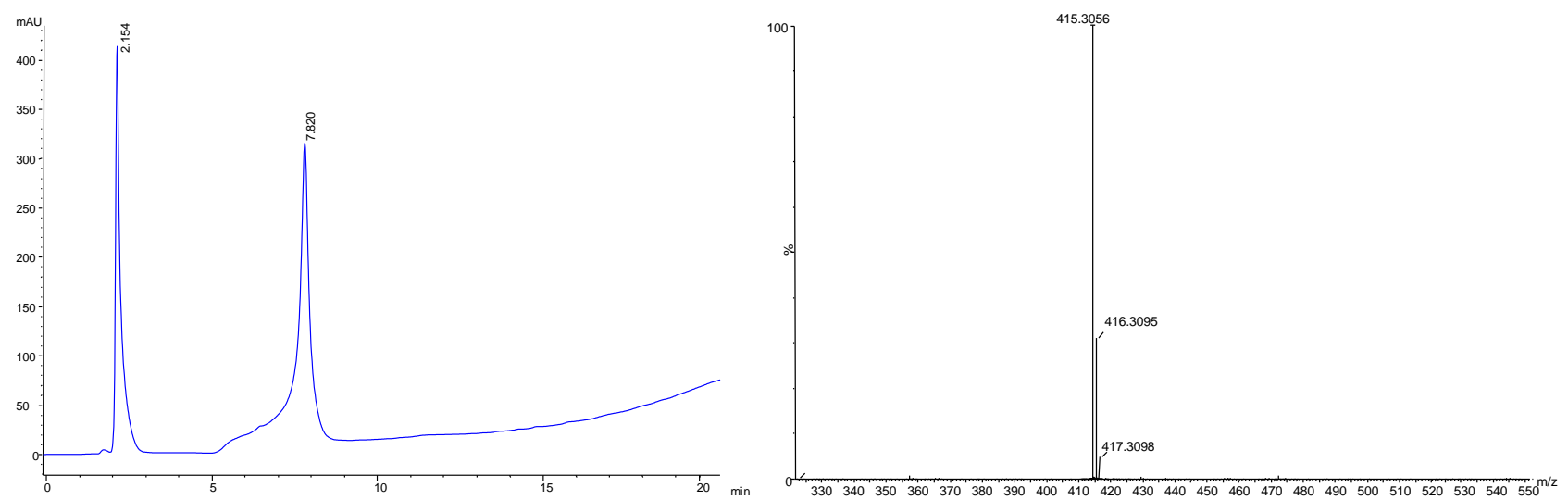


\section{${ }^{1}$ H NMR}

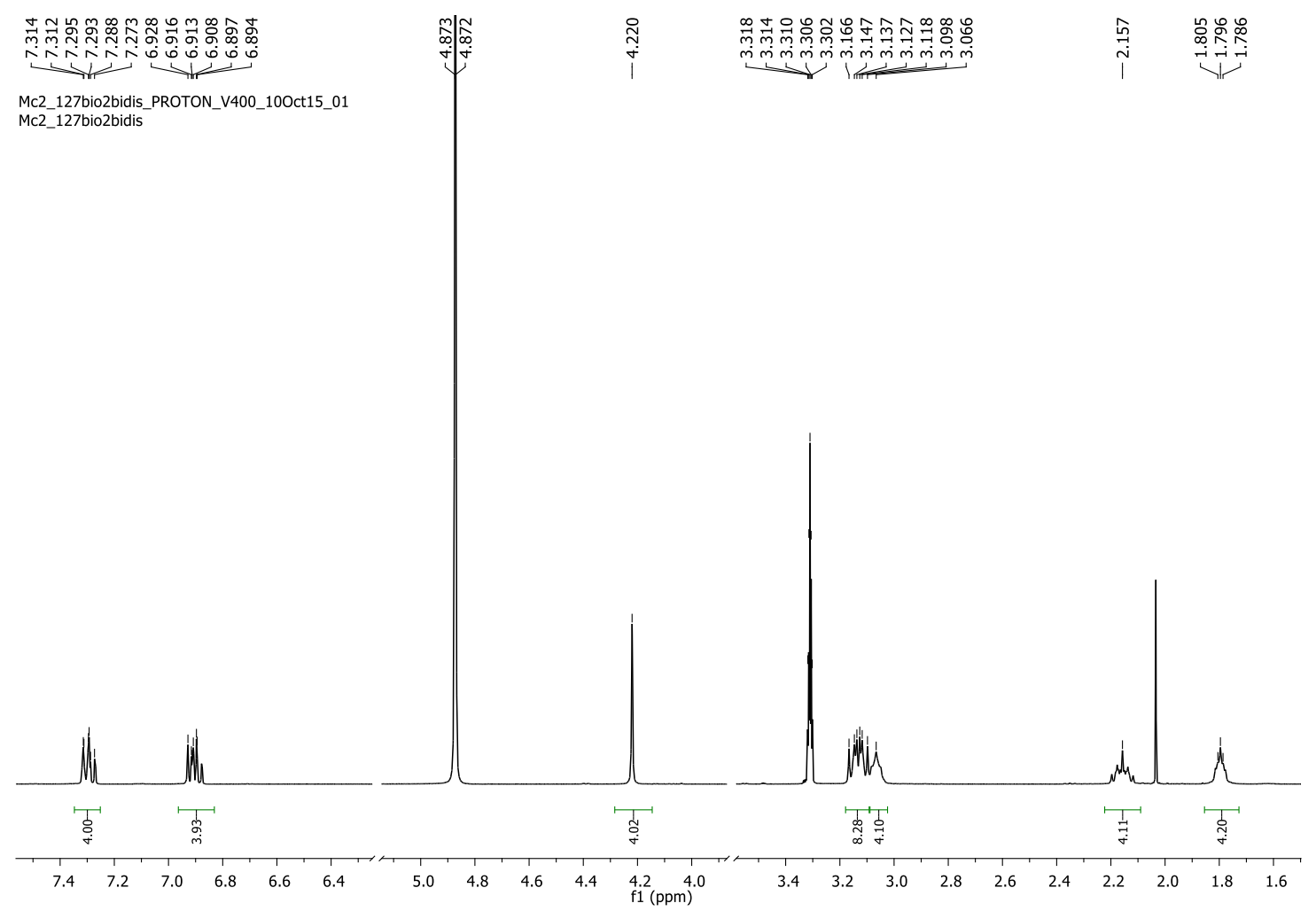

${ }^{13}$ C NMR

Mc2_127bio2bidis_CARBON_V400_100ct15_01
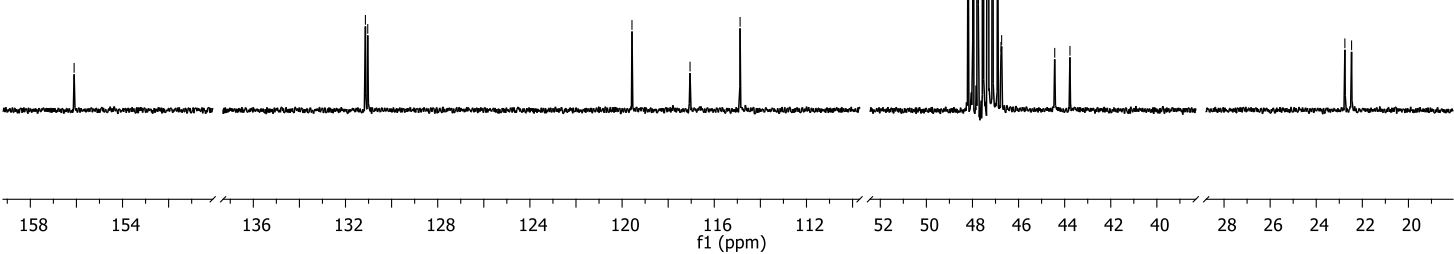
${ }^{1} \mathrm{H}-{ }^{13} \mathrm{C}$ HSQC

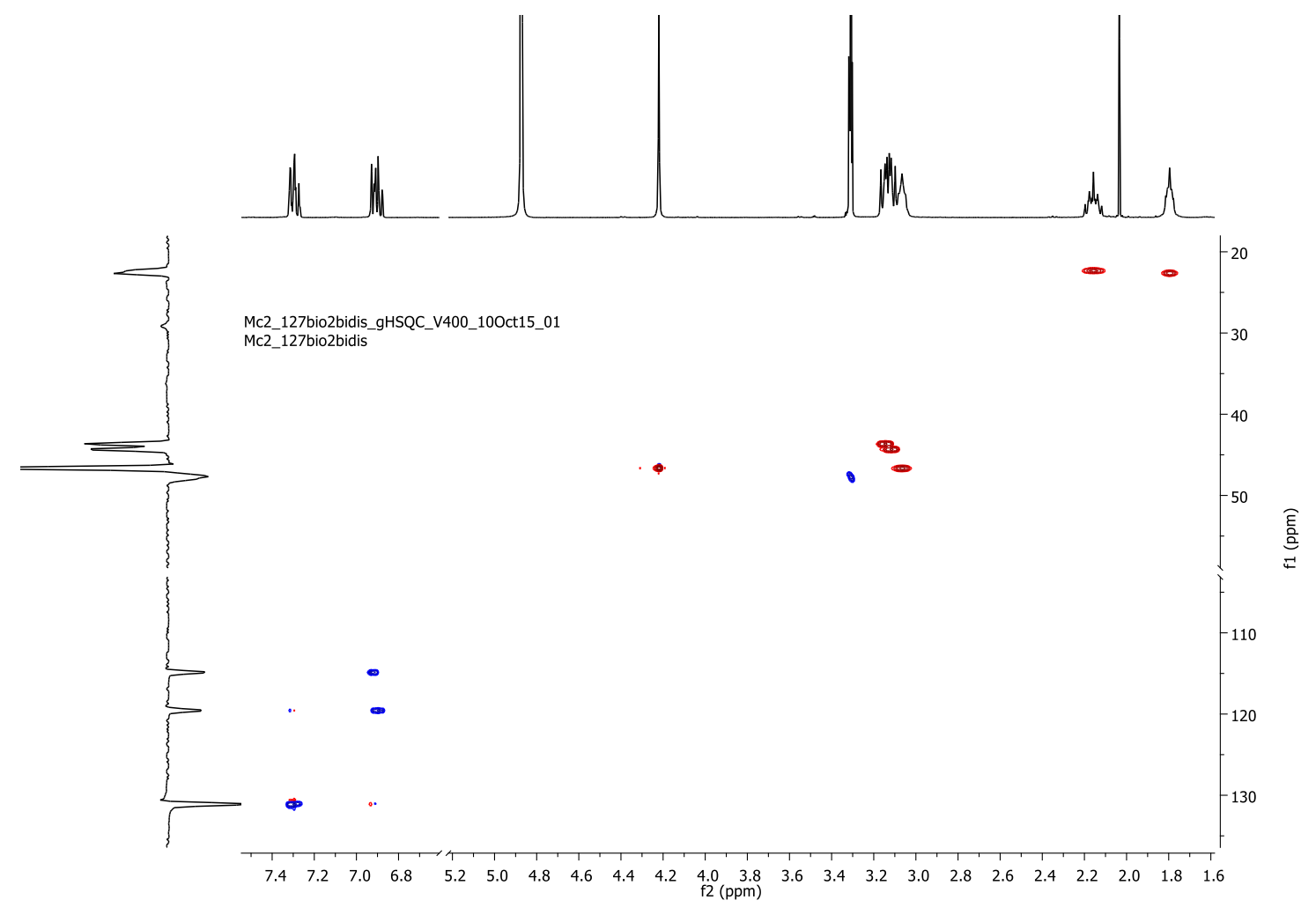

\section{${ }^{1} \mathrm{H}-{ }^{13} \mathrm{C}$ HMBC}

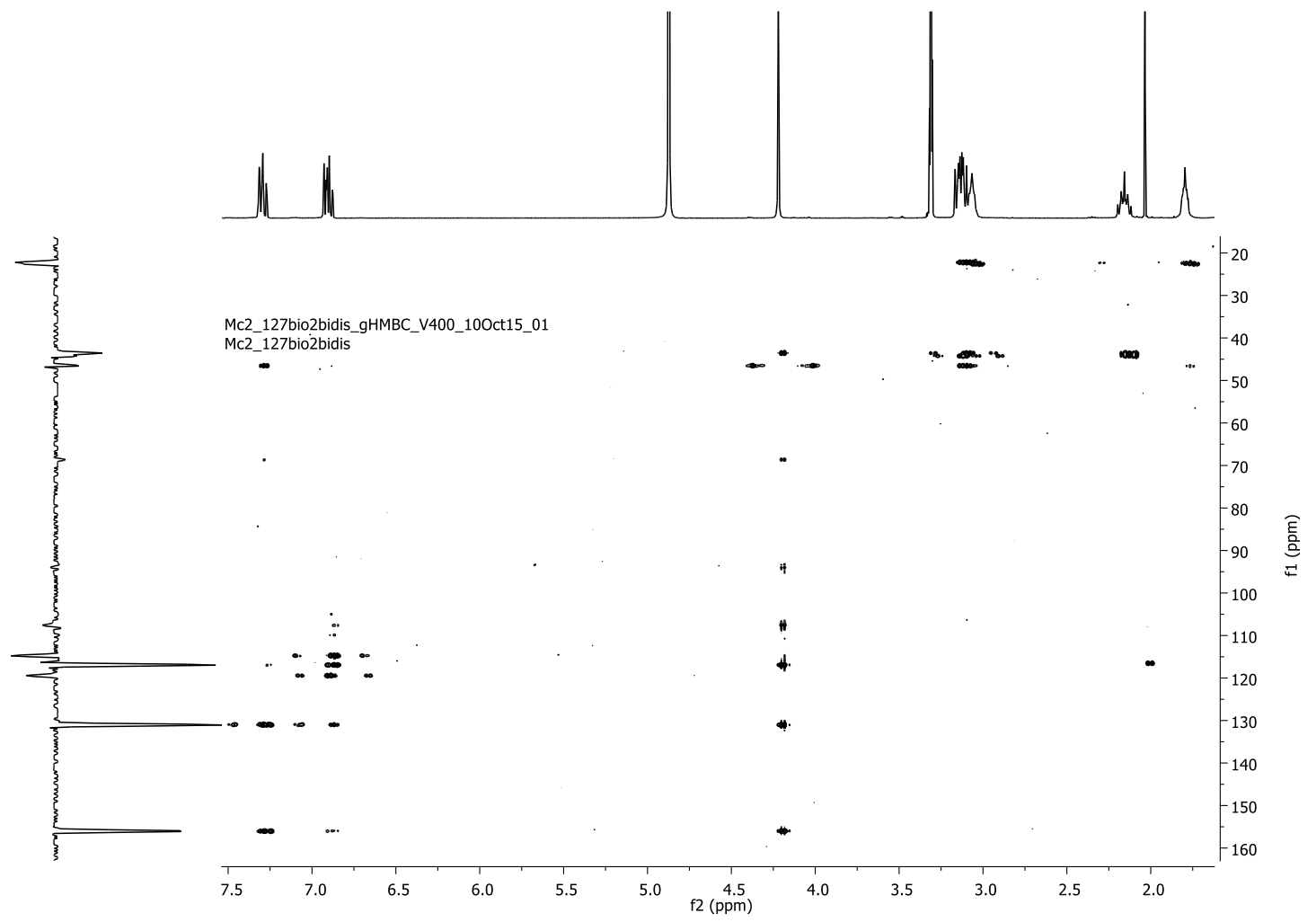




\section{Synthesis of 3LL:}<smiles>COCCCNCCCNCCCNCCCNCCCNCCCNCc1cccc2ccccc12</smiles>

To a spermine $(81 \mathrm{mg}, 0.4 \mathrm{mmol})$ solution in $\mathrm{MeOH}(2 \mathrm{~mL})$ a solution of 1-naphthylaldehyde (108 $\mu \mathrm{L}, 0.8 \mathrm{mmol})$ in $\mathrm{MeOH}(1 \mathrm{~mL})$ was added. The resulting reaction mixture was stirred overnight at ambient temperature. Then, $\mathrm{NaBH}_{4}(120 \mathrm{mg}, 8 \mathrm{eq})$ was added and the reaction was stirred for 6 hours. After addition of $\mathrm{H}_{2} \mathrm{O}(1 \mathrm{~mL})$ and $\mathrm{HCl} 2 \mathrm{~N}(2 \mathrm{~mL})$, the reaction mixture was stirred for 3 hours, evaporated and purified by reverse phase chromatography with a gradient of ACN (1\% TFA) and water (1\% TFA) to yield $30 \mathrm{mg}(0.03 \mathrm{mmol}, 8 \%)$ of product as a TFA salt with $95 \%$ purity, because the mono-substituted product is obtained during the reaction.<smiles>CCCNCCCNCCCNCc1cccc2ccccc12</smiles>

${ }^{1} \mathrm{H}-\mathrm{NMR}$ (MeOD, $400 \mathrm{MHz}$ ): $\delta$ (ppm) 8.16 (d, $\left.J=8.5 \mathrm{~Hz}, 2 \mathrm{H}, \mathrm{H} 15\right), 8.01$ (dd, $J=10.0,8.5 \mathrm{~Hz}, 4 \mathrm{H}, \mathrm{H} 10,12$ ), 7.68 (ddd, $J=8.5,7.0,1.0 \mathrm{~Hz}, 4 \mathrm{H}, \mathrm{H8}, 14$ ), 7.61 (ddd, $J=8.0,7.0,1.0 \mathrm{~Hz}, 2 \mathrm{H}, \mathrm{H} 13$ ), 7.57 (dd, $J=8.0,7.0 \mathrm{~Hz}, 2 \mathrm{H}, \mathrm{H9}$ ), $4.72(\mathrm{~s}, 4 \mathrm{H}, \mathrm{H} 1), 3.29(\mathrm{~m}, 4 \mathrm{H}, \mathrm{H} 2), 3.14(\mathrm{~m}, 4 \mathrm{H}, \mathrm{H} 4), 3.07(\mathrm{t}, \mathrm{J}=6.8 \mathrm{~Hz}, 4 \mathrm{H}, \mathrm{H} 5), 2.18(, 4 \mathrm{H}, \mathrm{H} 3), 1.79(\mathrm{~m}, 4 \mathrm{H}, \mathrm{H} 6)$ ${ }^{13} \mathrm{C}-\mathrm{NMR}$ (MeOD, $100 \mathrm{MHz}$ ): $\delta$ (ppm) 135.5 (C7), 132.6 (C11), 131.8 (C12), 130.4 (C8), 130.2 (C10), 128.5 (C14), 128.3 (C16), 127.7 (C13), 126.5 (C9), 123.7 (C15), 49.3 (C1), 48.1 (C5), 45.9 (C2), 45.8 (C4), 24.2 (C6), 24.1 (C3) HRMS for $\mathrm{C}_{32} \mathrm{H}_{42} \mathrm{~N}_{4}$ : Calculated: $483.3488(\mathrm{M}+\mathrm{H})^{+}$; found: 483.3482

\section{HPLC and HRMS}
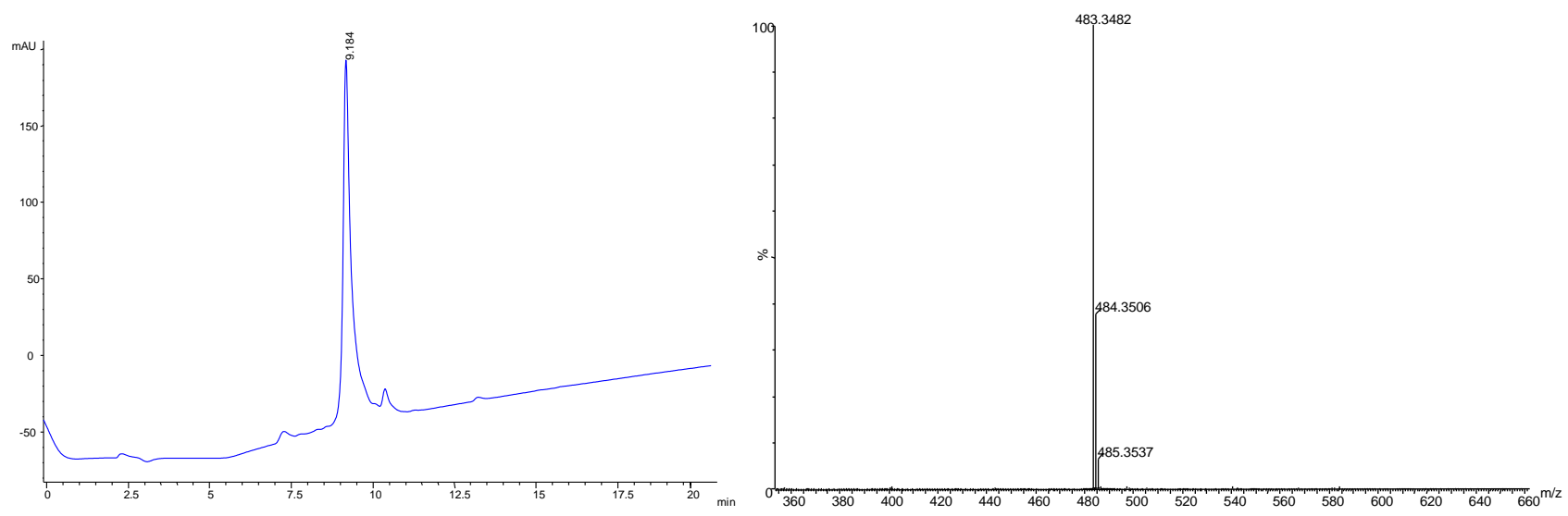


\section{${ }^{1} \mathrm{H}$ NMR}

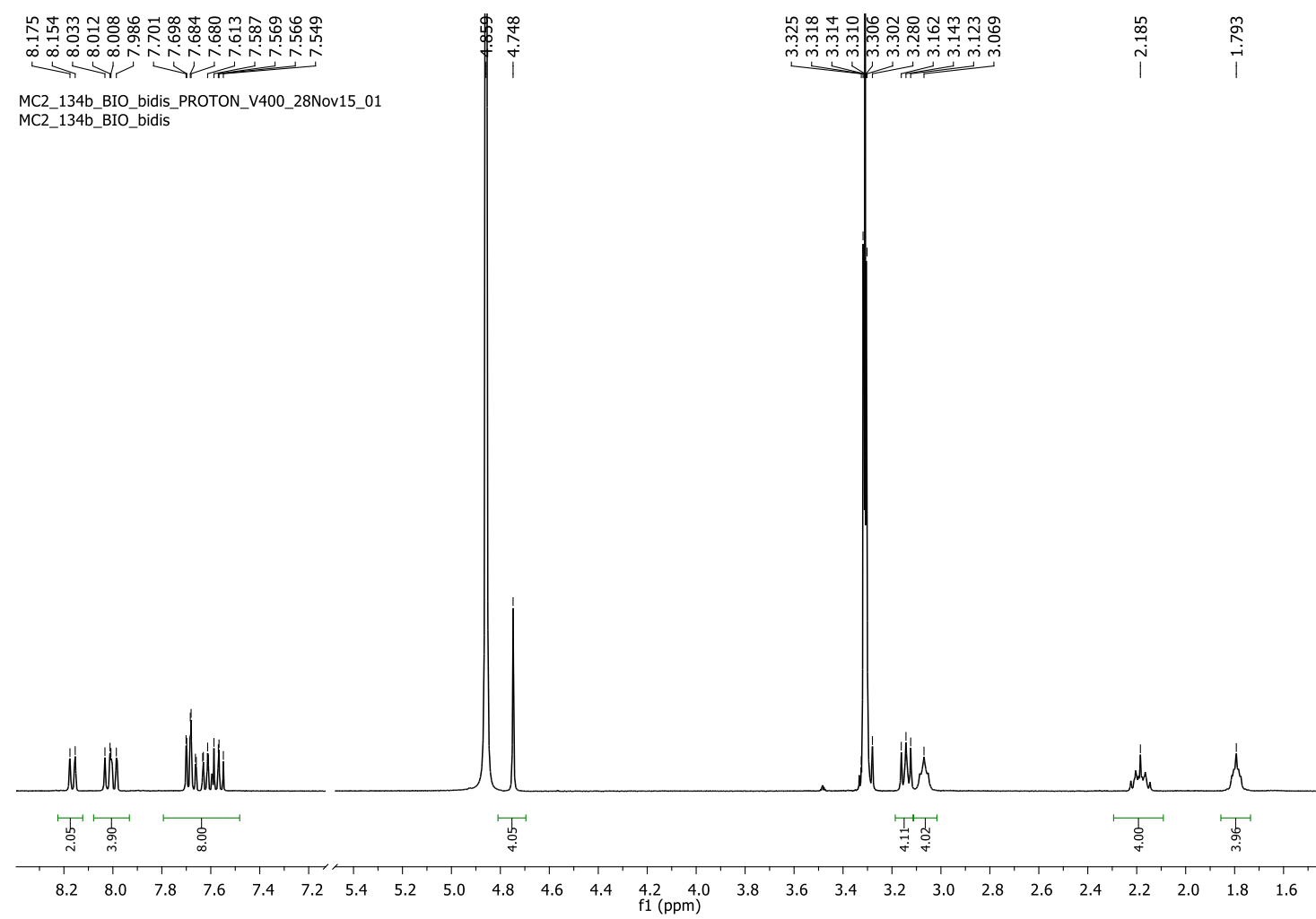

${ }^{1} \mathrm{H}-{ }^{13} \mathrm{C}$ HSQC

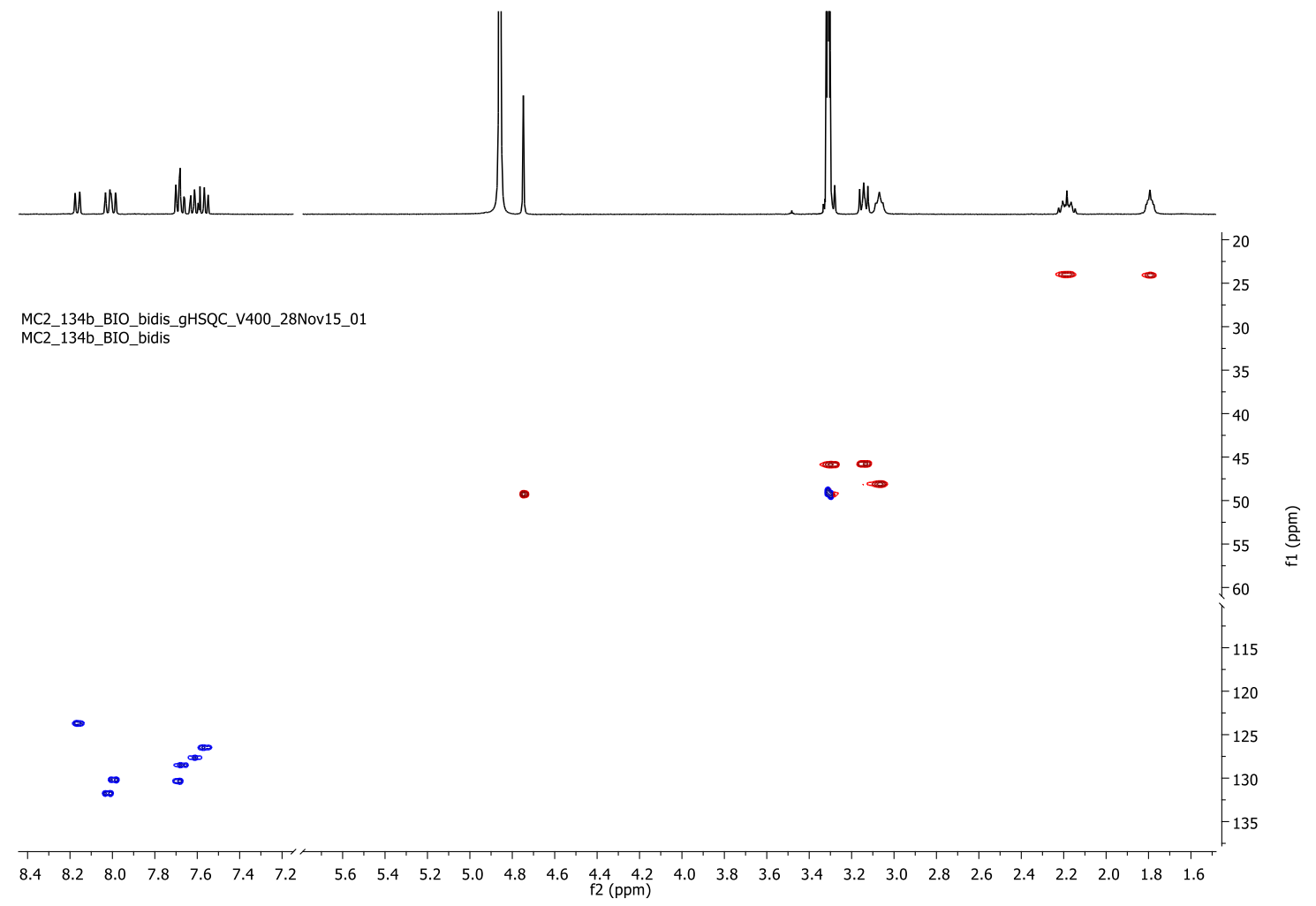


${ }^{1} \mathrm{H}-{ }^{13} \mathrm{C}$ HMBC

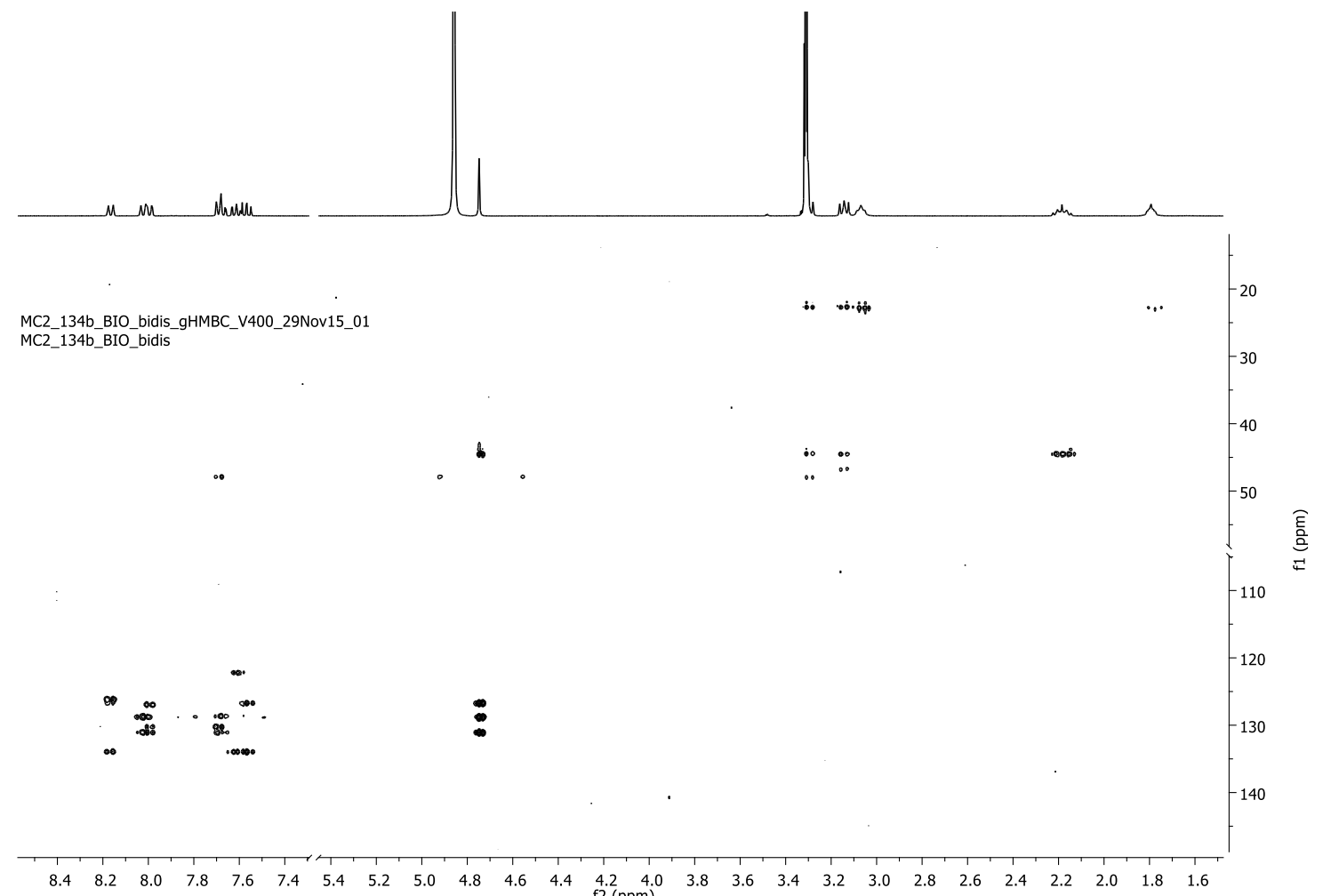




\section{Synthesis of asymmetric compound $3 A L$}

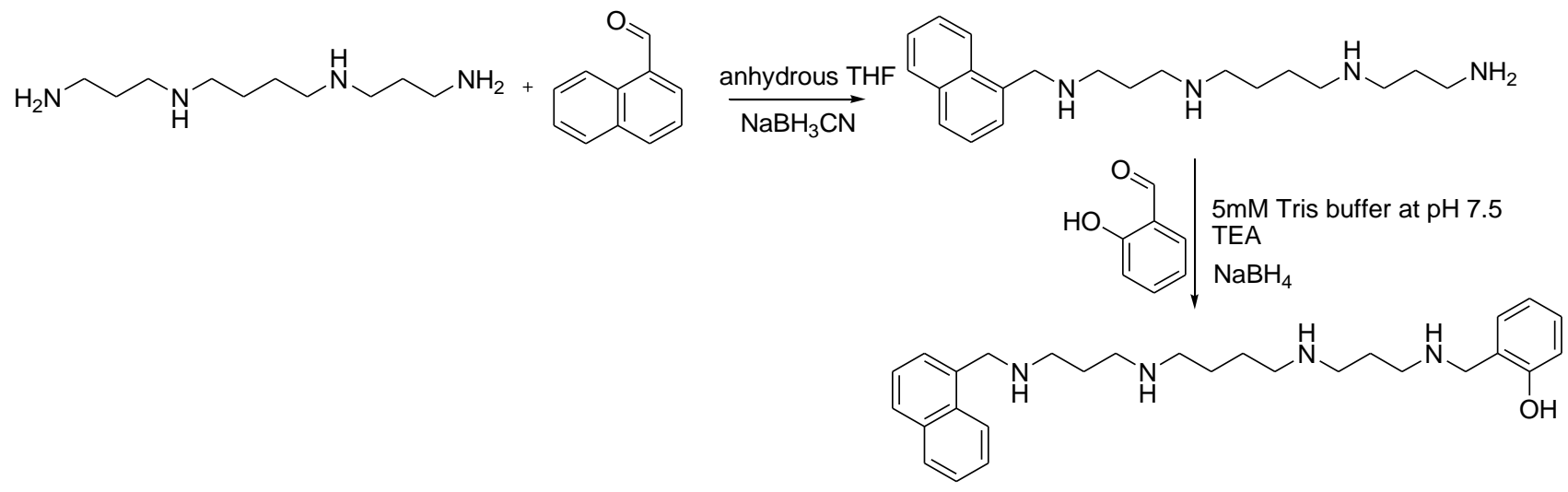

Monoalkylated spermine with aldehyde L (3L): To an ice-solution of spermine (121 $\mathrm{mg}, 0.6 \mathrm{mmol})$ in anhydrous THF ( $2 \mathrm{~mL}$ ), a solution of 1-naphthylaldehyde $(54 \mu \mathrm{L}, 0.4 \mathrm{mmol})$ was added dropwise. The resulting reaction mixture was stirred at ambient temperature overnight. Then $\mathrm{NaBH}_{3} \mathrm{CN}(201 \mathrm{mg}, 3.2 \mathrm{mmol}$ ) was added and the reaction was stirred overnight. After the addition of $1 \mathrm{~mL}$ of $\mathrm{H}_{2} \mathrm{O}$, the reaction was stirred one hour, and then $2 \mathrm{~mL}$ of $\mathrm{HCl}(2 \mathrm{~N})$ were added and the reaction mixture was stirred for two more hours. The crude was purified by reverse phase chromatography leading $44 \mathrm{mg}(0.07 \mathrm{mmol}, 18 \%$ yield $)$ of final product as a TFA salt.<smiles>CC(N)CCNCCCCNCCCNC=Cc1cccc2ccccc12</smiles>

${ }^{1} \mathrm{H}-\mathrm{NMR}$ (MeOD, $400 \mathrm{MHz}$ ): $\delta(\mathrm{ppm}) 8.17(\mathrm{~d}, J=8.5 \mathrm{~Hz}, 1 \mathrm{H}, \mathrm{H} 2 \mathrm{O}), 8.10-7.94(\mathrm{~m}, 2 \mathrm{H}, \mathrm{H} 15,17), 7.80-7.64(\mathrm{~m}, 2 \mathrm{H}$, $\mathrm{H} 13,19), 7.64-7.50(\mathrm{~m}, 2 \mathrm{H}, \mathrm{H} 14,18), 4.72(\mathrm{~s}, 2 \mathrm{H}, \mathrm{H} 11), 3.3(\mathrm{~m}, 2 \mathrm{H}, \mathrm{H} 10), 3.20-3.10(\mathrm{~m}, 4 \mathrm{H}, \mathrm{H} 3,8), 3.10-3.0(\mathrm{~m}$, 6H, H1,4,7), 2.19 (m, 2H, H9), 2.09 (m, 2H, H2), 1.80 (m, 4H, H5, $6{ }^{13} \mathrm{C}-\mathrm{NMR}$ (MeOD, $100 \mathrm{MHz}$ ): $\delta$ (ppm) 135.5 (C12), 132.7 (C16), 131.7 (C17), 130.4 (C21), 130.3 (C19), 130.2 (C15), 128.5 (C13), 127.7 (C18), 126.5 (C14), 123.8 (C20), 49.3 (C11), 48.2 (C4,7), 46.1 (C10), 45.9 (C3,8), 37.8 (C1), 25.4 (C2), 24.2 (C5,6), 24.1 (C9) HRMS for $\mathrm{C}_{21} \mathrm{H}_{34} \mathrm{~N}_{4}$ : Calculated: $343.2862(\mathrm{M}+\mathrm{H})^{+}$; found: 343.2820 .

\section{HPLC and HRMS}
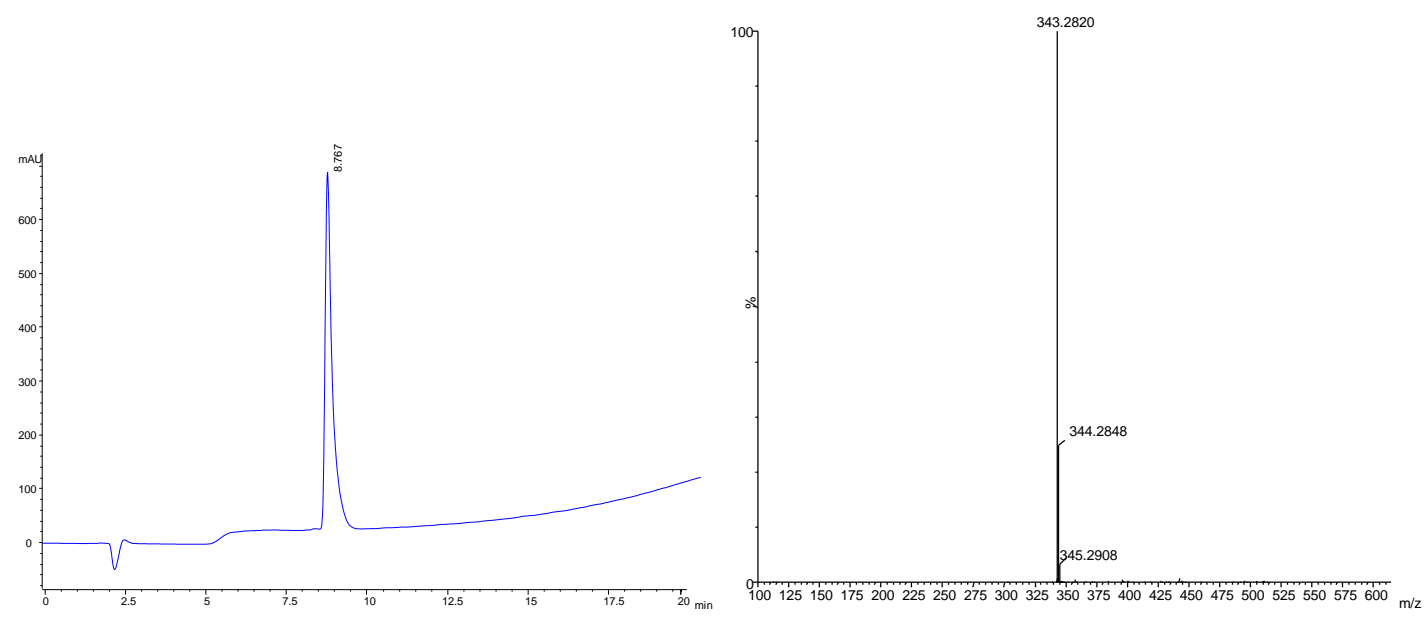


\section{${ }^{1}$ H NMR}

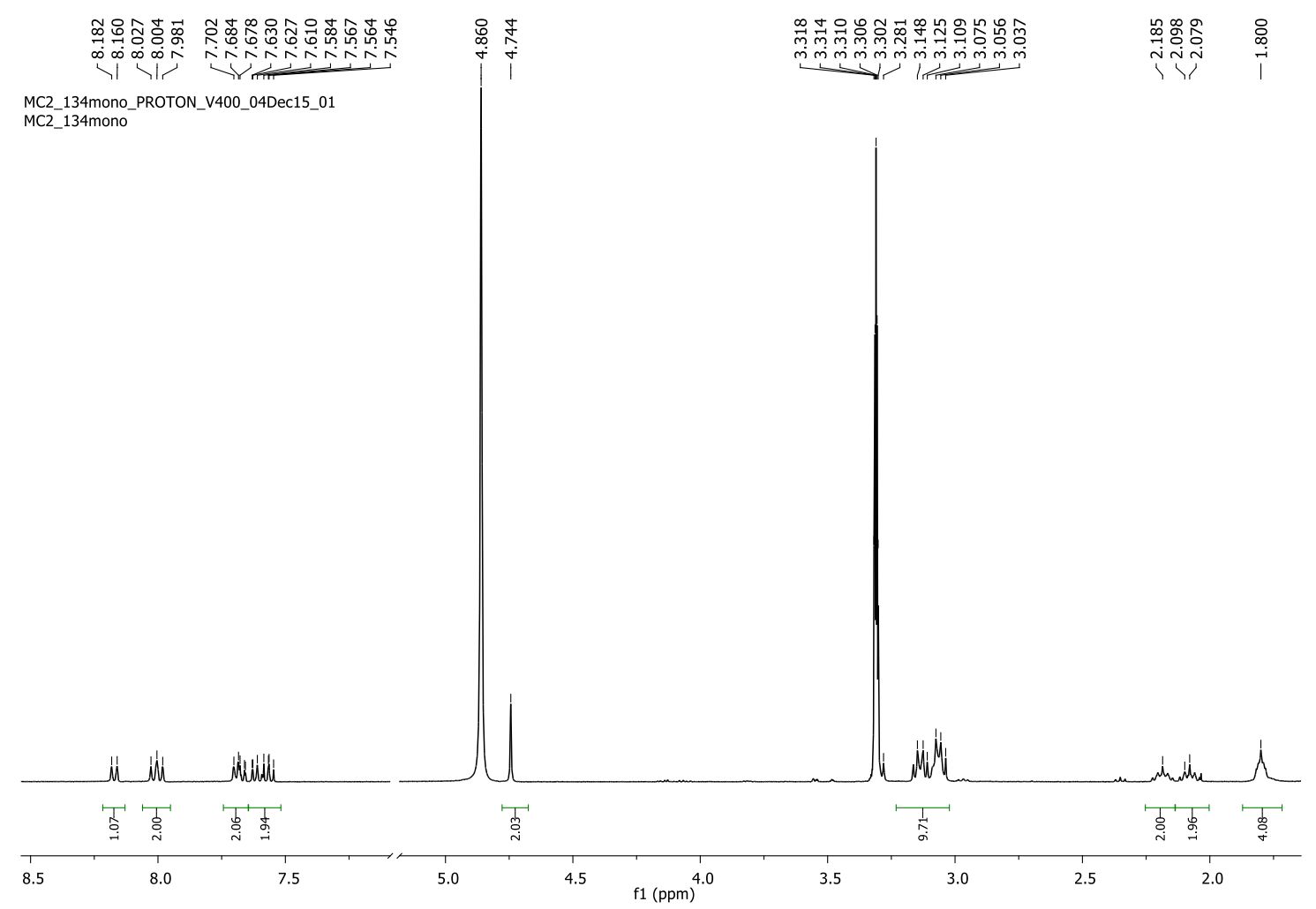

${ }^{13}$ C NMR

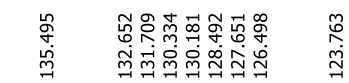

MC2_134mono_CÁrBón_v400_04ेDec15_o1

MC2_134mono

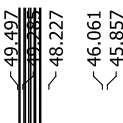

$\stackrel{\substack{0 \\ \dot{m}}}{\dot{m}}$

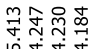

$\sqrt{\sqrt[4]{4}}$

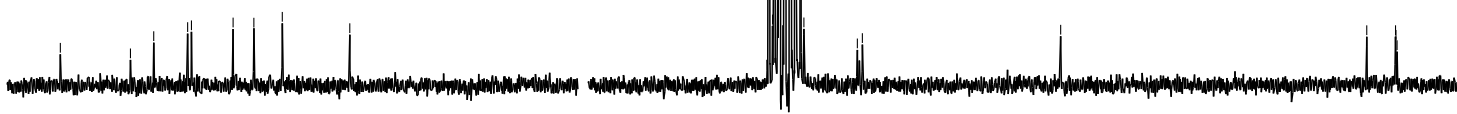

$\begin{array}{llllllllllllllllllllllllllllllllllllllll}136 & 134 & 132 & 130 & 128 & 126 & 124 & 122 & 120 & 118 & 116 & 56 & 54 & \begin{array}{r}52 \\ \mathrm{f} 1\end{array}(\mathrm{ppm}) & 48 & 46 & 44 & 42 & 40 & 38 & 36 & 34 & 32 & 30 & 28 & 26 & 24 & 22\end{array}$ 


\section{${ }^{1} \mathrm{H}-{ }^{1} \mathrm{H}$ gCOSY}

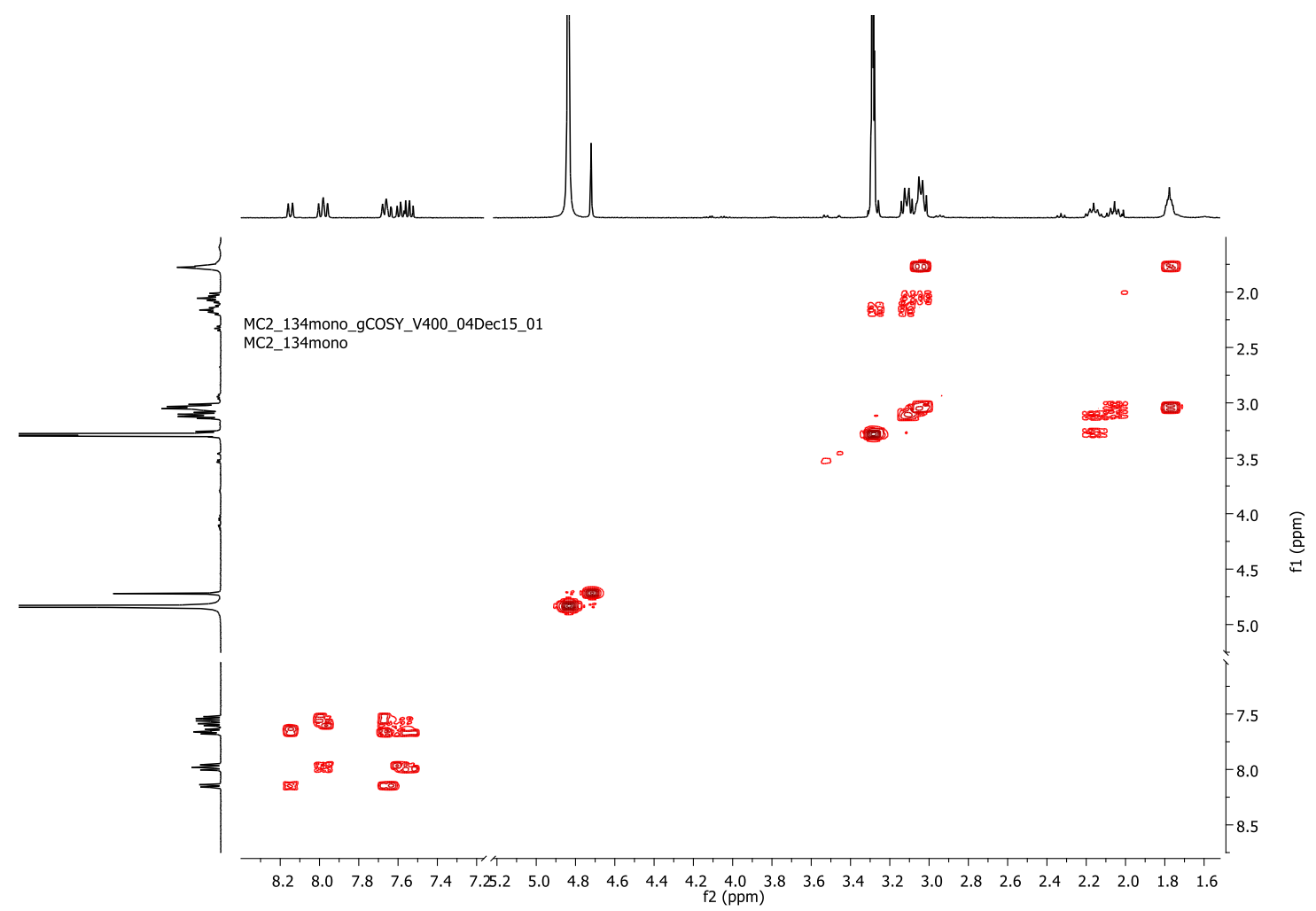

\section{${ }^{1} \mathrm{H}-{ }^{13} \mathrm{C}$ gHSQC}

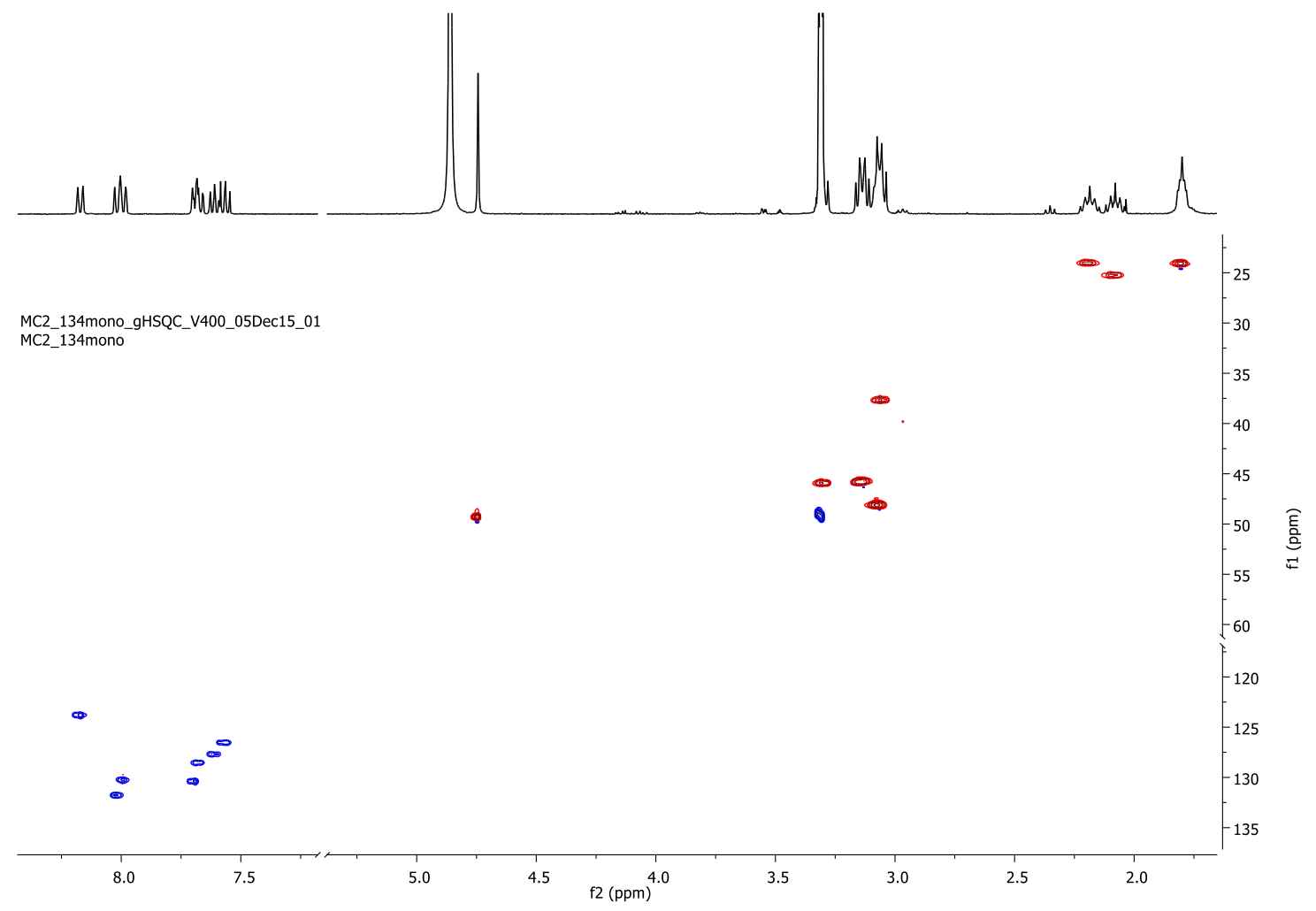


${ }^{1} \mathrm{H}-{ }^{13} \mathrm{C}$ gHMBC

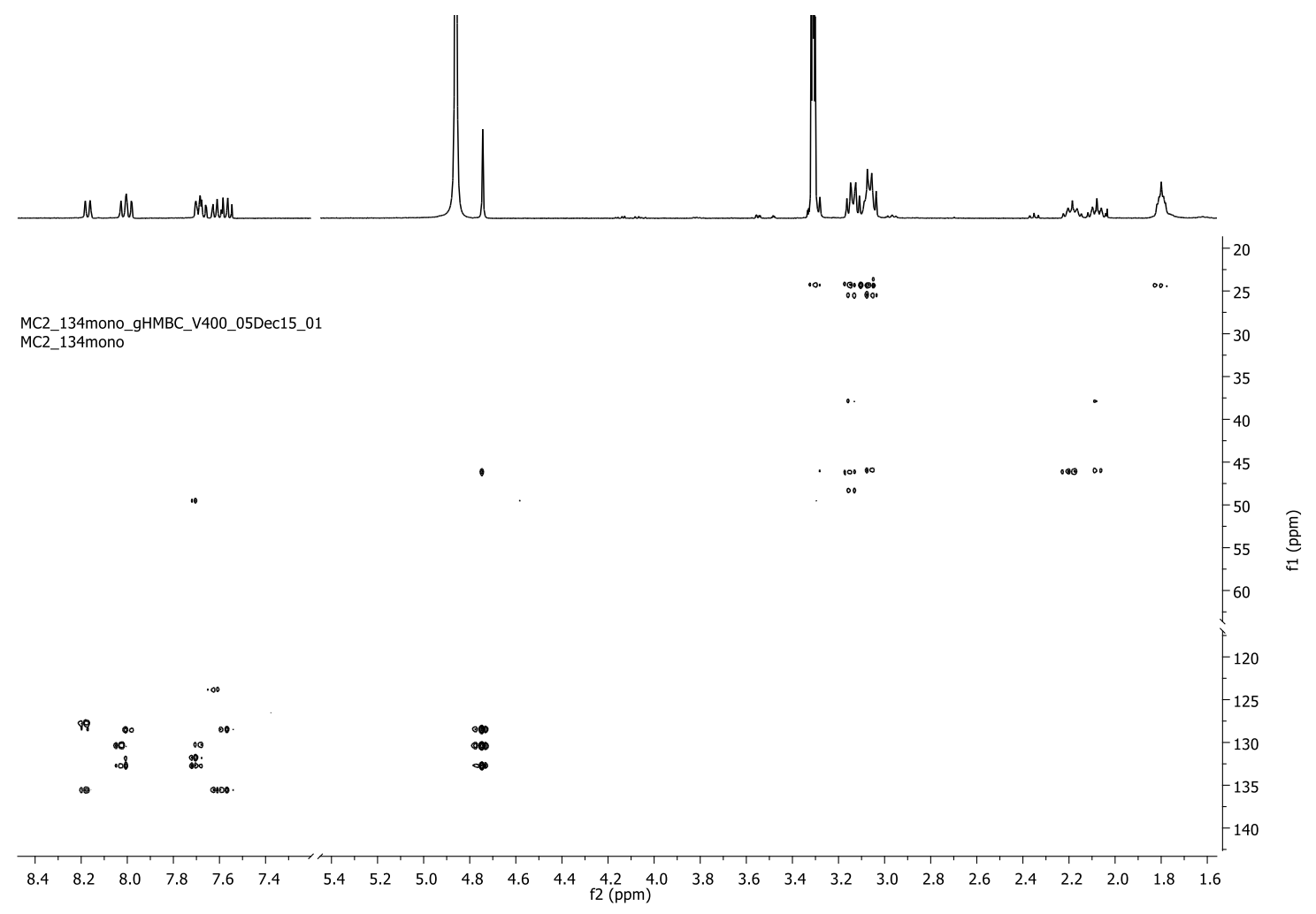


Synthesis of 3AL: To a solution of the amine $3 \mathrm{~L}(44 \mathrm{mg}, 0.07 \mathrm{mmol})$ in $1 \mathrm{~mL}$ of Tris buffer at pH 7.5, TEA ( $20 \mu \mathrm{L}$, 2eq) and salicylaldehyde $(6.5 \mu \mathrm{L}, 0.06 \mathrm{mmol})$ were added. The mixture was stirred overnight at room temperature. Then $\mathrm{NaBH}_{4}(10 \mathrm{mg}, 4 \mathrm{eq})$ was added and the reaction mixture was stirred for 6 hours.

The reaction was treated with $\mathrm{HCl} 2 \mathrm{~N}(2 \mathrm{~mL})$ and stirred for two hours, after evaporating the solvent, it was purified by reverse phase chromatography using a gradient of ACN (1\%TFA) and water (1\% TFA) to yield $10 \mathrm{mg}$ $(0.01 \mathrm{mmol}, 18 \%)$ of the final product as a TFA salt.

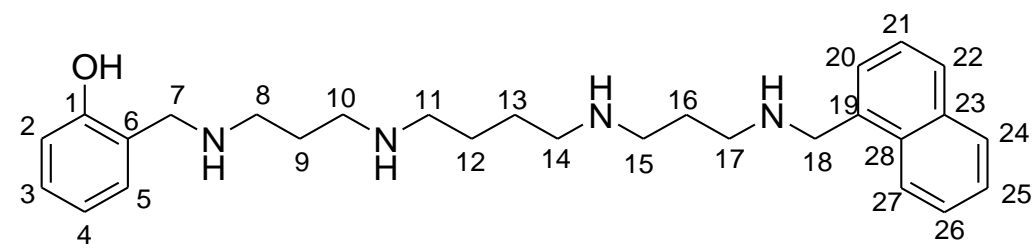

${ }^{1} \mathrm{H}-\mathrm{NMR}$ (MeOD, $400 \mathrm{MHz}$ ): $\delta$ (ppm) 8.17 (d, J = 8.0 Hz, 1H, H27), 8.01 (dd, J = 10.0, $\left.8.5 \mathrm{~Hz}, 2 \mathrm{H}, \mathrm{H} 22,24\right), 7.79$ $7.65(\mathrm{~m}, 2 \mathrm{H}, \mathrm{H} 2 \mathrm{O}, 26), 7.64-7.49(\mathrm{~m}, 2 \mathrm{H}, \mathrm{H} 21,25), 7.29(\mathrm{~m}, 2 \mathrm{H}, \mathrm{H} 3,5), 6.91(\mathrm{~m}, 2 \mathrm{H}, \mathrm{H} 2,4), 4.75(\mathrm{~s}, 2 \mathrm{H}, \mathrm{H} 18), 4.22$ $(\mathrm{s}, 2 \mathrm{H}, \mathrm{H} 7), 3.31(\mathrm{~m}, 2 \mathrm{H}, \mathrm{H} 17), 3.14(\mathrm{~m}, 6 \mathrm{H}, \mathrm{H8}, 10,15), 3.08(\mathrm{~m}, 4 \mathrm{H}, \mathrm{H} 11,14), 2.17(\mathrm{~m}, 4 \mathrm{H}, \mathrm{H} 9,16), 1.79(\mathrm{~m}, 4 \mathrm{H}$, H12,13) ${ }^{13} \mathrm{C}-N M R$ (MeOD, 100 MHz): $\delta$ (ppm) 157.5 (C1), 135.5 (C19), 132.7 (C23), 132.6 (C3), 132.5 (C5), 131.8 (C24), 130.4 (C20), 130.2 (C22), 128.5 (C26), 128.2 (C28), 127.7 (C25), 126.5 (C21), 123.7 (C27), 121.1 (C4), 118.5 (C6), 116.4 (C2), 49.2 (C18), 48.2 (C7), 48.2 (C11,14), 45.9 (C17), 45.8,45.2 (C8,10,15), 24.2 (C12,13), 24.1 (C16), 23.9 (C9) HRMS for $\mathrm{C}_{28} \mathrm{H}_{40} \mathrm{~N}_{4} \mathrm{O}$ : Calculated: $449.328(\mathrm{M}+\mathrm{H})^{+}$; found: 449.3281.

\section{HPLC and HRMS}
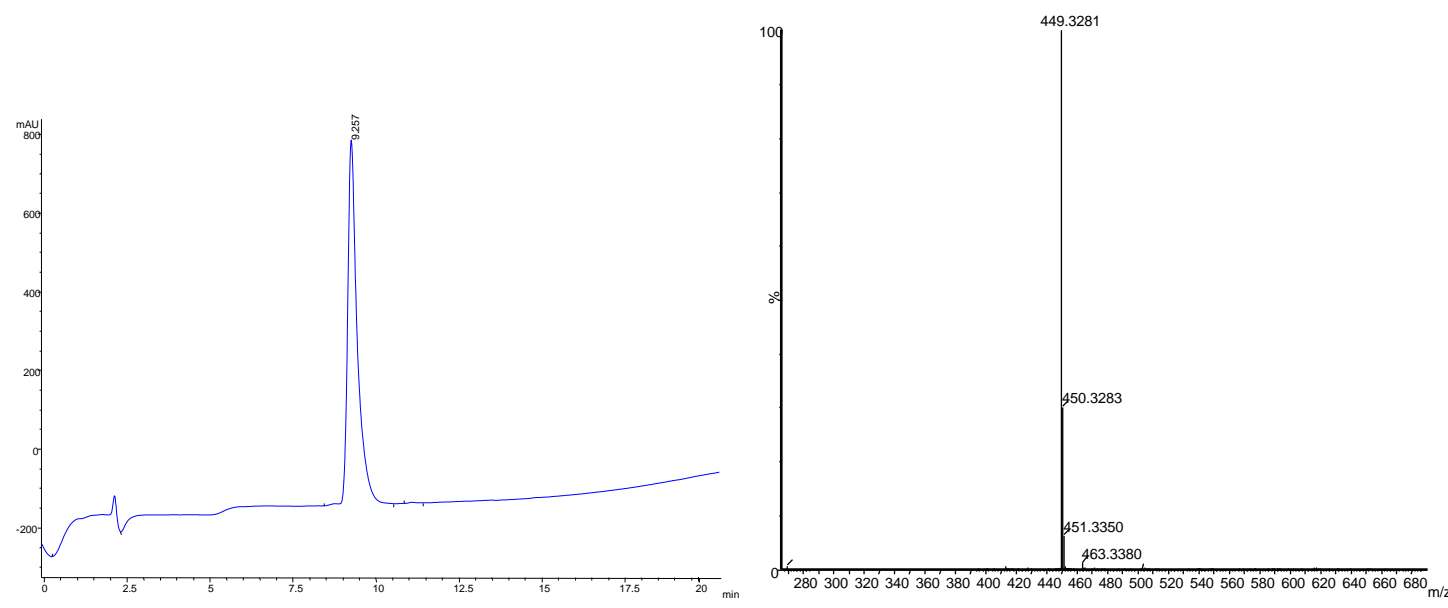


\section{${ }^{1} \mathrm{H}$ NMR}

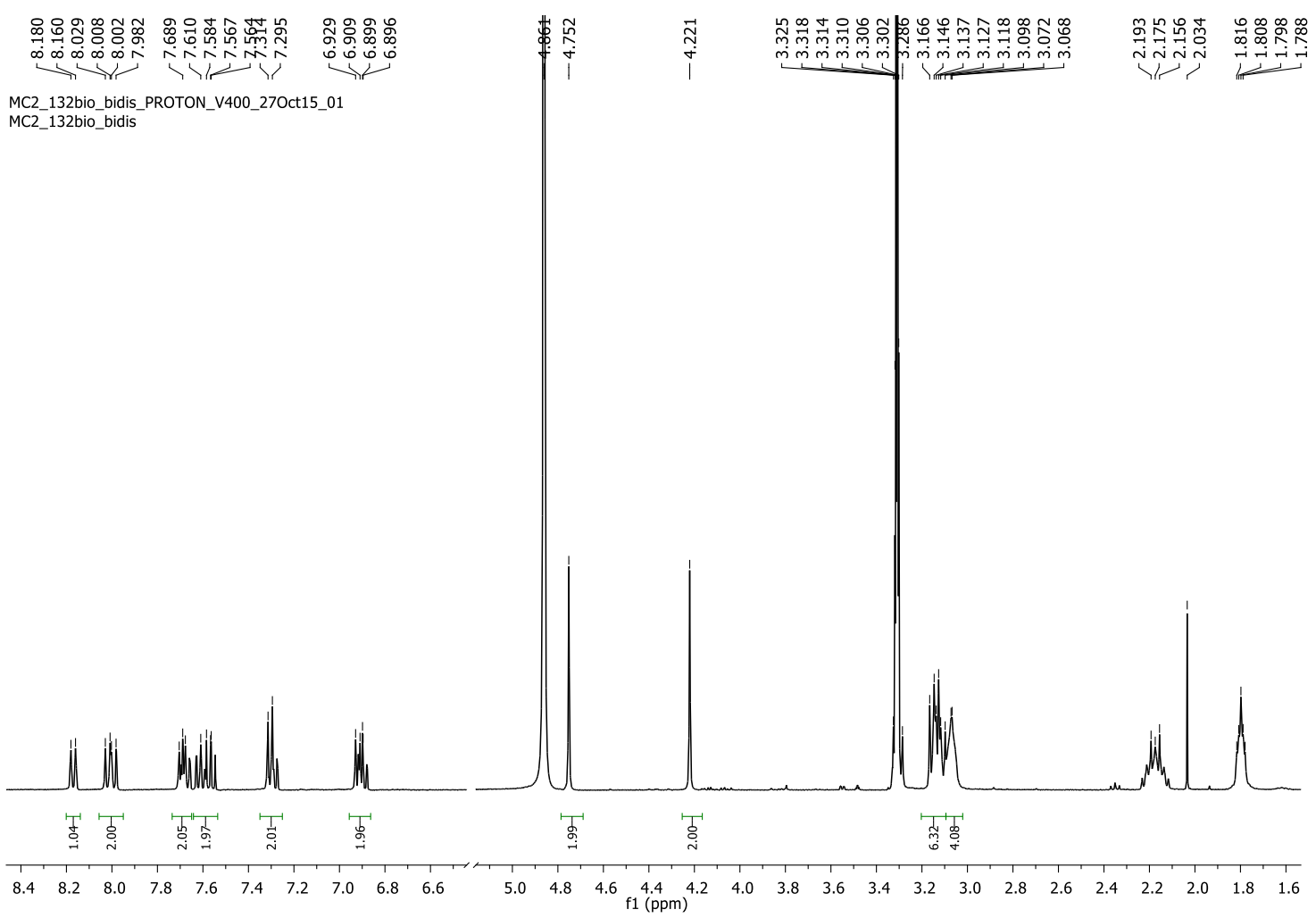

${ }^{13}$ C NMR

MC2_132biobidis_CARBOn_V400_290ct15_01
MC2_32bibidis

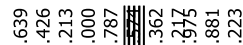

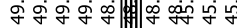

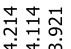

늄 MC2 132biobidis

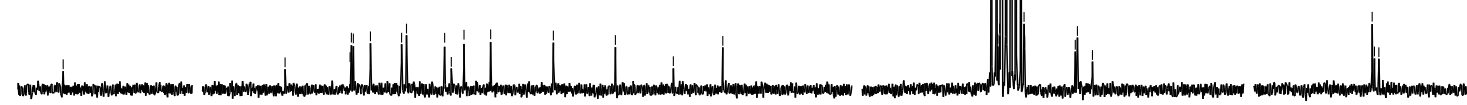

$\begin{array}{llllllllllllllllllllllll}158 & 154 & 138 & 134 & 130 & 126 & 122 & 118 & 114 & 54 & 52 & 50 & 48 & 46 & 44 & 42 & 40 & 28 & 26 & 24 & 22\end{array}$ 
${ }^{1} \mathrm{H}^{13} \mathrm{C}$ HSQC

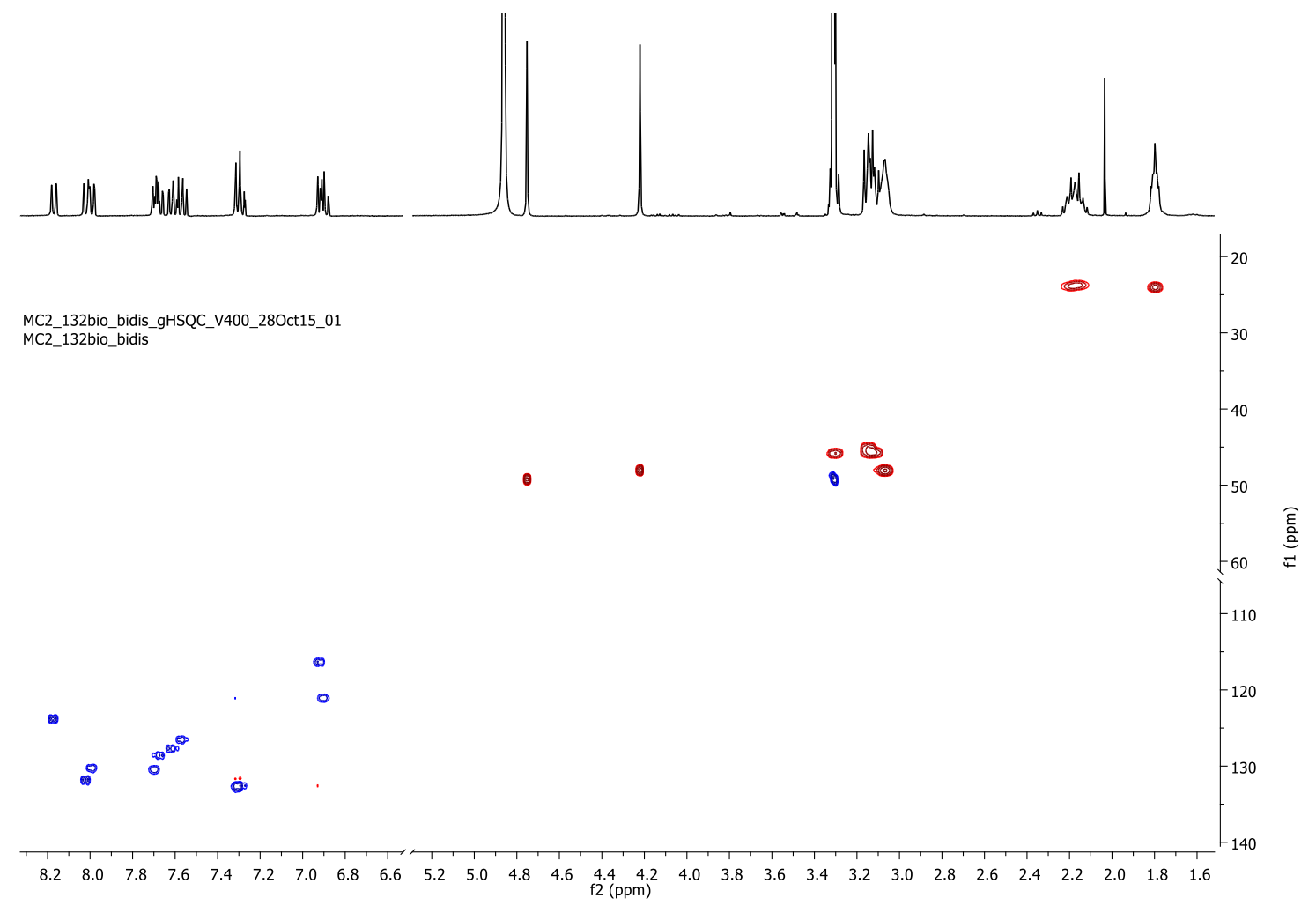

${ }^{1} \mathrm{H}^{13} \mathrm{C}$ HMBC

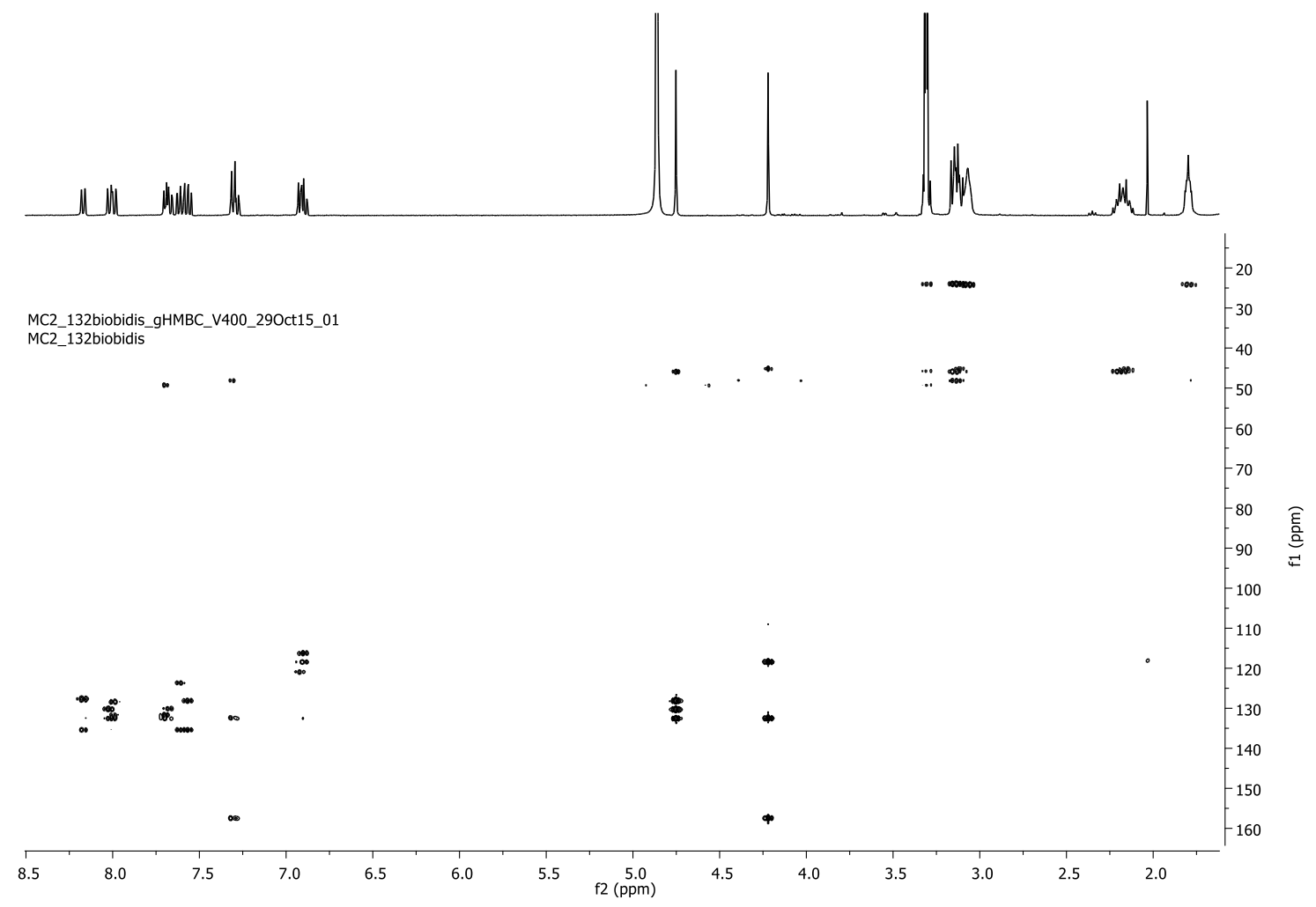




\section{Fluorescence titration experiments}

Stock solutions of the corresponding ligand $(49 \mu \mathrm{M})$ and heparin $(0.4 \mathrm{mM}$ in the disaccharide repeating unit) were prepared in $5 \mathrm{mM}$ Tris buffer at pH 7.5. $2 \mathrm{~mL}$ of the ligand solution was placed on a quartz cell and the emission fluorescence spectrum was measured upon excitation at $280 \mathrm{~nm}$. Then, small volumes of the heparin stock solution were added to the cell, and the fluorescence spectra was acquired after each addition. The normalized relative fluorescence increase of the intensity at $400 \mathrm{~nm}$ was plotted against the equivalents of heparin added, considering the concentration of the repeating disaccharide unit. The titration isotherm showed a complex shape that was impossible to reliably fit to a reasonable binding model. However, the qualitative comparison between the $\mathbf{3 A L}$ and $\mathbf{3} \mathbf{L L}$ curves showed a stronger interaction of heparin with $\mathbf{3 A L}$. Thus, the titration of $3 \mathrm{AL}$ reaches the maximum fluorescence change at 2.5 equivalents of repeating units of $\mathbf{1}$, while the curve for $\mathbf{3 L L}$ is still growing at 4 equivalents of repeating units of $\mathbf{1}$. Moreover, the steepness of the titration isotherm of $\mathbf{3 A L}$ is much larger than that of $\mathbf{3 L L}$, suggesting a higher degree of complex formation with equivalent proportion of added heparin.

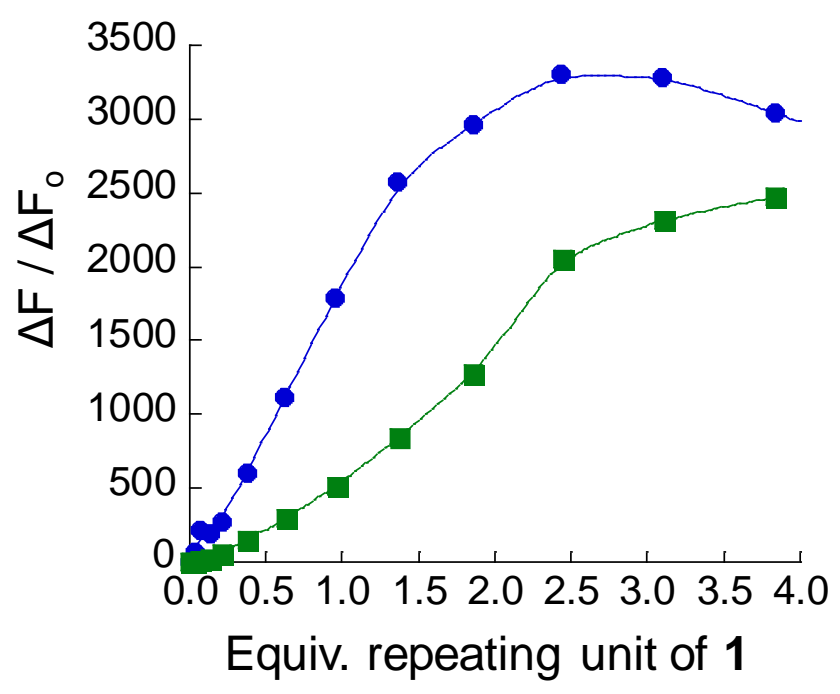

Figure S3. Fluorescence titration curves for 3AL (blue) and 3LL (green) upon addition of 1 


\section{Isothermal Titration Calorimetry experiments}

ITC was performed in a MicroCal VP-ITC instrument (GE Healthcare) in $5 \mathrm{mM}$ Tris-HCl buffer pH 7.5 at $298 \mathrm{~K}$. The cell (volume $\sim 1.4 \mathrm{~mL}$ ) contained $80 \mu \mathrm{M}$ of the ligand while the syringe (volume $0.3 \mathrm{~mL}$ ) contained 200 $\mu \mathrm{M}$ heparin (considering the average molecular weight of the corresponding polysaccharide). Experimental conditions were as follows: a first injection of $2 \mu \mathrm{L}$ followed by 40 injections of $5 \mu \mathrm{L}$ with a spacing of $180 \mathrm{~s}$ between injections, and a stirring speed of $300 \mathrm{rpm}$. A blank titration was performed by injecting buffer into the products in the same conditions. Raw data were analyzed with the MicroCal Origin software (OriginLab, Northampton, MA, USA) using a one-site model for the fittings.

For the calculation of the molar concentration of heparin, we considered the averaged $\mathrm{MW}$ of the specific heparin used $(12 \mathrm{kD})$, despite it was polydisperse. The influence of the heparin heterogeneity on the determined parameters was not limiting in our case, since our objective was to estimate the affinity and to compare the results for the different ligands under the same conditions.

\section{ITC experiments with $3 \mathrm{AL}$}<smiles>Oc1ccccc1CNCCCNCCCCNCCCNCc1cccc2ccccc12</smiles>

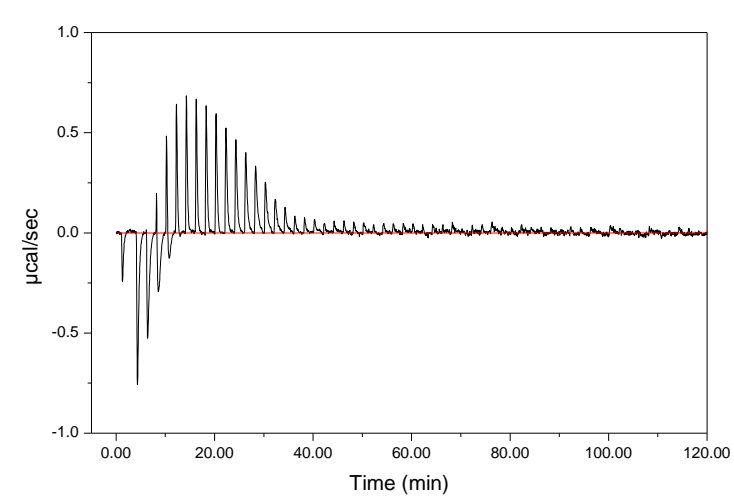

- MC323a_NDH

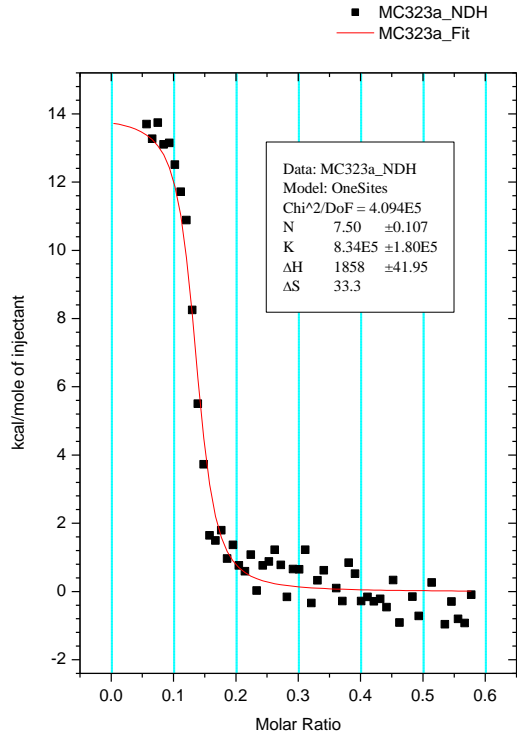

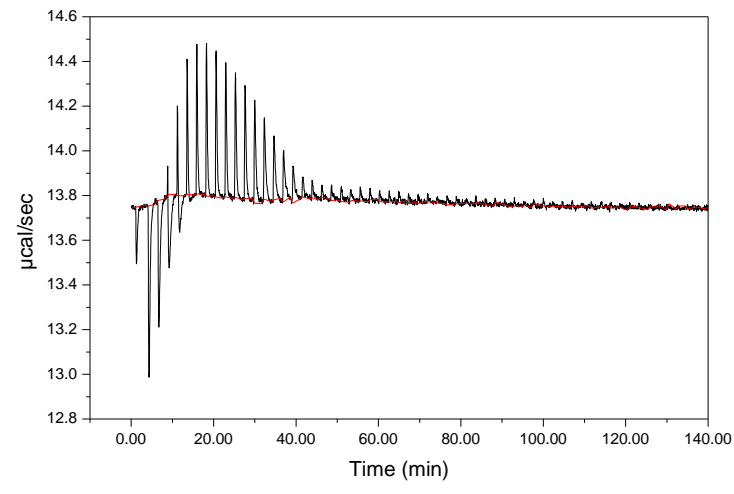

- MC323b_NDH

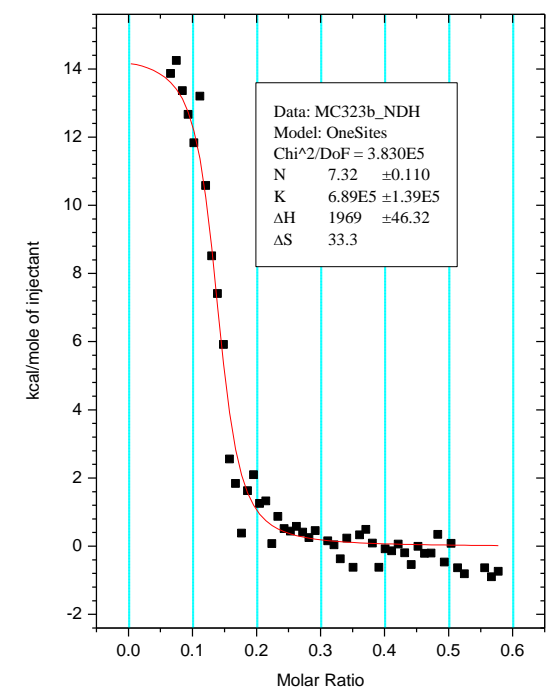

Figure S4. Raw data (up) and processed data (down) for two ITC experiments of 3AL with heparin.

The ITC curves showed an exothermic process in the initial titration points and a consistent endothermic process after a certain point of the titration. This behavior has been previously observed in the titration of 
GAGs with cationic peptides ${ }^{[1]}$ and peptidomometics, ${ }^{[2]}$ and can be ascribed to an initial non-specific aggregation process by purely electrostatic interactions. In this case, we have confirmed this aggregation with two additional independent experiments. First, the ${ }^{1} \mathrm{H}$ NMR titration of $3 \mathrm{AL}$ with non-fractioned heparin, using a relaxation-filtering pulse sequence (Figure S12) showed the disappearance of the NMR signals of $3 A$ L in the first titration points, which is consistent with the formation of very large species in solution with a very fast cross-relaxation (short $T_{2}$ and thus efficiently filtered with the CPMG sequence). The signals of the 3AL ligand were recovered upon further addition of heparin, suggesting the formation of discrete species with smaller apparent sizes. These discrete species would correspond to the ligand-to-heparin ratios of the consistent endothermic process observed in the ITC curves.

In order to confirm this hypothesis, we have measured the dynamic light scattering (DLS) of samples containing 3AL and 1 at relative concentrations similar to those of the first points of the ITC titrations $(20 \mu \mathrm{M}$ of $3 \mathrm{AL}$ and $0.2 \mu \mathrm{M}$ of heparin, corresponding to 3.4-3.6 $\mu \mathrm{M}$ in the disaccharide repeating unit). The DLS data confirmed the formation of very large species of a hydrodynamic radius of $61 \pm 4 \mathrm{~nm}$ and a polydispersity of $0.3 \pm 0.2$. The DLS of the corresponding samples of either $3 A L$ or heparin alone showed no scattering in separate control experiments. Thus, we concluded that the first points of the titration experiments correspond to large aggregates formed by non-specific electrostatic interactions between $\mathbf{B A L}$ and $\mathbf{1}$ and, accordingly, we used just the endothermic points for the fitting. Despite this is an oversimplification of the true process, we considered that the obtained data can be used for comparison purposes.
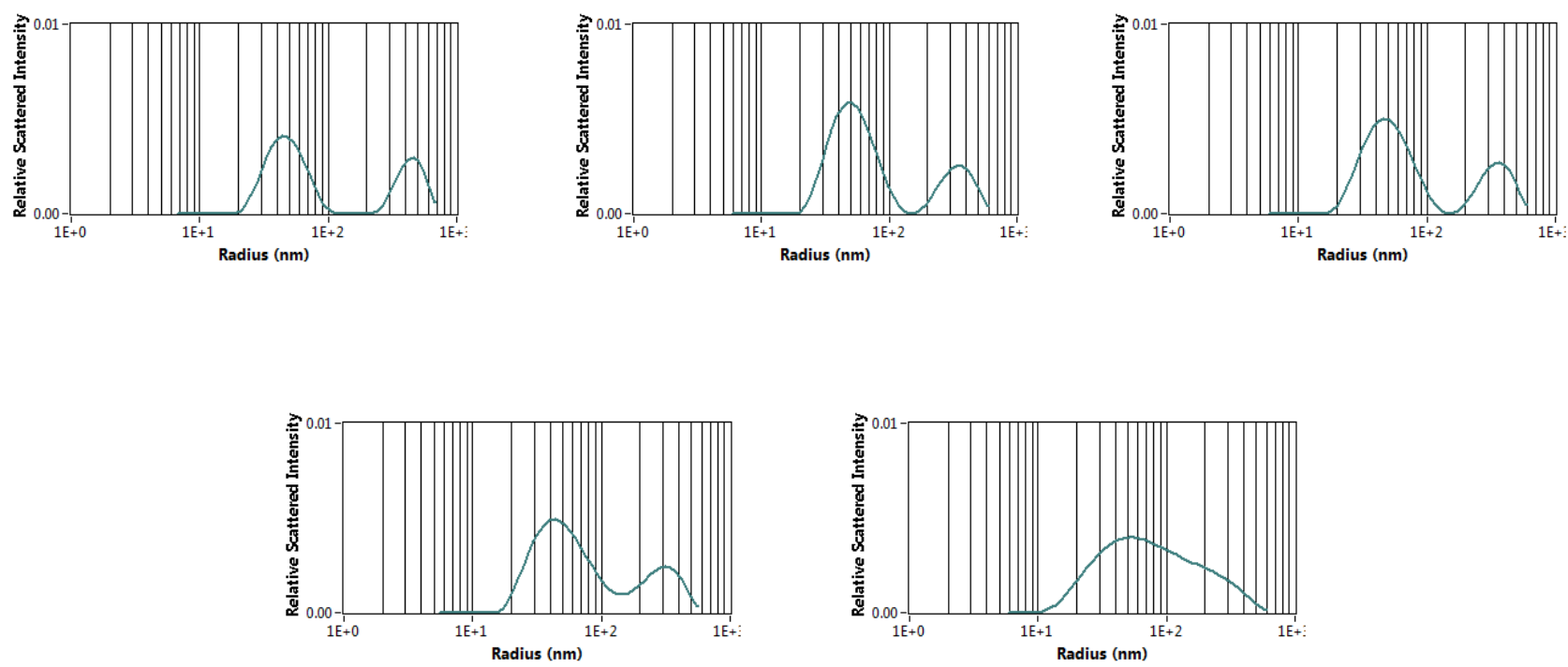

Figure S5. Size distribution obtained by DLS analysis of a sample containing $3 A$ L $(20 \mu \mathrm{M})$ and $\mathbf{1}(0.2 \mu \mathrm{M}, 3.4$ 3.6 $\mu \mathrm{M}$ in the disaccharide repeating unit). The analyses of five replicates are shown. 


\section{ITC experiments with $3 L L$}<smiles>c1ccc2c(CNCCCNCCCCNCCCNCc3cccc4ccccc34)cccc2c1</smiles>
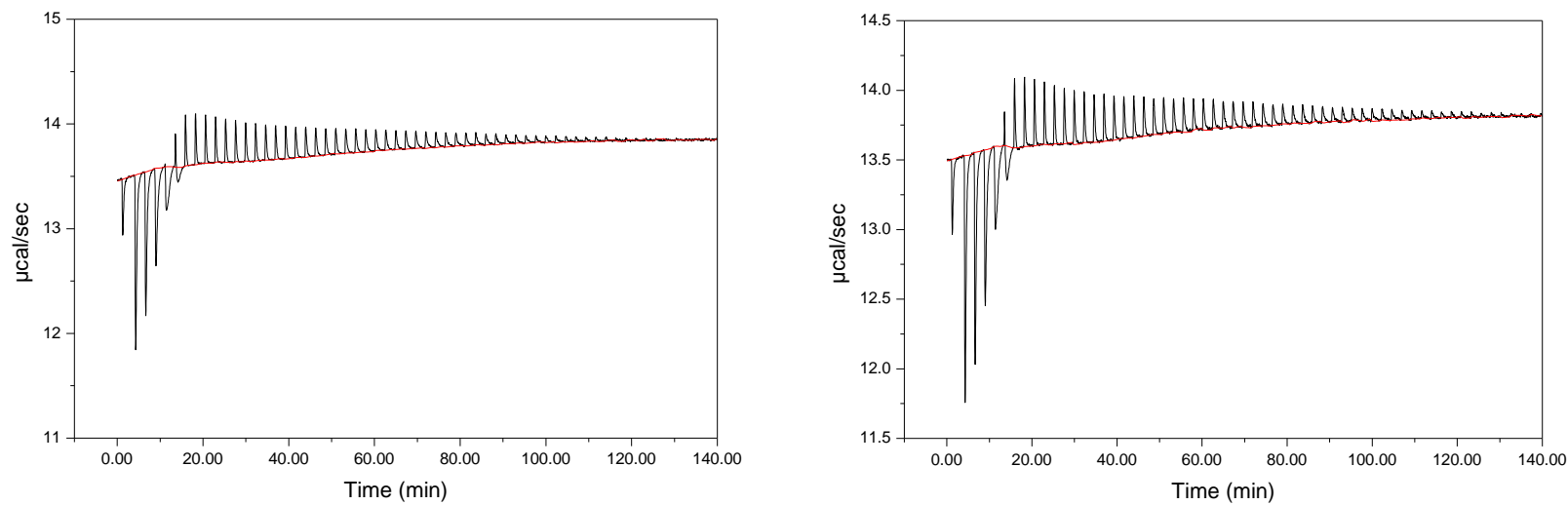

Figure S6. Raw data for two ITC experiments of 3LL with heparin.

In this case, we were unable to fit the observed heat change to any available binding model. Moreover, the shape of the heat peaks during the experiment suggested a weaker and less specific interaction with heparin. 


\section{ITC experiments with $3 A A$}

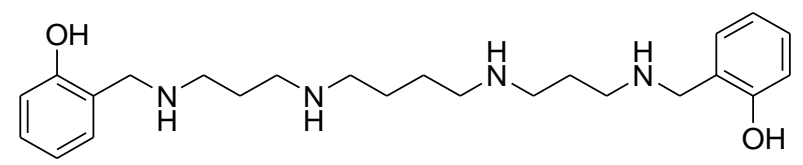

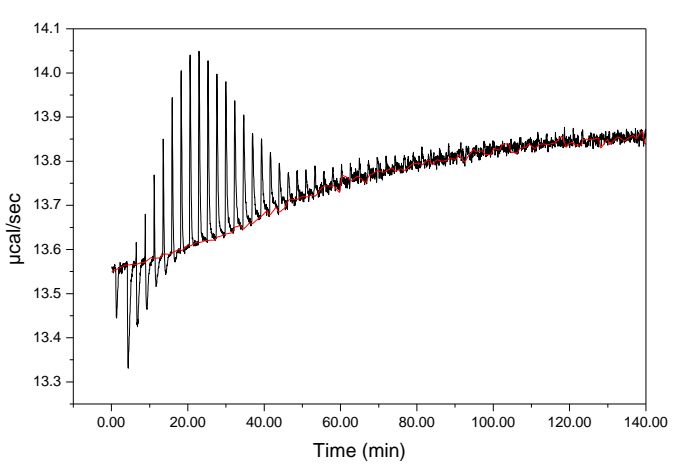

- MC327a_NDH

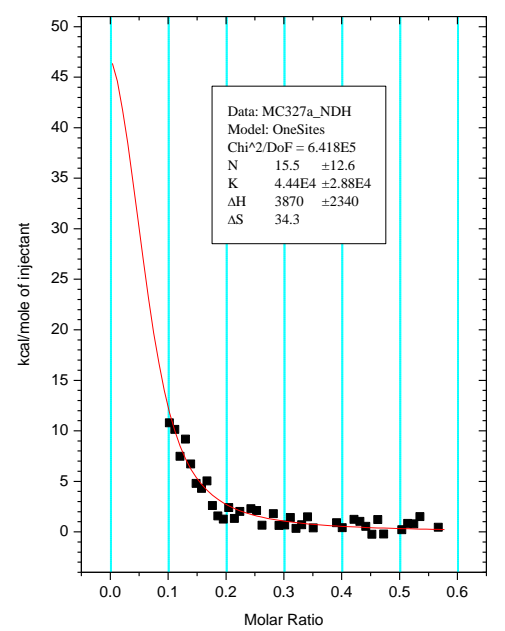

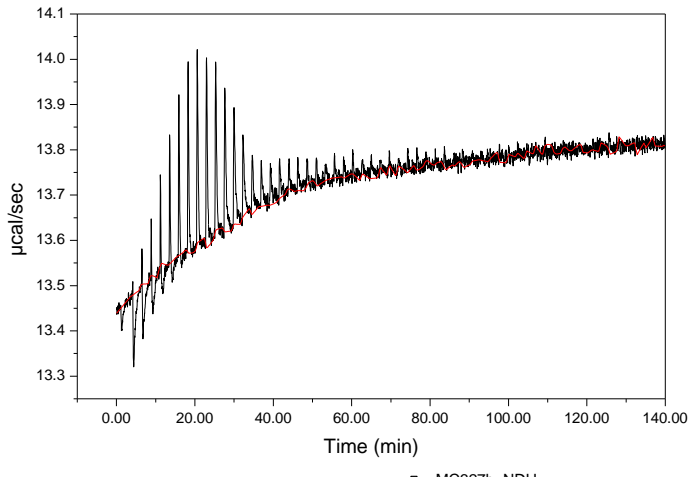

- MC327b_NDH

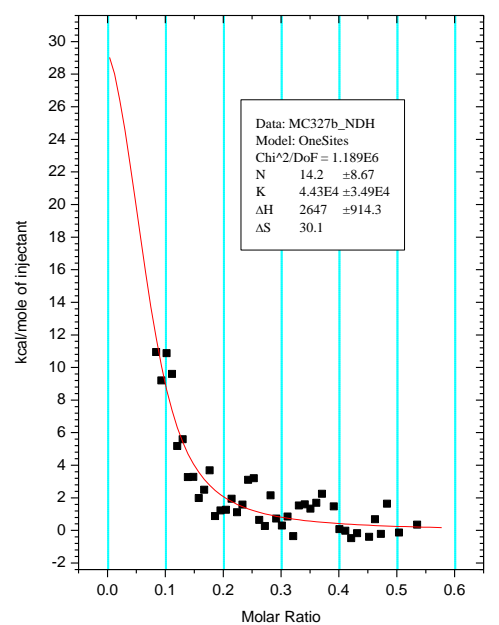

Figure S7. Raw data (up) and processed data (down) for two ITC experiments of 3AA with heparin. 


\section{$\underline{\text { ITC results }}$}

Despite the fitting for 3AA was not very accurate, we used the obtained values for comparison (Table S1). The results obtained from the fitting of the data for $\mathbf{3 A L}$ and $\mathbf{3 A A}$ clearly showed that $3 \mathbf{A L}$ is a stronger binder to heparin, by at least one order of magnitude in the affinity $\left(K_{\mathrm{d}}\right)$ and a more favorable Gibbs energy (ca. 2 $\mathrm{kcal} / \mathrm{mol}$ ). Moreover, the apparently larger stoichiometry with $3 A A$ also reflects a less efficient interaction.

Table S1: Thermodynamic parameters obtained by fitting the ITC data to a simple one-site binding mode:

\begin{tabular}{|l|l|l|l|l|}
\hline \multicolumn{3}{|l|}{$3 \mathrm{l}$} & \multicolumn{3}{l|}{ 3AA } \\
\hline $\mathbf{N}$ & $7.5 \pm 0.1$ & $7.3 \pm 0.1$ & $15.5 \pm 12$ & $14.2 \pm 8$ \\
\hline $\boldsymbol{K}_{\text {association }}\left(\mathrm{M}^{-1}\right)$ & $8.34 \cdot 10^{5} \pm 1.8 \cdot 10^{5}$ & $6.89 \cdot 10^{5} \pm 1.4 \cdot 10^{5}$ & $4.44 \cdot 10^{4} \pm 2.9 \cdot 10^{4}$ & $4.43 \cdot 10^{4} \pm 3.5 \cdot 10^{4}$ \\
\hline $\boldsymbol{K}_{\text {dissociation }}(\mu \mathrm{M})$ & $1.20 \pm 0.20$ & $1.45 \pm 0.20$ & $22.5 \pm 8.9$ & $22.5 \pm 9.9$ \\
\hline $\boldsymbol{\Delta H}\left(\mathrm{cal} \cdot \mathrm{mol}^{-1}\right)$ & $1858 \pm 42$ & $1969 \pm 46$ & $3870 \pm 2340$ & $2647 \pm 914$ \\
\hline$\Delta \boldsymbol{S}\left(\mathrm{cal} \cdot \mathrm{K}^{-1} \cdot \mathrm{mol}^{-1}\right)$ & 33.3 & 33.3 & 34.3 & 30.1 \\
\hline$\Delta \boldsymbol{G}\left(\mathrm{cal} \cdot \mathrm{mol}^{-1}\right)$ & -8065 & -7954 & -6351 & -6333 \\
\hline
\end{tabular}




\section{NMR binding experiments}

\section{NMR characterization of $3 A L$ in aqueous buffer}
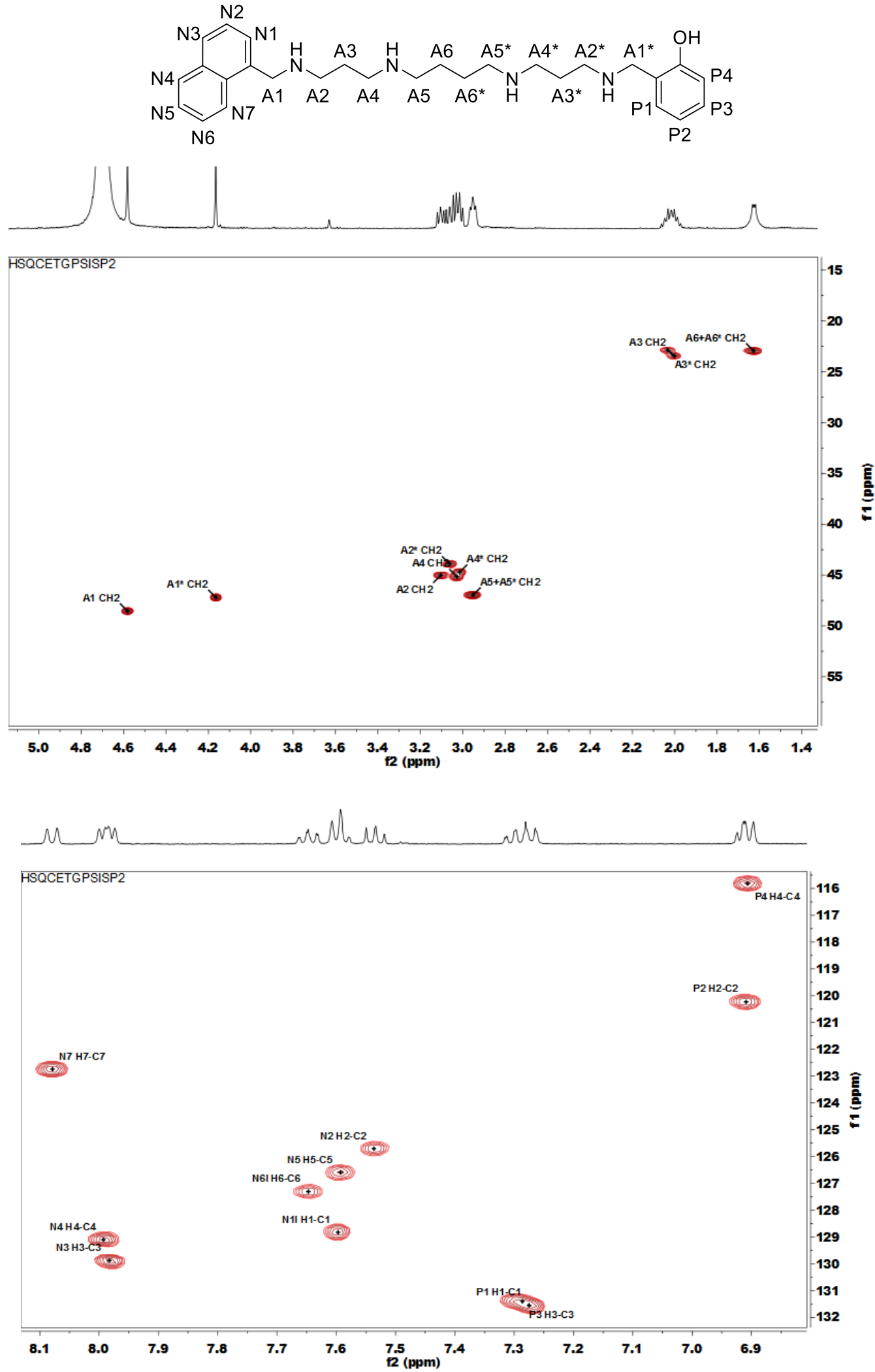

Figure S8. ${ }^{1} \mathrm{H}-{ }^{13} \mathrm{C}$ HMBC spectrum of compound $3 \mathrm{AL} 1 \mathrm{mM}\left(500 \mathrm{MHz}, 5 \mathrm{mM}\right.$ Tris-d11 and $50 \mathrm{mM} \mathrm{NaCl}$ in $\mathrm{D}_{2} \mathrm{O}$, $\mathrm{pH} 7.5$ ) and chemical structure of $3 \mathrm{AL}$ with labelling numbers used in the NMR assignment. 

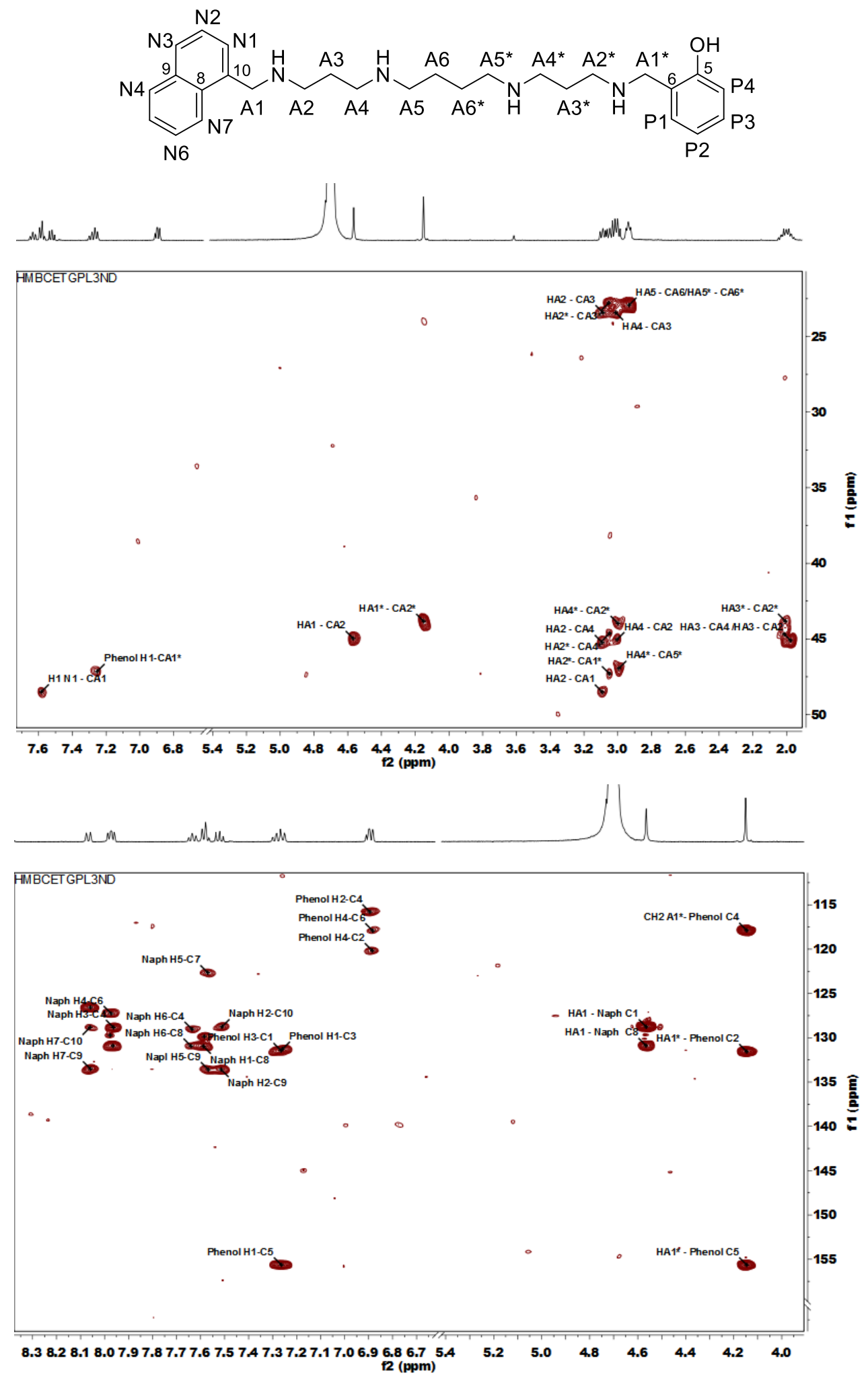

Figure S9. ${ }^{1} \mathrm{H}-{ }^{13} \mathrm{C} \mathrm{HSQC}$ spectrum of compound $3 \mathrm{AL} 1 \mathrm{mM}\left(500 \mathrm{MHz}, 5 \mathrm{mM}\right.$ Tris-d11 and $50 \mathrm{mM} \mathrm{NaCl}$ in $\mathrm{D}_{2} \mathrm{O}$, $\mathrm{pH}$ 7.5) and chemical structure of $3 \mathrm{AL}$ with labelling numbers used in the NMR assignment. 

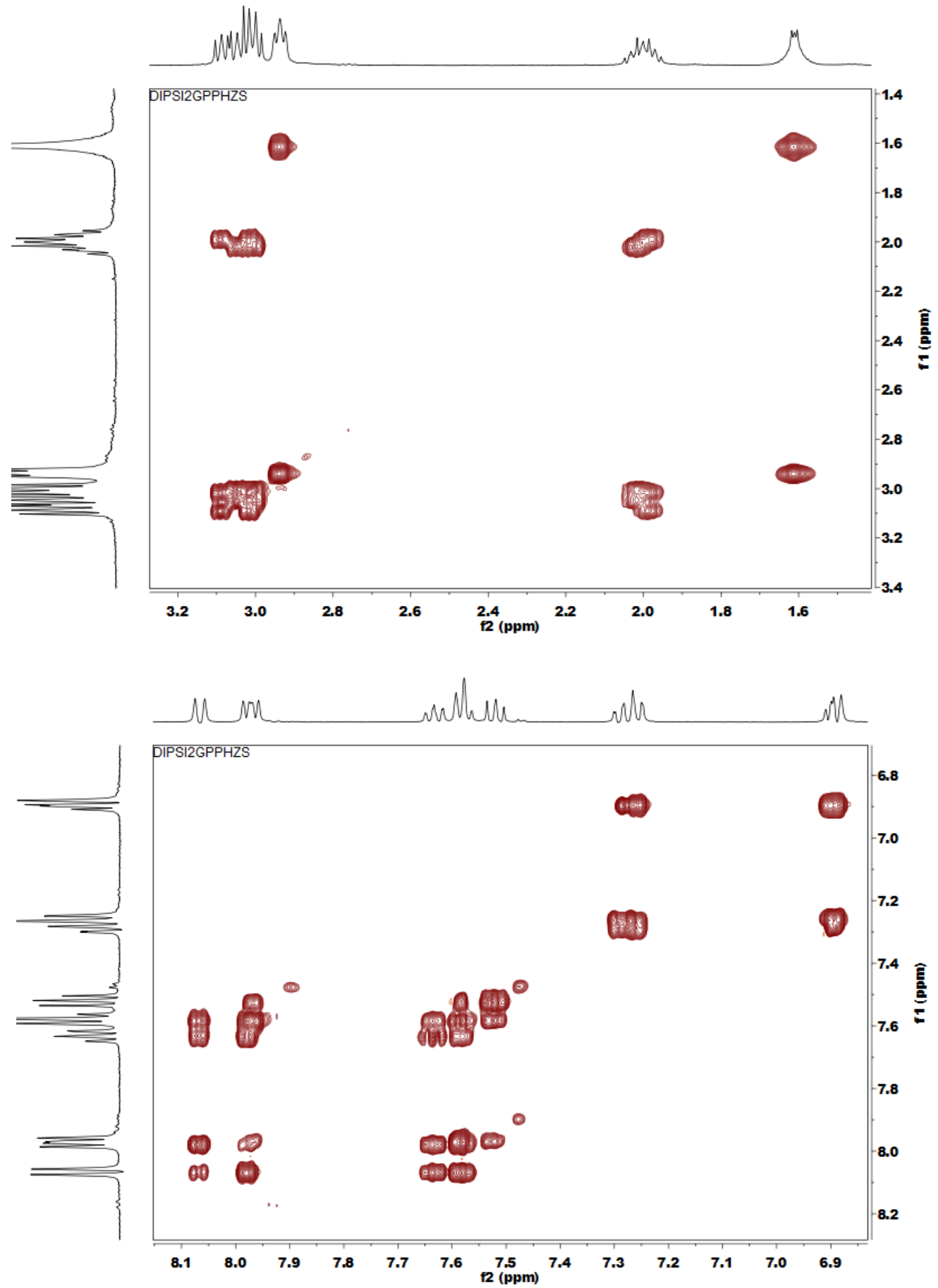

Figure S10. ${ }^{1} \mathrm{H}-{ }^{1} \mathrm{H}$ TOCSY spectrum of compound $3 \mathrm{AL} 1 \mathrm{mM}\left(500 \mathrm{MHz}, 5 \mathrm{mM}\right.$ Tris-d11 and $50 \mathrm{mM} \mathrm{NaCl}$ in $\mathrm{D}_{2} 0$, $\mathrm{pH} 7.5)$. 

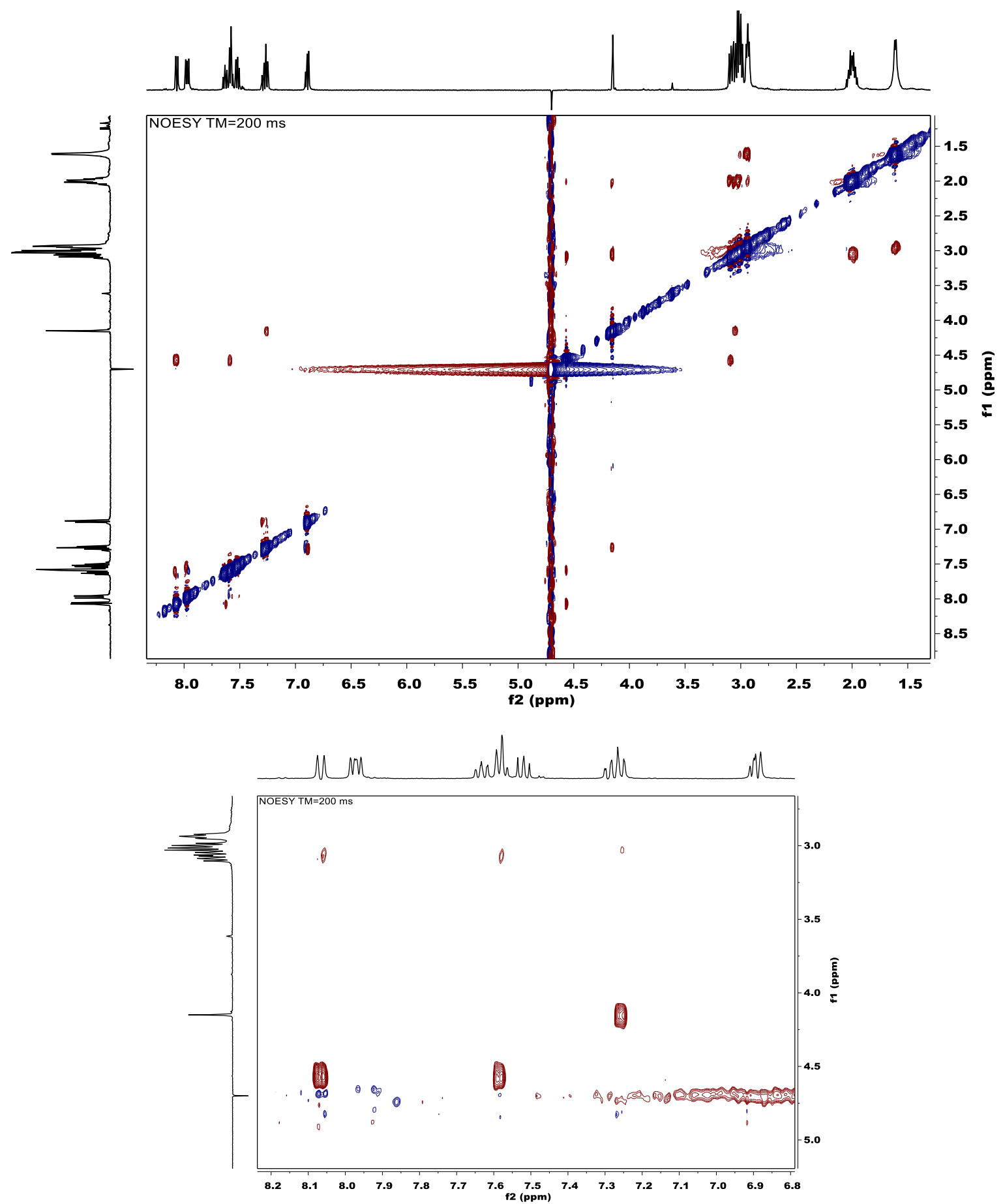

Figure S11. ${ }^{1} \mathrm{H}-{ }^{1} \mathrm{H}$ NOESY spectrum of compound $3 \mathrm{AL} 1 \mathrm{mM}\left(500 \mathrm{MHz}, 5 \mathrm{mM}\right.$ Tris-d11 and $50 \mathrm{mM} \mathrm{NaCl}$ in $\mathrm{D}_{2} 0$, $\mathrm{pH}$ 7.5). 


\section{AL-heparin interaction studies by NMR}

3AL $0.70 \mathrm{mM}$

Heparin $3.65 \mathrm{mM}$

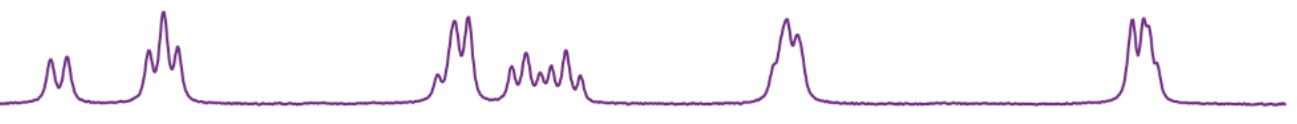

3AL $0.71 \mathrm{mM}$

Heparin $2.66 \mathrm{mM}$
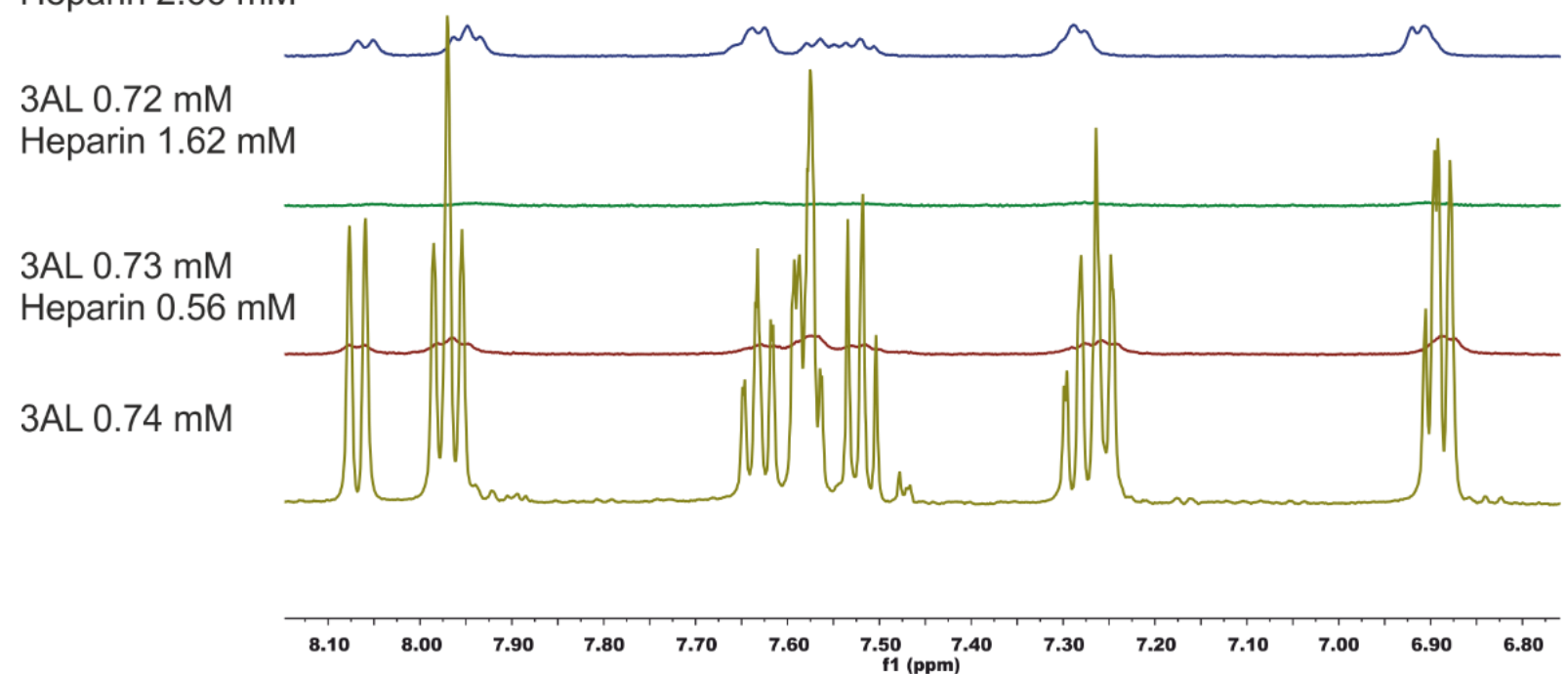

3AL $0.70 \mathrm{mM}$

Heparin $3.65 \mathrm{mM}$

3AL $0.71 \mathrm{mM}$

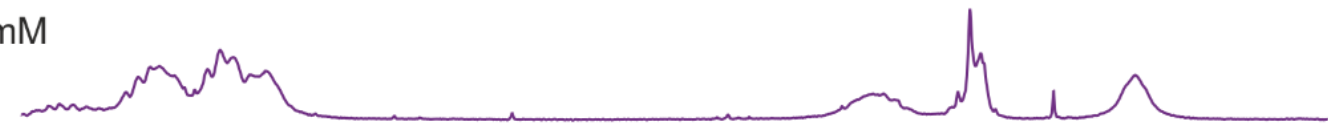

Heparin $2.66 \mathrm{mM}$

3AL $0.72 \mathrm{mM}$

Heparin $1.62 \mathrm{mM}$

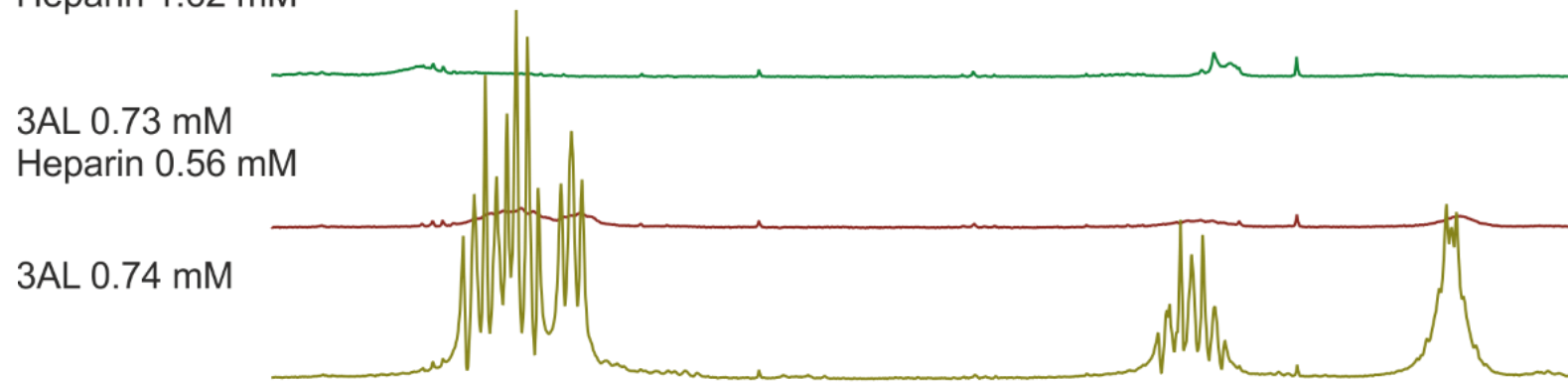

$\begin{array}{lllllllllllllllllll}3.3 & 3.2 & 3.1 & 3.0 & 2.9 & 2.8 & 2.7 & 2.6 & 2.5 & 2.4 & 2.3 & 2.2 & 2.1 & 2.0 & 1.9 & 1.8 & 1.7 & 1.6 & 1.5\end{array}$

Figure S12. ${ }^{1} \mathrm{H}$ CPMGPR1D NMR spectra of compound 3AL in the presence of increasing amounts of heparin. The concentrations of the heparin are referred to the concentration of the disaccharide repeating unit, considering the average molecular weight and the composition of the heparin sample here used. All spectra were acquired at $500 \mathrm{MHz}$ in $5 \mathrm{mM}$ Tris-d11 and $50 \mathrm{mM} \mathrm{NaCl}$ in $\mathrm{D}_{2} \mathrm{O}, \mathrm{pH}$ 7.5. 


\section{AL-dp14 heparin interaction studies by NMR}

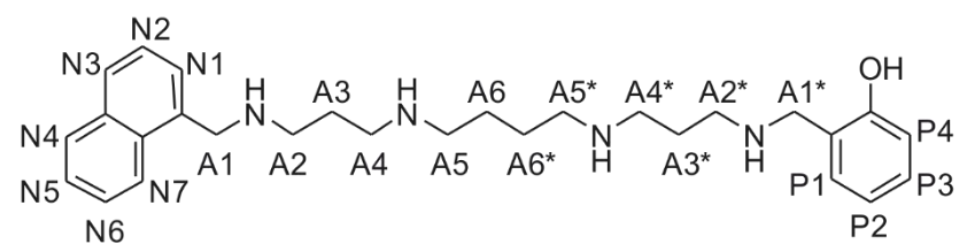

c)

b)

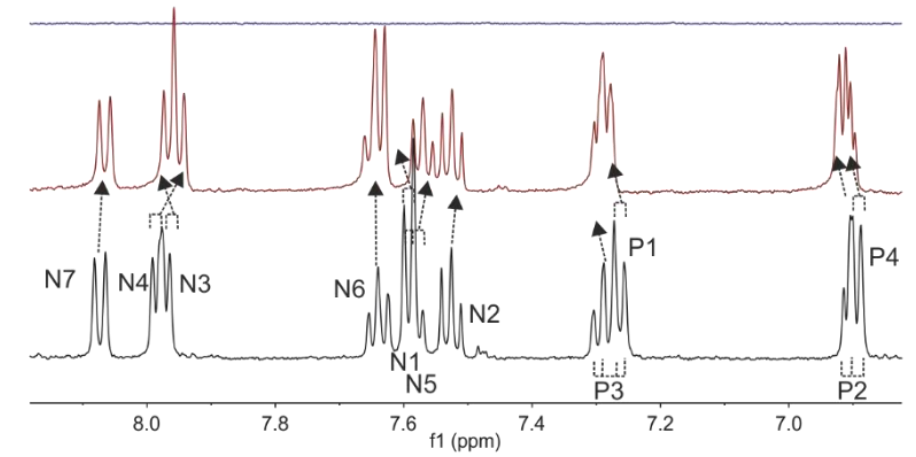

c)

b)

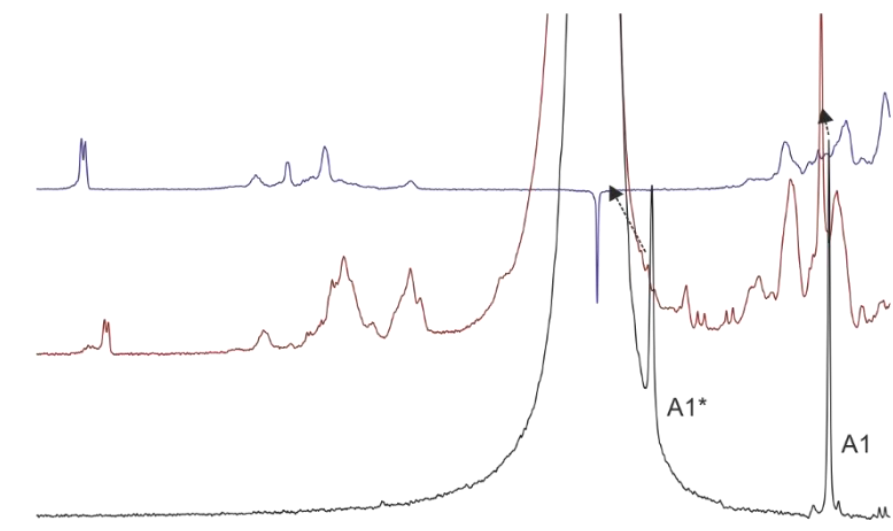

a)

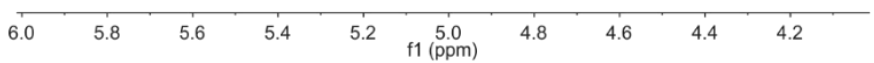

c)

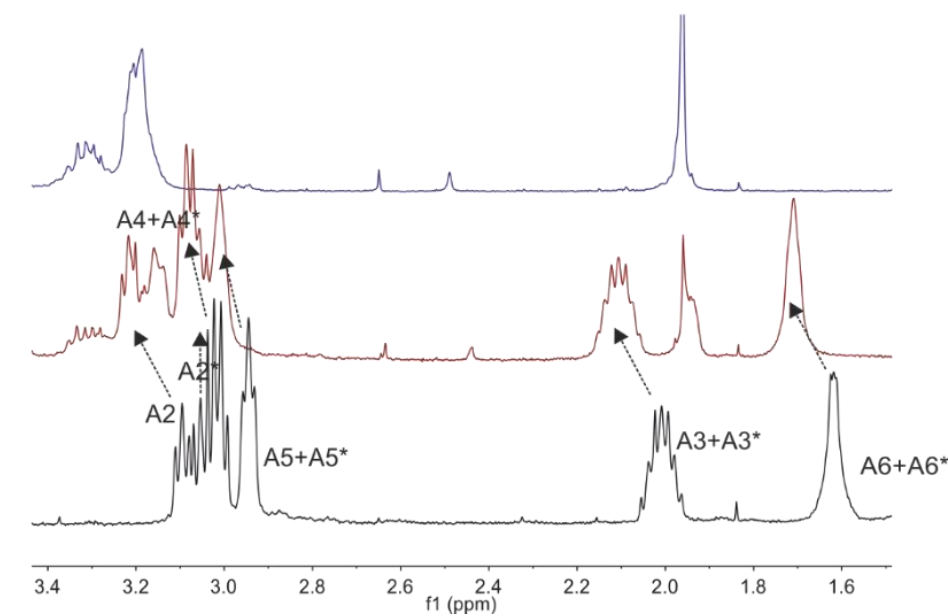

Figure S13. Selected regions of the ${ }^{1} \mathrm{H}$ NMR spectra of: (a) compound $3 \mathrm{AL}(0.55 \mathrm{mM})$ (c) dp14 heparin (2.8 mM in the corresponding disaccharide repeating unit) and (b) mixture of $3 A L$ and $\mathbf{d p 1 4}$. All spectra were acquired at $500 \mathrm{MHz}$ in $5 \mathrm{mM}$ Tris-d11 and $50 \mathrm{mM} \mathrm{NaCl}$ in $\mathrm{D}_{2} 0, \mathrm{pH} 7.5$. 

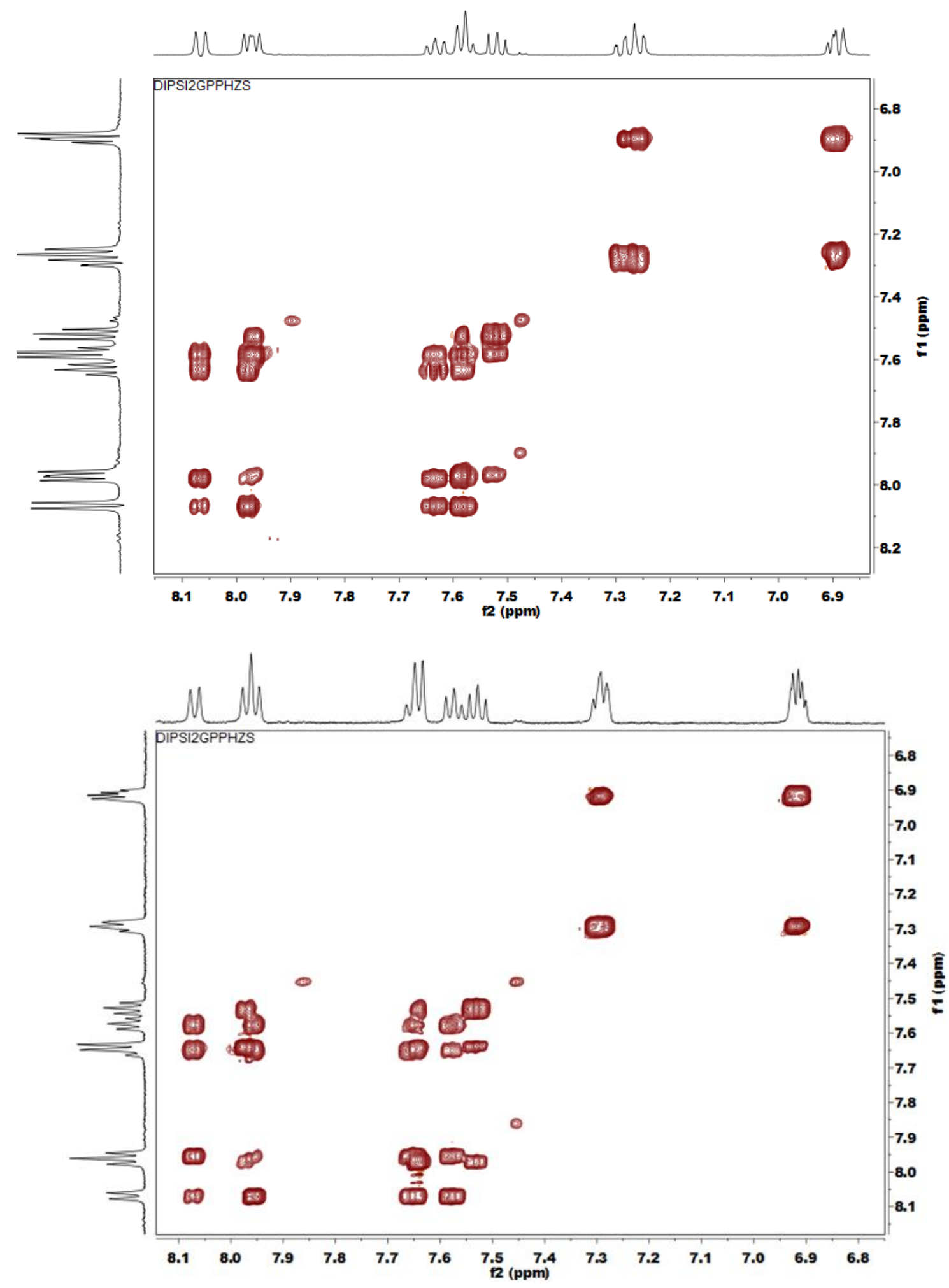

Figure S14. ${ }^{1} \mathrm{H}-{ }^{1} \mathrm{H}$ TOCSY spectrum $\left(500 \mathrm{MHz}, 5 \mathrm{mM}\right.$ Tris-d11 and $50 \mathrm{mM} \mathrm{NaCl}$ in $\mathrm{D}_{2} 0, \mathrm{pH}$ 7.5) of compound 3AL $(0.55 \mathrm{mM})$ in the presence of dp14 heparin ( $2.8 \mathrm{mM}$ in the corresponding disaccharide repeating unit). 


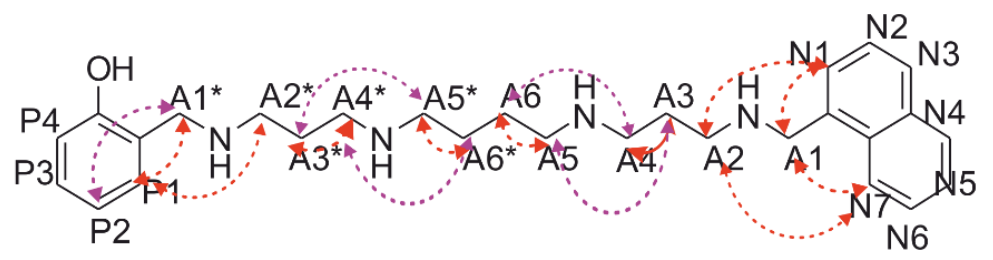

- 3AL 1H-1H NOESY 200 ms

- - 3AL+ dp14 1H-1H TROESY 250 ms
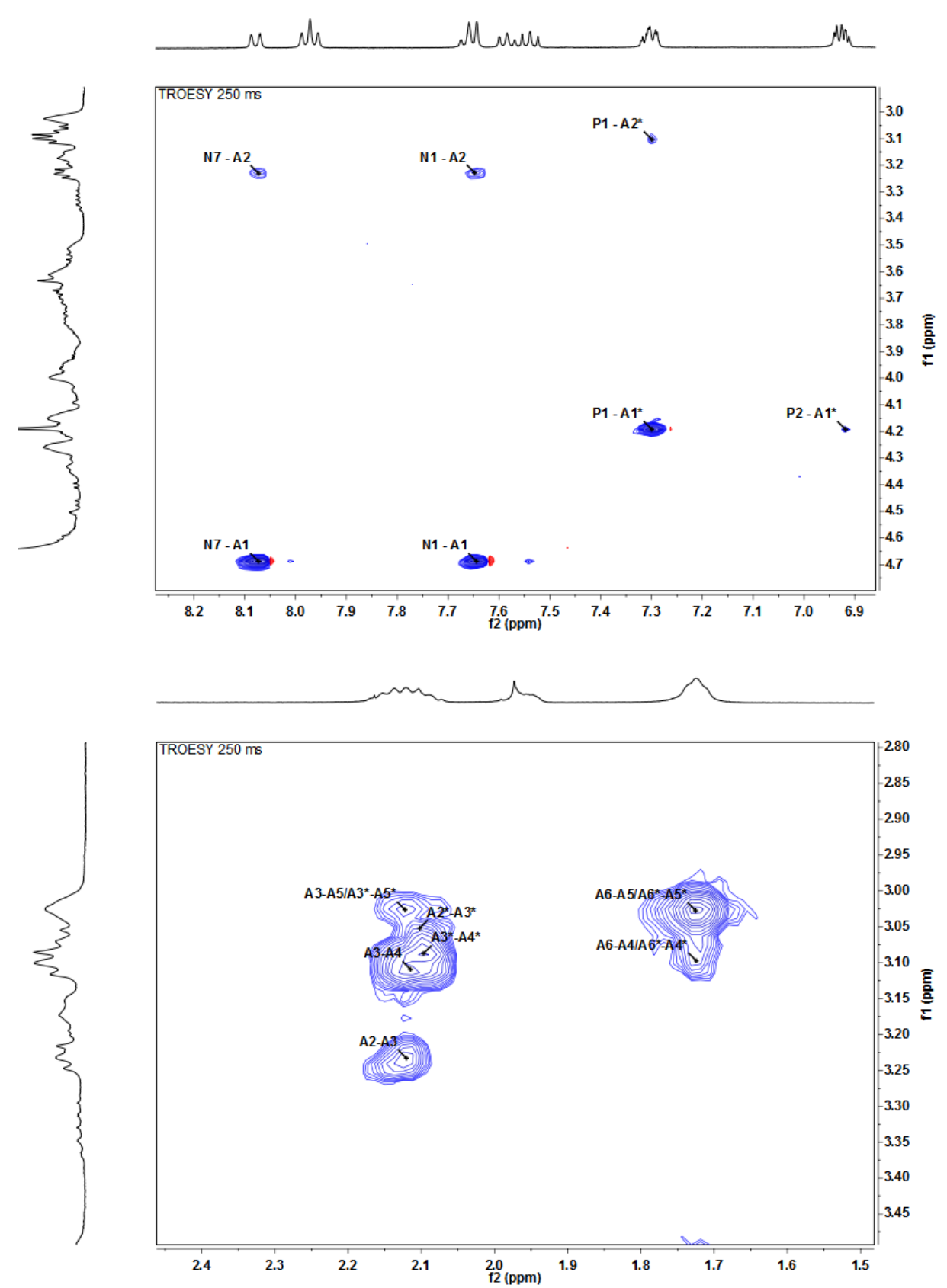

Figure S15. ${ }^{1} \mathrm{H}-{ }^{1} \mathrm{H}$ TROESY spectrum ( $500 \mathrm{MHz}, 5 \mathrm{mM}$ Tris-d11 and $50 \mathrm{mM} \mathrm{NaCl}$ in $\mathrm{D}_{2} \mathrm{O}, \mathrm{pH} 7.5$ ) of compound 3AL $(0.55 \mathrm{mM})$ in the presence of $\mathbf{d p} 14$ heparin ( $2.8 \mathrm{mM}$ in the corresponding disaccharide repeating unit). 


\section{Blood coagulation factor enzymatic assays}

Recombinant antithrombin III and coagulation Factor Xa were obtained from the Berichrom Heparin test, supplied by SIEMENS. Following the indications of the test kit, stock solutions were prepared as follows: Human antithrombin III $(1 \mathrm{IU} / \mathrm{mL})$, Factor Xa reagent $(0.4 \mu \mathrm{g} / \mathrm{mL}$, human plasma fraction with the additives Tris, sodium chloride and EDTA) and a chromogenic substrate specific for factor Xa (4 mM of Z-D-Leu-Gly-ArgANBA-methyl amide). On the other hand, 4-nitroaniline (Sigma Aldrich) was added to the substrate solution at a concentration of $1.6 \mathrm{mM}$ and was used as internal standard to quantify the cleavage of the chromogenic substrate. Heparin (sodium salt from porcine intestinal mucosa, polydisperse, from 6000 to 30000 Daltons) was purchased from Sigma-Aldrich. All compounds were dissolved in miliQ water at the desired stock concentrations prior to start the assays and kept at $4^{\circ} \mathrm{C}$.

Various concentrations of the ligand (3AL or $3 A A)$, heparin $(0.4 \mathrm{IU} / \mathrm{mL}$ or $0.6 \mathrm{IU} / \mathrm{mL}$ ), human antithrombin III solution $(10 \mu \mathrm{L})$ and Factor Xa reagent solution $(100 \mu \mathrm{L})$ were added in that order in an Eppendorf and brought to a total volume of $120 \mu \mathrm{L}$. Then, $40 \mu \mathrm{L}$ of Reagent Substrate solution was added to start the experiment and the mixture was vigorously shaken at $25^{\circ} \mathrm{C}$. $20 \mu \mathrm{L}$ samples were taken at minutes 5/10/15/20/30/50/80/120, diluted with $40 \mu \mathrm{L}$ of acetic acid $(20 \% \mathrm{v} / \mathrm{v})$, and injected in the analytical HPLC. The gradient ranged from $5 \%$ of $A C N$ ( $0.1 \%$ formic acid) in water (0.1\% formic acid) to $100 \%$ of $A C N$ in 24 minutes using a $15 \times 4.6 \mathrm{~mm}$ KROMAPHASE C18 $5.0 \mu \mathrm{m}$ column (retention time of cleaved chromophore $9.1 \mathrm{~min}$, retention time of chromogenic substrate $13.9 \mathrm{~min}$, retention time of 4-nitroaniline $15.4 \mathrm{~min}$ ).

FXa/ATIII activity was represented as percent of hydrolysis, which was calculated from the normalized area of cleaved peptide at $405 \mathrm{~nm}$ at each corresponding time point. Experiment carried out in absence of heparin was considered as maximum of activity while experiment with heparin and no ligand was considered as negative control (maximum inhibition of FXa by heparin). Concentration of heparin was selected for the measurement to render a significant inhibition within experimental time, while allowing the reaction to proceed.

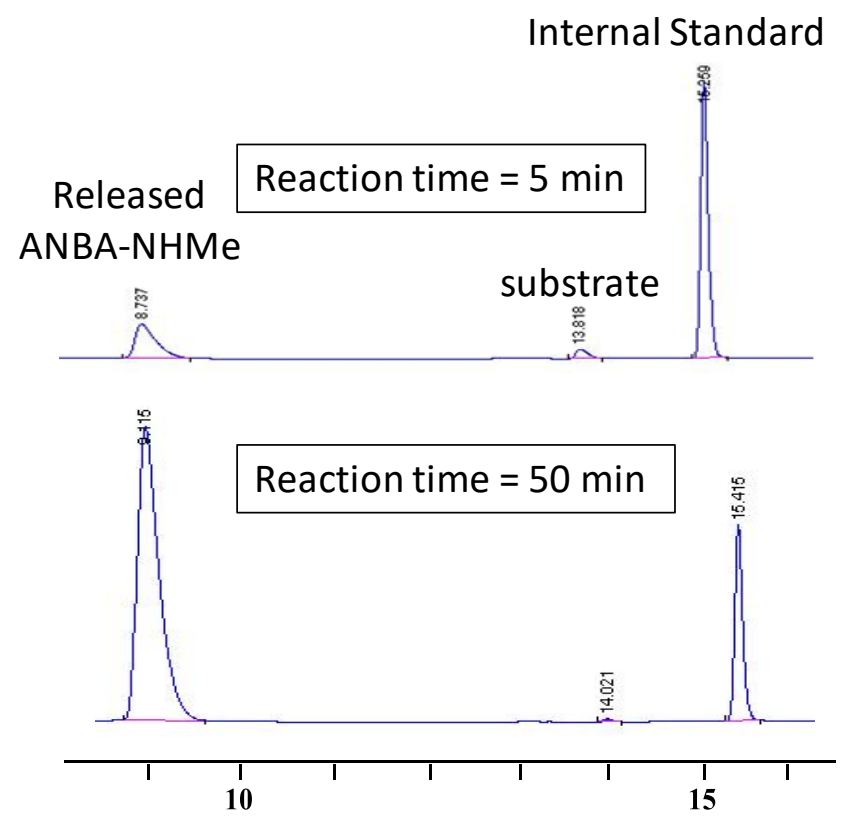

Figure S16. Typical HPLC traces showing the progression of the hydrolysis reaction 


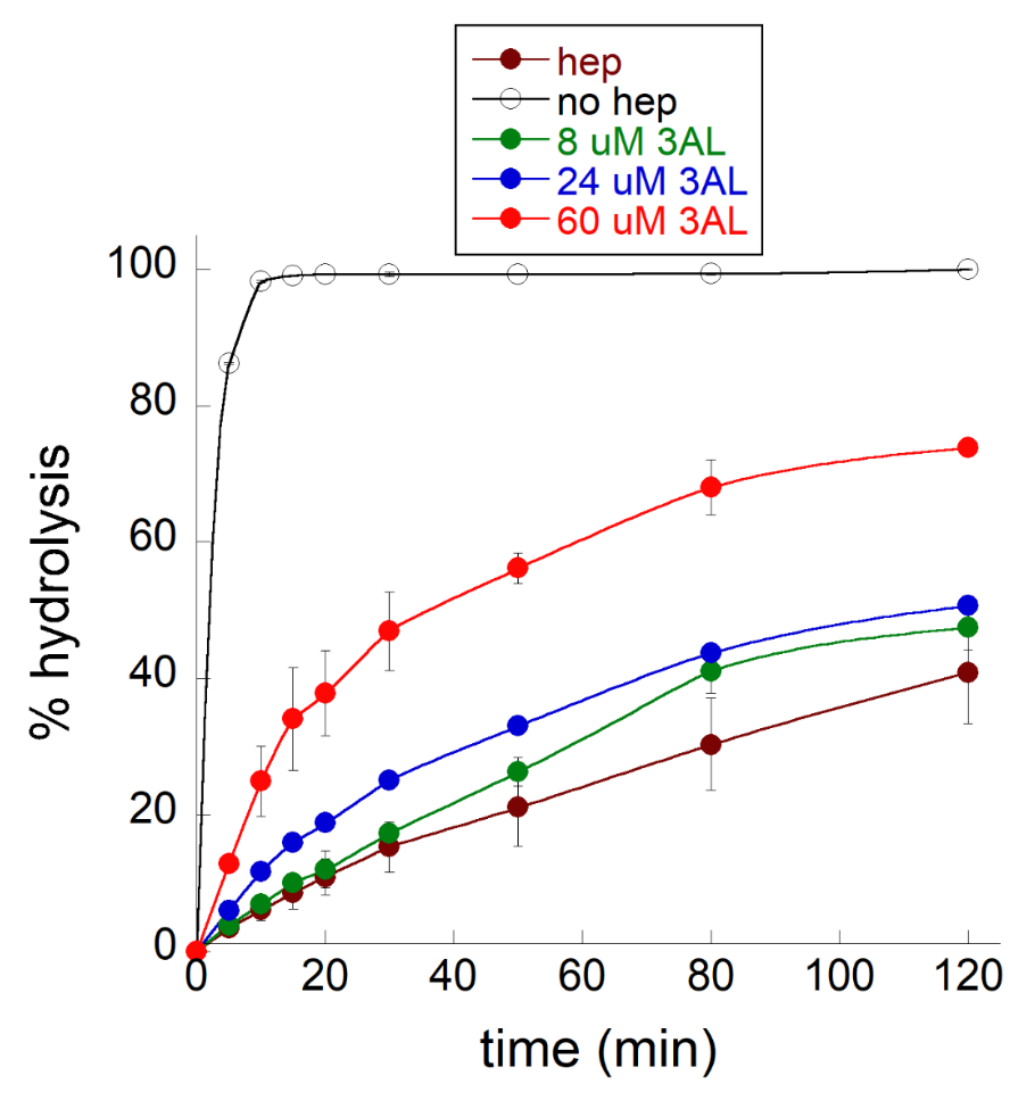

Figure S17. Plot of the percent of the hydrolysis of the Z-D-Leu-Gly-Arg-NMe-AMBA peptide (measured by HPLC at $405 \mathrm{~nm}$ ) catalyzed by the FXa/AT III system in the absence (black) or in the presence of $0.6 \mathrm{IU} / \mathrm{mL} 1$ (brown). Increasing concentrations of the ligand 3AL (green $8 \mu \mathrm{M}$, blue $24 \mu \mathrm{M}$, red $60 \mu \mathrm{M}$ ) produces an increase of the rate of the hydrolysis of the peptide, which is lower than in the presence of a smaller amount of heparin (compare with Figure 4B of the manuscript). 
Another control experiment was performed with 3AL. A reaction was carried out with $0.4 \mathrm{IU} / \mathrm{mL}$ of heparin and $8 \mu \mathrm{M}$ 3AL, also containing AT ${ }_{I I I}, F X a$ and the peptide substrate Z-D-LGR-N(Me)ANBS. The additional background reactions without heparin (maximum activity of FXa enzyme) or with heparin but without 3AL (maximum inhibition of FXa by heparin) were also done within the same batch. The percent of hydrolysis was monitored at different time points as in the previous cases. After 120 minutes, a 50\% additional heparin was added to the two reactions that initially contained heparin (with/without 3AL), whereas new fresh substrate was added to the three reaction vessels, and the evolution of the hydrolysis was monitored for other 120 minutes. The normalized hydrolysis of the peptide substrate (corrected considering the amount of hydrolyzed substrate already present in the reaction) showed that the presence of additional heparin induced a much efficient inhibition of the FXa enzyme. These results unambiguously show that the ligand $\mathbf{3 A L}$ only binds heparin and has no other unexpected effects on the enzymatic assay.

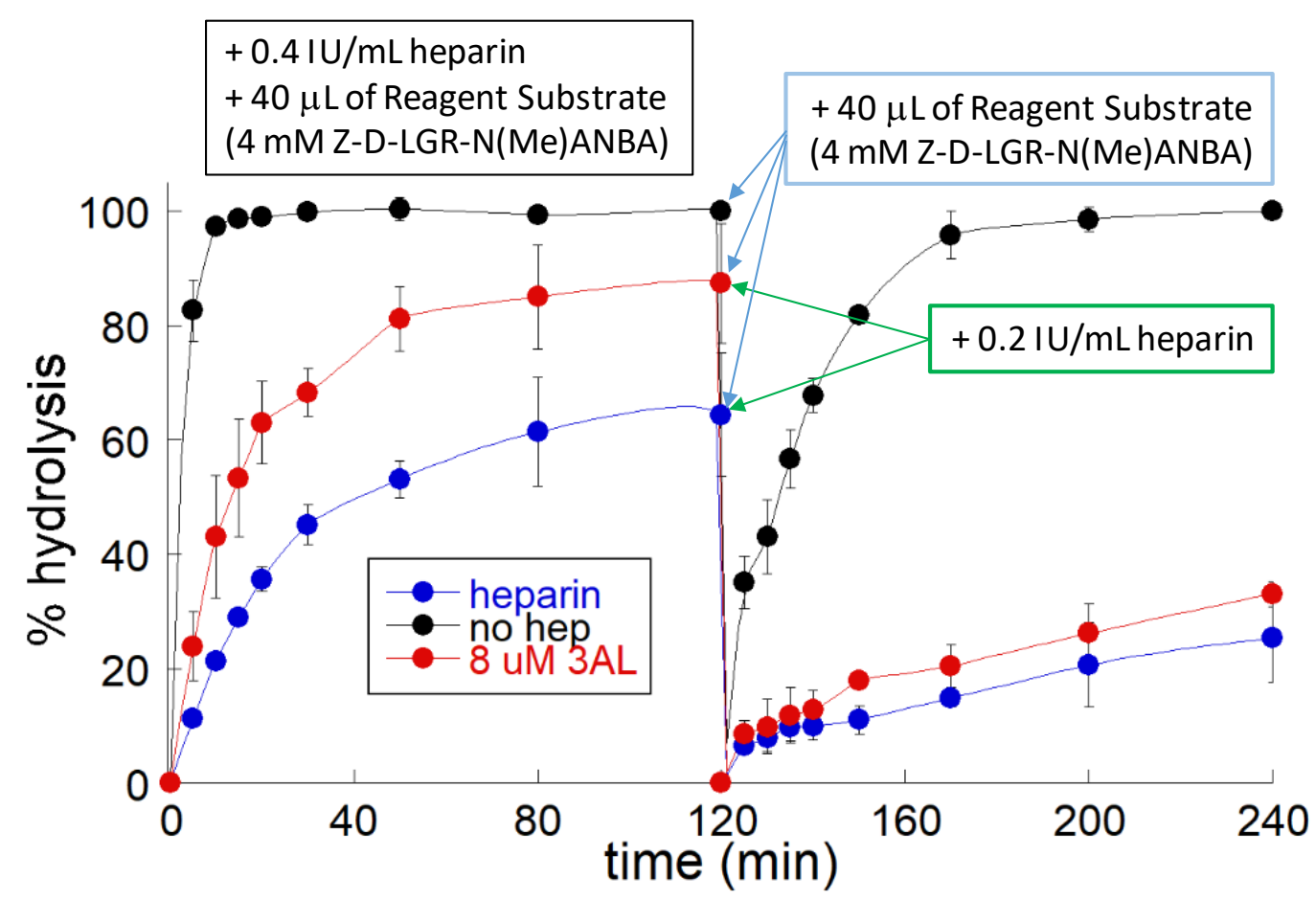

Figure S18. Plot of the percent of the hydrolysis of the Z-D-Leu-Gly-Arg-NMe-AMBA peptide (measured by $\mathrm{HPLC}$ at $405 \mathrm{~nm}$ ) catalyzed by the FXa/AT III system in the absence (black) or in the presence of $0.4 \mathrm{IU} / \mathrm{mL}$ of 1 (blue). Addition of the ligand $\mathbf{3 A L}$ (red $8 \mu \mathrm{M}$ ) induced the partial recovery of the enzymatic activity. At 120 min, additional heparin $(+0.2 \mathrm{lU} / \mathrm{mL})$ was added to the two reactions that already contained heparin, whereas peptide substrate was added to all the reactions. The percent of the hydrolysis of the substrate (normalized and corrected) showed a decrease of the enzymatic activity. 


\section{Molecular Dynamics Simulation Methods}

All molecular simulations were carried out with the package Schrödinger Suite $2017{ }^{[3]}$ through its graphical interface Maestro. ${ }^{[4]}$ The program Macromodel, ${ }^{[5]}$ with its default force field OPLS3 ${ }^{[6]}$ and GB/SA water solvation conditions, ${ }^{[7]}$ was used for energy minimization. Molecular dynamics simulations were performed with the program Desmond, ${ }^{[8]}$ using the OPLS3 force field. A heparin hexadecamer model (dp16) was derived from residues 3-19 of chain A of the reported solution structure of heparin DP36 (PDB 3IRL). ${ }^{[9]}$ Ligand 3AL was built within Maestro. Heparin dp16 was modelled with all its sulfate and carboxylate groups in their ionized state (-32 total charge), while the $3 \mathrm{AL}$ ligand was modelled with its four amino groups protonated, as suggested by pKa calculations carried out with Epik. ${ }^{[10]}$ Both structures were energy minimized before building the simulation system. To approach the high stoichiometric ratio of the heparin-3AL complex determined in our ITC experiments, a system composed of a dp16 molecule plus five unbound and arbitrarily placed 3AL molecules was set up in a cubic box whose sides were at $15 \AA$ of the closest solute atom, with added $\mathrm{Na}^{+}$ions to reach neutrality and the whole system solvated with TIP3P water ( 26300 TIP3P molecules), using the System Builder of the Maestro-Desmond interface. ${ }^{[11]}$

The full system ( 80000 atoms) was subjected to steepest descent minimization, first with the solute restrained and then without restraints until a gradient threshold of $0.1 \mathrm{kcal} / \mathrm{mol} / \AA ̊ \AA$ was reached. Then it was heated stepwise until $300 \mathrm{~K}$ with short MD runs under periodic boundary conditions (PBC, NPT, Berendsen thermostatbarostat) ( $12 \mathrm{ps}$ at $0.1,10,100$ and $300 \mathrm{~K}$ ), and equilibrated for $2 \mathrm{~ns}$ at the last temperature and 1.0 bar in the NPT ensemble. A production MD simulation ( $500 \mathrm{~ns}, 2 \mathrm{fs}$ time step) was performed under the same conditions (PBC, NPT ensemble, $300 \mathrm{~K}$ and $1.0 \mathrm{bar}$ ) using the Nose-Hoover thermostat method ${ }^{[12]}$ with a relaxation time of 1.0 ps and the Martyna-Tobias-Klein barostat method ${ }^{[13]}$ with isotropic coupling and a relaxation time of 2 ps. Integration was carried out with the RESPA integrator ${ }^{[14]}$ using time steps of 2.0, 2.0, and 6.0 fs for the bonded van der Waals and short range and long range electrostatic interactions, respectively. A cut-off of $9 \AA$ was applied to van der Waals and short-range electrostatic interactions, while long-range electrostatic interactions were computed using the smooth particle mesh Ewald method with an Ewald tolerance of 10-9. ${ }^{[15]}$ Bond lengths to hydrogen atoms were constrained using the Shake algorithm. ${ }^{[16]}$ Coordinates were saved every 200 ps, hence 2500 snapshots (frames) were obtained. The Simulation Event Analysis application included in the Desmond-Maestro interface and different ad-hoc scripts were used to analyze the simulations results. The 2500 snapshots were clustered based on the atomic RMSD of the heavy atoms using the hierarchical clustering with average linkage method implemented in the Schrodinger Suite and fixing the number of clusters to 10. 


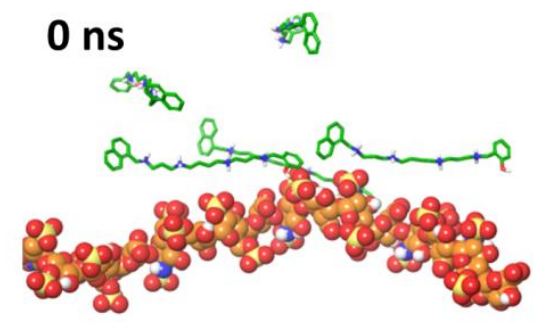

$50 \mathrm{~ns}$

100 ns

150 ns
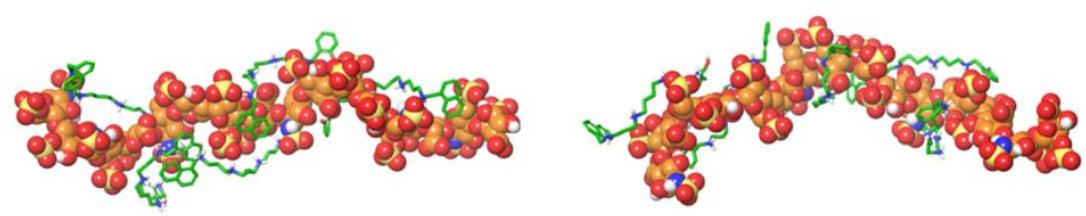

$200 \mathrm{~ns}$

$250 \mathrm{~ns}$
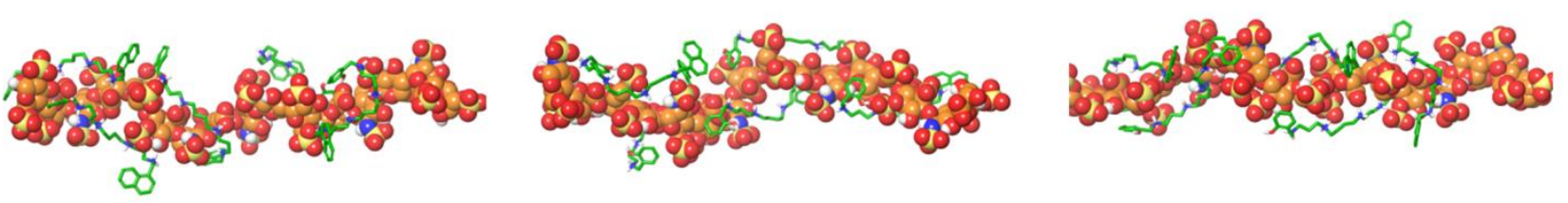

$300 \mathrm{~ns}$

$350 \mathrm{~ns}$

$400 \mathrm{~ns}$
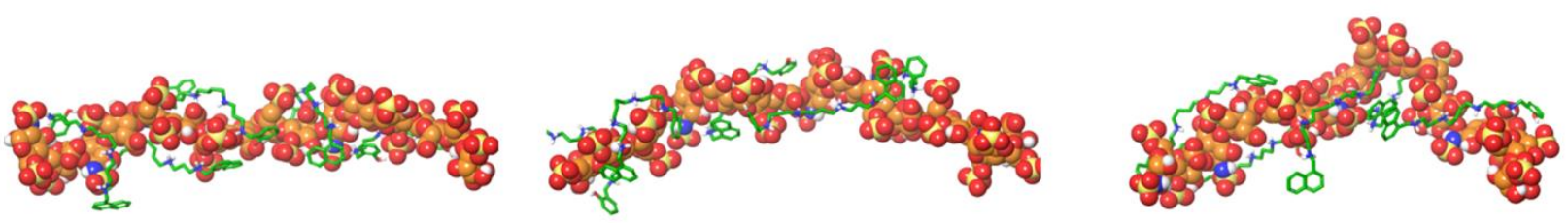

450 ns

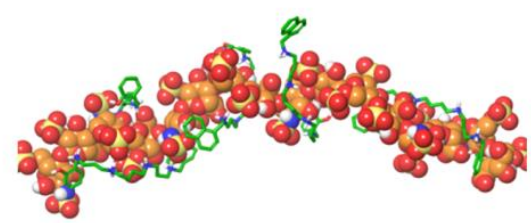

500 ns

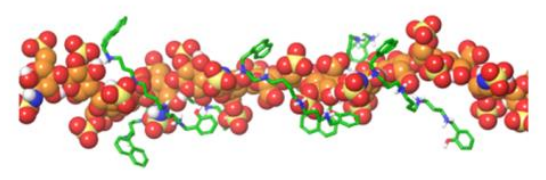

Figure S19. Snapshots from the $500 \mathrm{~ns}$ MD simulation of a system containing one dp16 heparin model (spheres) and five 3AL (green sticks) molecules. Water molecules and ions are omitted for clarity. 


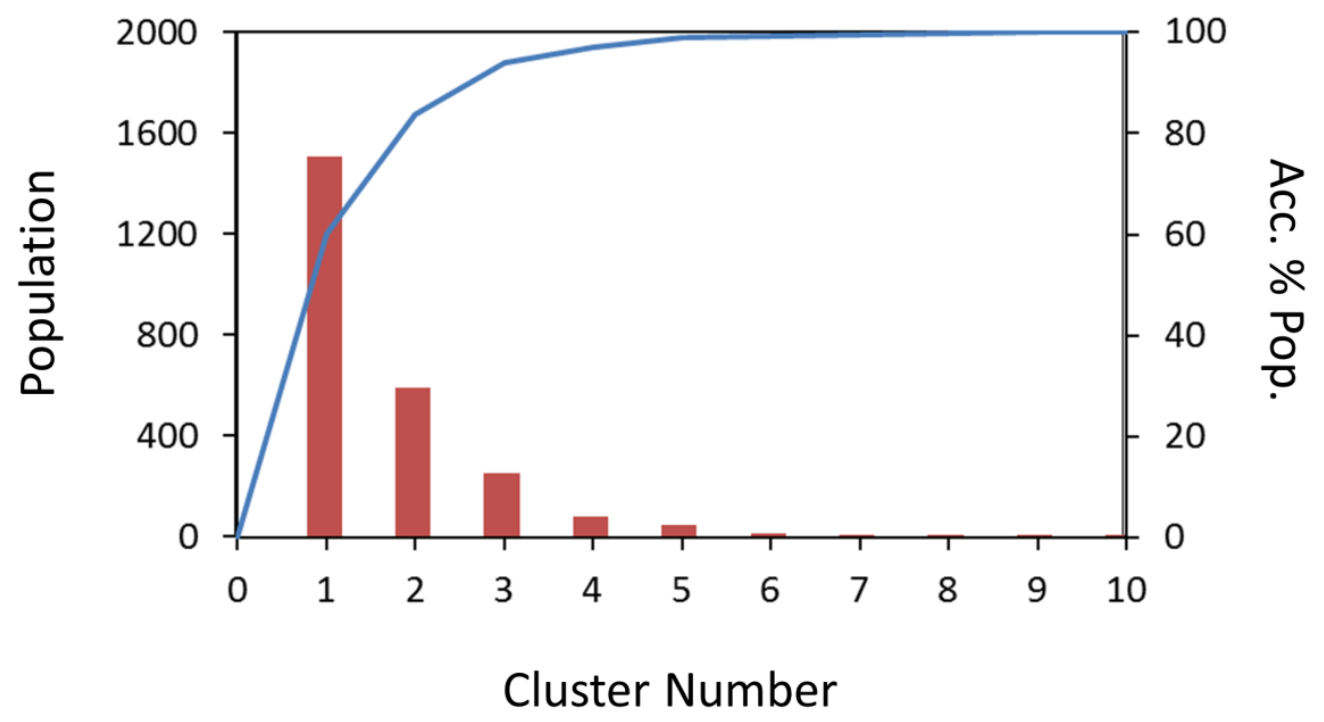

Figure S20. Results from clustering the 2500 snapshots obtained from molecular dynamics, by applying a hierarchical clustering method with 10 clusters. The graph shows the population distribution among the clusters (red bars, left axis) and the accumulated \% of population (blue line, right axis). 




Figure S21. Results from molecular dynamics. For each of the five 3AL molecules in the simulation, the graphics show the dependence on simulation time of: (1) the number of hydrogens bonds established with dp16

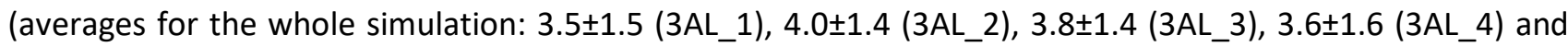
$\left.3.8 \pm 1.6\left(3 \mathrm{AL} \_5\right)\right)$ and (2) the minimum distance (A)) between protons on positions $A 3$ and $A 5, A 4$ and $A 6, A 3 *$ and $\mathrm{A} 5^{*}$, and $\mathrm{A} 4 *$ and $\mathrm{A} 6^{*}$. 


\section{References.}

[1] G. Klocek, J. Seelig, Biochemistry 2008, 47, 2841-2849.

[2] M. Corredor, R. Bonet, A. Moure, C. Domingo, J. Bujons, I. Alfonso, Y. Pérez, À. Messeguer, Biophysical Journal 2016, 110, 1291-1303.

[3] Schrödinger, Schrödinger, LLC, New York, NY, 2017.

[4] Schrödinger, Schrödinger, LLC, New York, NY, 2017.

[5] Schrödinger, Schrödinger, LLC, New York, NY, 2017.

[6] E. Harder, W. Damm, J. Maple, C. Wu, M. Reboul, J. Y. Xiang, L. Wang, D. Lupyan, M. K. Dahlgren, J. L. Knight, J. W. Kaus, D. S. Cerutti, G. Krilov, W. L. Jorgensen, R. Abel, R. A. Friesner, Journal of chemical theory and computation 2016, 12, 281-296.

[7] W. C. Still, A. Tempczyk, R. C. Hawley, T. Hendrickson, J. Am. Chem. Soc. 1990, 112, 6127-6129.

[8] aSchrödinger, D. E. Shaw Research, New York, NY, 2017; bK. J. Bowers, E. Chow, H. Xu, R. O. Dror, M. P. Eastwood, B. A. Gregersen, J. L. Klepeis, I. Kolossváry, M. A. Moraes, F. D. Sacerdoti, J. K. Salmon, Y. Shan, D. E. Shaw, in Proceedings of the ACM/IEEE Conference on Supercomputing (SCO6), Tampa, Florida, 2006.

[9] S. Khan, J. Gor, B. Mulloy, S. J. Perkins, J Mol Biol 2010, 395, 504-521.

[10] aSchrödinger, Schrödinger, LLC, New York, NY, 2017; bJ. R. Greenwood, D. Calkins, A. P. Sullivan, J. C. Shelley, J. Comput. Aided Mol. Des. 2010, 24, 591-604; cJ. C. Shelley, A. Cholleti, L. L. Frye, J. R. Greenwood, T. M. R., M. Uchiyama, J. Comput. Aided Mol. Des. 2007, 21, 681-691.

[11] Schrödinger, D. E. Shaw Research, New York, NY, 2017.

[12] aD. J. Evans, B. L. Holian, The Journal of Chemical Physics 1985, 83, 4069-4074; bG. J. Martyna, M. L. Klein, M. Tuckerman, The Journal of Chemical Physics 1992, 97, 2635-2643.

[13] G. J. Martyna, D. J. Tobias, M. L. Klein, The Journal of Chemical Physics 1994, 101, 4177-4189.

[14] M. Tuckerman, B. J. Berne, G. J. Martyna, The Journal of Chemical Physics 1992, 97, 1990-2001.

[15] aT. Darden, D. York, L. Pedersen, The Journal of Chemical Physics 1993, 98, 10089-10092; bU. Essmann, L. Perera, M. L. Berkowitz, T. Darden, H. Lee, L. G. Pedersen, The Journal of Chemical Physics 1995, 103, 8577-8593.

[16] V. Kräutler, W. F. van Gunsteren, P. H. Hünenberger, Journal of Computational Chemistry 2001, 22, 501-508. 